\title{
Síntese, Caracterização e Estudo de Propriedades de Ftalocianinas Metálicas na Forma de Filmes de Langmuir e Langmuir-Blodgett
}

\section{LUCIANA GAFFO}

Tese apresentada à área de Interunidades em Ciência e Engenharia de Materiais, da Universidade de São Paulo, como parte dos requisitos para a obtenção do título de Doutora em Ciência e Engenharia de Materiais.

Orientador: Prof. Dr. Osvalto Novais de Oliveira Jr. USPAFSCISBA

$$
o^{u}
$$

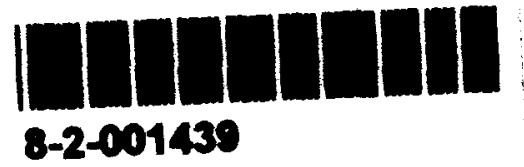

\section{São Carlos - SP}


Gaffo, Luciana

"Síntese, caracterizaçáo e estudo de propriedades de ftalocianinas metálicas na forma de filmes de Langmuir e Langmuir-Blodgett"/Luciana Gaffo - São Carlos, 2002

Tese (Doutorado) - Escola de Engenharia de São Carlos/Instituto de Física de São Carlos/Instituto de Química de São Carlos da Universidade de São Paulo, 2002 páginas: 106

Área Interunidades: Ciência e Engenharia de Materiais

Orientador: Prof. Dr. Osvaldo Novais de Oliveira Júnior

1.: Filmes Langmuir-Blodgett, 2. Ftalocianinas, 3. Espectroscopia Raman 

22-02-2002.

\section{COMISSÃO JULGADORA:}

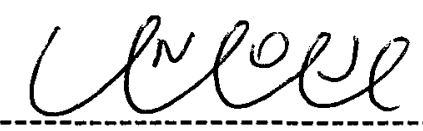

Prof. Dr. Osvaldo Novais de Oliveira Júnior (Orientador e Presidente) - IFSC

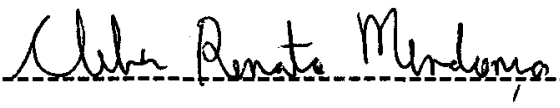

Prof. Dr. Cleber Renato Mendonça - IFSC

Prof. Dr. José Alberto Giacometti - UNESP

Irok fewic Liam fore

Profa. Dra. Ieda Lúcia Viana Rosa - UFSCar

Profa. Dra. Maria El ząbete Darbello Zaniquelli - FFCLRP-USP 


\section{AGRADECIMENTOS}

Agradeço ao Prof. Dr. Osvaldo Novais de Oliveira Jr. pela orientação durante esses quatro anos de doutorado.

Agradeço à Profa. Dra. Wania da Conceição Moreira e ao Prof. Dr. Ricardo Aroca pela co-orientação e auxílio na interpretação de dados nesse período.

Ao Prof. Dr. Cléber Renato Mendonça pelo auxílio na interpretação de resultados de óptica não-linear.

Ao Casé e à Patrícia pelo tempo que estivemos juntos no Canadá e pelos helps na interpretação de resultados de Raman.

Aos técnicos Bertho e Níbio por todos o apoio técnico prestado nesses anos.

Ao técnico Ademir, pelo auxílio com os computadores e programas utilizados.

A Profa. Dra. Débora Balogh por todo o apoio no laboratório de química.

A Rosângela pela força em toda a parte burocrática e pela amizade.

Ao técnico Ademir (UFSCar), por todos os serviços de vidraria prestados.

Aos técnicos da química da USP, principalmente ao Mauro, que fez muitas medidas de i.v. dos meus compostos.

À Vladerez e à Érica, pelo apoio na parte administrativa

Ao Dhanabalan, pelo apoio e ajuda prestados na etapa de meu trabalho realizado na USP. 
Aos companheiros de sala: Carla, Clarissa, Karen, Patricia, Marystela e Thiago, que foram muito importantes para mim durante esses anos.

Agradeço ao Xuxa, que apesar de falar demais e sempre deixar a porta da sala aberta, é uma pessoa muito legal.

Ao Lucas, que não é da minha sala mas não sai de lá, pelos momentos engraçados.

À Sarita, pela companhia no trabalho, nas festas, em casa e pela grande amizade que temos até hoje.

Ao Rodrigo e a Andrea, pelos momentos de amizade no trabalho e fora dele.

À minha mãe Hilda e às minhas irmãs, Marcia Cristina e Josiane, que apesar da distância sempre me apoiaram em minha caminhada.

A meu pai Antonio, que mesmo no descanso eterno, sei que sempre esteve e estará a meu lado em todos os momentos.

Aos amigos da UFSCar, Aílton, Marilza, Bete e Marisi, pelos conselhos e companhia em muitos momentos.

Às minhas amigas e companheiras desde a época da UFSCar, Elaine e Renata, que dividiram comigo muitos momentos de alegria.

Agradeço ao Fabrício pelos conselhos e pela amizade.

À Letícia e Adriana pela companhia nas festas e momentos de laser.

À Fundação de Amparo à Pesquisa do Estado de São Paulo (FAPESP), pelo auxílio financeiro recebido. 


\section{Sumário}

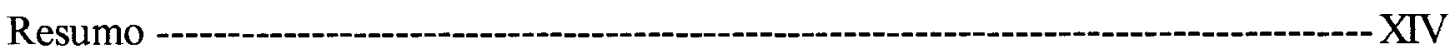

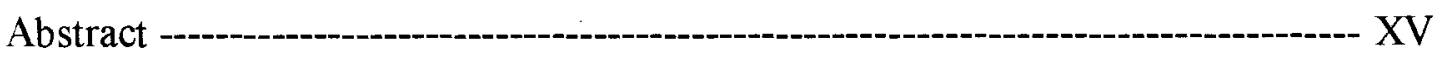

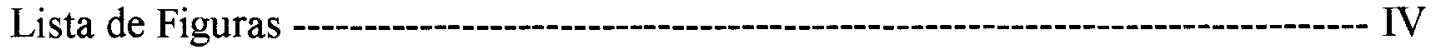

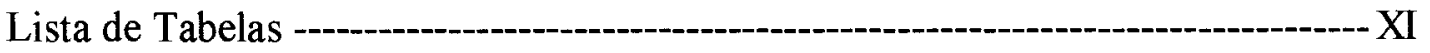

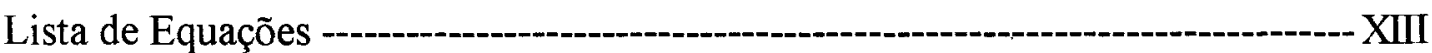

\section{CAPÍTULO I}

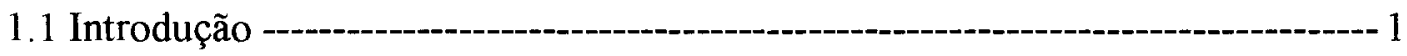

1.2 Objetivos do Trabalho de Doutorado -

\section{CAPÍtulo II}

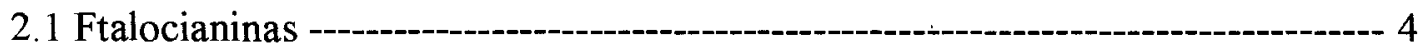

2.2 Síntese e Purificação das Ftalocianinas ---:-_-

2.2.1 Síntese e Purificação da Ftalocianina de Paládio (PdPc) ------------- 11

2.2.2 Síntese e Purificação da Ftalocianina de Ródio (RhPc) ---------- 15

2.2.3 Síntese e Purificação da Ftalocianina de Rutênio (RuPc) ------------ 18

2.3 Conclusões ---1

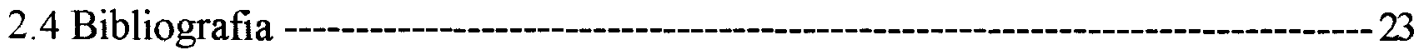

\section{CAPÍtULO III}

3.1 Filmes de Langmuir da Bisftalocianina de Itérbio $\left(\mathrm{YbPc}_{2}\right)$ e Ftalocianina de Ródio (RhPc) --- 25

3.2 A Técnica Langmuir-Blodgett (LB) - - 25

3.3 Filmes de Langmuir da $\mathrm{YbPc}_{2}-\mathrm{C}_{2}$

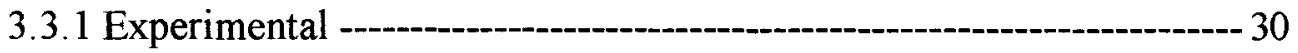

3.3.2 Resultados e Discussão - 31

3.4 Filmes de Langmuir da RhPc -- 38

38

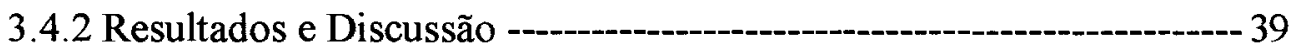

3.5 Conclusões -

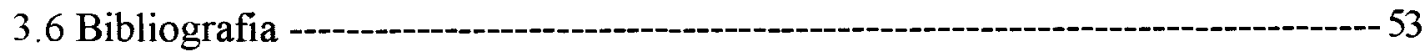




\section{CAPÍtTuLO IV}

4.1 Espectroscopia Raman das Ftalocianinas ----o- 55

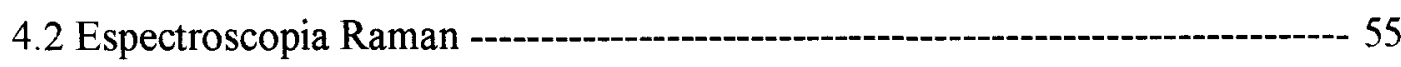

4.3 Resultados de Espectroscopia Raman para a

Bisftalocianina de Itérbio $\left(\mathrm{YbPc}_{2}\right)$ - - 59

4.3.1 Parte Experimental --- 59

4.3.2 Resultados e Discussão - - 60

4.4 Resultados de Espectroscopia Raman para a Ftalocianina de Paládio $(\mathrm{PdPc})$ - 73

4.4.1 Experimental -- 73

4.4.2 Resultados e Discussão - 73

4.5 Resultados de Espectroscopia Raman para a Ftalocianina de Ródio $(\mathrm{RhPc})$--

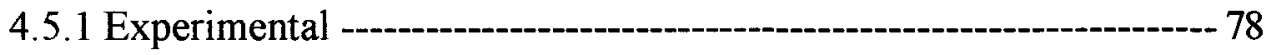

4.5.2 Resultados e Discussão - 78

4.6 Conclusões - - 85

4.7 Bibliografia ----o--o- 86

\section{CAPÍTULO V}

5.1 Voltametria Cíclica e Eletrocromismo da Bisftalocianina de Itérbio e da Ftalocianina de Paládio ---

5.2 Voltametria Cíclica da Bistalocianina de Itérbio $\left(\mathrm{YbPc}_{2}\right)$

5.2.1 Experimental -- 88

5.2.2 Resultados e Discussão -

5.3 Voltametria Cíclica da Ftalocianina de Paládio (PdPc) -.-_- 96

5.3.1 Experimental --

5.3.2 Resultados e Discussão --_- 97

5.4 Conclusões --- 101

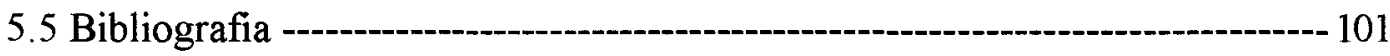




\section{CAPítulo VI}

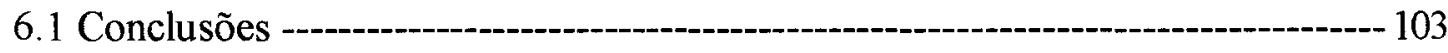

6.2 Perspectivas de Trabalho Futuro --_- 105

6.3 Artigos Produzidos neste Trabalho de Tese --_o-_- 106 
LISTA DE FIGURAS

Figura 2.1: Ftalocianina Metálica

Figura 2.2: Bisftalocianina Metálica

Figura 2.3: Transições eletrônicas para ftalocianinas nas formas de 9 monômero e dímero

Figura 2.4: Transições eletrônicas para uma bisftalocianina na forma eletrocrômica verde

Figura 2.5: Espectros de absorção na região do i.v. da PdPc

Figura 2.6: Espectro de absorção na região do UV-Vis. da PdPc em diferentes solventes

Figura 2.7: Espectro de absorção na região do UV-Vis. da PdPc em diclorometano

Figura 2.8: Representação da PdPc em forma de dímero

Figura 2.9: Espectro de absorção na região do UV-Vis. da RhPc após purificação

Figura 2.10: Espectro de absorção na região do i.v. da $\mathrm{RhPc}$ após purificação

Figura 2.11: Espectro de absorção na região do UV-Vis. da RuPc em clorofórmio (fração solúvel em clorofórmio)

Figura 2.12: Espectro de absorção na região do i.v. da RuPc (fração 20 solúvel em clorofórmio) 
Figura 2.13: Espectro de absorção na região do UV-Vis. da RuPc em clorofórmio (fração restante no papel de filtro)

Figura 2.14: Espectro de absorção na região do i.v. da RuPc (fração restante no papel de filtro)

Figura 3.1: Cuba de Langmuir

Figura 3.2: Aparato usado para medida do potencial de superfície de uma monocamada

Figura 3.3: Representação da formação de dupla camada

Figura 3.4: Sensor na posição perpendicular

Figura 3.5: Sensor na posição paralela

Figura 3.6: Isotermas $\pi$-A para a $\mathrm{YbPc}_{2}$, com o sensor de pressão em diferentes posições; $\mathrm{T}=22^{\circ} \mathrm{C}$; Volume $=800 \mu \mathrm{L}$; Concentração da solução $=0,1 \mathrm{mg} / \mathrm{mL} ;$ Velocidade de compressão $=10 \mathrm{~mm} / \mathrm{min}$

Figura 3.7: Isotermas $\pi$-A para a $\mathrm{YbPc}_{2}$, com o sensor de pressão em diferentes posições; $\mathrm{T}=14^{\circ} \mathrm{C}$; Volume $=800 \mu \mathrm{L}$; Concentração da solução $=0,1 \mathrm{mg} / \mathrm{mL}$; Velocidade de compressão $=10 \mathrm{~mm} / \mathrm{min}$

Figura 3.8: Isoterma $\Delta \mathrm{V}-\mathrm{A}$ para a $\mathrm{YbPc}_{2}$ com diferentes volumes espalhados; $\mathrm{T}=22^{\circ} \mathrm{C} ;$ Concentração da solução $=0,1 \mathrm{mg} / \mathrm{mL}$; Velocidade de compressão $=10 \mathrm{~mm} / \mathrm{min}$

Figura 3.9: Isotermas $\pi$-A para a $\mathrm{YbPc}_{2}$, variando-se a quantidade de 35 material espalhado; $\mathrm{T}=22^{\circ} \mathrm{C}$, Concentração da solução $=0,1 \mathrm{mg} / \mathrm{mL}$; Velocidade de compressão $=10 \mathrm{~mm} / \mathrm{min}$ 
Figura 3.10: Isotermas $\Delta \mathrm{V}-\mathrm{A}$ da $\mathrm{YbPc}_{2}$ em diferentes velocidades na ausência de $\mathrm{NaCl}$ na subfase

Figura 3.11: Isotermas $\triangle \mathrm{V}-\mathrm{A}$ da $\mathrm{YbPc}_{2}$ em diferentes velocidades na 38 presença de $\mathrm{NaCl}$ na subfase

Figura 3.12: Isotermas $\pi$ - $\mathrm{A}$ e $\Delta \mathrm{V}$-A para a RhPc/ácido esteárico; Temperatura $=22^{\circ} \mathrm{C} ;$ Volume $=400 \mu \mathrm{L}$; Concentração da Solução $=$ $0,5 \mathrm{mg} / \mathrm{mL}$; Velocidade de Compressão $=10 \mathrm{~mm} / \mathrm{min}$

Figura 3.13: Isotermas $\pi-A$ para a RhPc feitas no dia em que foi preparada a solução e nos dias posteriores; Temperatura $=22^{\circ} \mathrm{C}$; Concentração da Solução $=0,4 \mathrm{mg} / \mathrm{mL}$; Velocidade de Compressão $=$ $10 \mathrm{~mm} / \mathrm{min}$

Figura 3.14: Isoterma $\Delta \mathrm{V}-\mathrm{A}$ para a uma solução de RhPc/ácido 42 esteárico $75 / 25 \%$, Temperatura $=22^{\circ} \mathrm{C}$, Volume $=130 \mu \mathrm{L}$, Concentração da Solução $=0,7 \mathrm{mg} / \mathrm{mL}$, Velocidade de Compressão $=$ $10 \mathrm{~mm} / \mathrm{min}$

Figura 3.15: Espectros de absorção na região do UV-Vis. de uma solução RhPc/ácido esteárico em clorofórmio e de uma solução da RhPc pura

Figura 3.16: Espectros de absorção na região do UV-Vis. de um filme LB da RhPc pura e de um filme LB misto da RhPc/ácido esteárico

Figura 3.17: Esquema representando como e quantas ligações os 44 metais $\mathrm{Rh}$ e $\mathrm{Yb}$ podem fazer em ftalocianinas metálicas

Figura 3.18: Espectros de absorção na região do i.v. de um filme LB 46 misto (RhPc/ácido esteárico), um filme LB puro ( $\mathrm{RhPc}$ ), da $\mathrm{RhPc}$ em pastilha de $\mathrm{KBr}$ e do ácido esteárico em pastilha de $\mathrm{KBr}$ 
Figura 3.19: Isotermas $\pi$-A para a $\mathrm{SmPc}_{2}, \mathrm{YbPc}_{2}$ e RhPc, Temperatura

$=22^{\circ} \mathrm{C}$, Velocidade de Compressão $=10 \mathrm{~mm} / \mathrm{min}$

Figura 3.20: Representação de uma molécula ftalocianina em diferentes posições em relação à superficie da água: 1) horizontal; 2, 3 e 4) sofrendo inclinação; 5) inclinada (saturação)

Figura 3.21: Curva de compressibilidade para a $\mathrm{YbPc}_{2}$

Figura 3.22: Curva de compressibilidade para a RhPc

Figura 3.23: Isotermas $\Delta \mathrm{V}-\mathrm{A}$ para a $\mathrm{YbPc}_{2}$, $\mathrm{RhPc}$ e $\mathrm{SmPc}_{2}$,

Temperatura $=22^{\circ} \mathrm{C}$, Velocidade de Compressão $=10 \mathrm{~mm} / \mathrm{min}$

Figura 4.1: Esquemas dos mecanismos de espalhamento

Figura 4.2: Esquemas dos mecanismos de espalhamento Raman e 58 Raman ressonante

Figura 4.3: Espectro de absorção na região do UV-Vis. da $\mathrm{YbPc}_{2} \mathrm{em}$ 60 clorofórmio

Figura 4.4: Espectros de absorção na região do UV-Vis. para a $\mathrm{YbPc}_{2}$ 61 em: solução de clorofórmio, filme LB depositado sobre vidro, filme LB depositado sobre ilhas de prata e prata depositada sobre vidro

Figura 4.5: Espectros RRS e SERRS (excitação em $633 \mathrm{~nm}$ ) de filmes 62 $\mathrm{LB}$ da $\mathrm{YbPc}_{2}$ puros depositados sobre vidro e ilhas de prata

Figura 4.6: Espectro RRS (excitação em $633 \mathrm{~nm}$ ) de filmes LB sobre 63 mica nas proporções: 25/75\% e 75/25\% $\mathrm{YbPc}_{2} /$ ácido esteárico 
Figura 4.7: Espectro RRS e SERRS (excitação em $633 \mathrm{~nm}$ ) para filmes

LB da $\mathrm{YbPc}_{2} /$ ácido esteárico $(25 \% / 75 \%)$ depositados sobre vidro e ilhas de prata

Figura 4.8: Espectro SERRS (excitação $633 \mathrm{~nm}$ ) para um filme LB da $\mathrm{YbPc}_{2}$ puro e misto, depositados sobre ilhas de prata (bandas harmônicas)

Figura 4.9: Espectro SERS (excitação $780 \mathrm{~nm}$ ) para filmes LB da 66 $\mathrm{YbPc}_{2}$ puro e misto depositados sobre ilhas de prata

Figura 4.10: Mapeamento Raman $\mathrm{YbPc}_{2}$ /ácido esteárico 25/75\%

Figura 4.11: Mapeamento Raman $\mathrm{YbPc}_{2} /$ ácido esteárico 75/25\%

Figura 4.12: Mapeamento de área RRS usando a área integrada para os picos 678 e $1524 \mathrm{~cm}^{-1}$ para filmes LB mistos 75/25\% e $25 / 75 \%$ $\mathrm{YbPc}_{2} /$ ácido esteárico (5 monocamadas) usando linha de laser $633 \mathrm{~nm}$

Figura 4.13: Imagem de $\mathrm{AFM}$ para um filme $\mathrm{LB}$ de $\mathrm{YbPc}_{2} /$ ácido esteárico $25 / 75 \%$

Figura 4.14: Análise da seção transversal de um filme LB de 71 $\mathrm{YbPc}_{2} /$ ácido esteárico 25/75\%

Figura 4.15: Imagem de AFM para um filme $\mathrm{LB} \mathrm{YbPc}_{2} /$ ácido esteárico 72 $75 / 25 \%$

Figura 4.16: Análise da seção transversal de um filme $L B$ de 72 $\mathrm{YbPc}_{2} /$ ácido esteárico $75 / 25 \%$

Figura 4.17: Espectros de absorção na região do UV-Vis. para a PdPc 74 em: solução em tolueno, filme sublimado sobre vidro, filme sublimado sobre ilhas de prata e prata depositada sobre vidro 
Figura 4.18: Espectro RRS (excitação $633 \mathrm{~nm}$ ) para um filme

sublimado da PdPc sobre vidro

Figura 4.19: Espectro amplificado (excitação $633 \mathrm{~nm}$ ) para um filme

sublimado da PdPc sobre ilhas de prata com prata depositada sobre a $\mathrm{PdPc}$

Figura 4.20: Espectro SERS (excitação $780 \mathrm{~nm}$ ) para um filme 76 sublimado da PdPc sobre ilhas de prata

Figura 4.21: Espectros de absorção na região do UV-Vis. para a RhPc 79 em: solução de clorofórmio, filme LB sobre vidro, filme LB sobre ilhas de prata e prata depositada sobre vidro

Figura 4.22: Espectros RRS e SERRS (excitação $633 \mathrm{~nm}$ ) para filmes 79

LB da RhPc depositados sobre vidro e ilhas de prata

Figura 4.23: Espectro SERS (excitação $780 \mathrm{~nm}$ ) para um filme LB da 80 RhPc sobre ilhas de prata

Figura 4.24: Espectro (excitação $633 \mathrm{~nm}$ ) para um filme LB da RhPc 82 sobre ilhas de prata (bandas harmônicas)

Figura 4.25: Mapeamento Raman para a RhPc

Figura 5.1: Isotermas $\pi-\mathrm{A}$ e $\Delta \mathrm{V}-\mathrm{A}$ da $\mathrm{YbPc}_{2} /$ ácido esteárico

Figura 5.2: Voltamograma cíclico de filmes LB em ITO com diferentes números de camada depositadas

Figura 5.3: Voltamograma cíclico para filmes LB em ITO da $\mathrm{YbPc}_{2} /$ ácido esteárico em diferentes velocidades de varredura

Figura 5.4: Gráfico da corrente em função da velocidade de 92 voltamogramas de um filme $\mathrm{LB}$ da $\mathrm{YbPc}_{2} /$ ácido esteárico (35 monocmadas) em diferentes velocidades de varredura 
Figura 5.5: Voltamograma cíclico para 20 ciclos de um filme LB em ITO da $\mathrm{YbPc}_{2} /$ ácido esteárico

Figura 5.6: Voltamograma cíclico de filmes $\mathrm{LB}$ da $\mathrm{YbPc}_{2}$ pura, e na 94 presença e ausência de estearato de cádmio

Figura 5.7: Espectro de absorção na região do i.v. de um filme LB 94 misto ( $\mathrm{YbPc}_{2}$ /ácido esteárico), um filme LB puro $\left(\mathrm{YbPc}_{2}\right)$ e da $\mathrm{YbPc}_{2}$ em pastilha de $\mathrm{KBr}$

Figura 5.8: Espectros de absorção na região do UV-Vis. para o filme 95 LB da $\mathrm{YbPc}_{2}$ /ácido esteárico (51 camadas) com a aplicação de diferentes potenciais

Figura 5.9: Voltamograma cíclico (primeiro e segundo ciclos) para um 98 filme casting da PdPc depositado sobre ITO (acetonitrila)

Figura 5.10: Voltamograma cíclico para um filme casting da PdPc 98 depositado sobre ITO $\left(\mathrm{CH}_{2} \mathrm{Cl}_{2}\right)$

Figura 5.11: Voltamograma cíclico para um filme da PdPc sublimado 99 sobre ITO em diferentes velocidades de varredura

Figura 5.12: Gráfico da corrente em função da velocidade de 99 voltamogramas de um filme cast da PdPc em diferentes velocidades de varredura

Figura 5.13: Espectro de absorção na região do UV-Vis. para filmes 100 cast da PdPc em ITO com a aplicação de diferentes potenciais 
Tabela 2.1: Números de onda e atribuições para o espectro i.v. da PdPc

Tabela 2.2: Resultados de análise elementar para a PdPc

Tabela 2.3: Números de onda e atribuições para o espectro na região do i.v. da RhPc

Tabela 2.4: Resultados de análise elementar para a RhPc

Tabela 3.1: Números de onda observados nos espectros de i.v. de pastilhas em KBr do ácido esteárico e da RhPc e de filmes LB da RhPc pura e mista. Os números em itálico indicam as intensidades das bandas

Tabela 3.2: Dados obtidos das isotermas $\pi$-A e $\Delta \mathrm{V}-\mathrm{A}$ para $\mathrm{YbPc}_{2}$, 49 $\mathrm{SmPc}_{2}$ e RhPc

Tabela 4.1: Deslocamentos Raman em filmes LB mistos da $\mathrm{YbPc}_{2}$ 64 usando excitação em $633 \mathrm{~nm}$. Os valores entre parênteses são as intensidades relativas das bandas

Tabela 4.2: Bandas harmônicas observadas em filmes LB puros e 66 mistos da $\mathrm{YbPc}_{2}$ usando excitação em $633 \mathrm{~nm}$

Tabela 4.3: Deslocamentos Raman observadas em filmes LB da $\mathrm{YbPc}_{2}$ 68 puros usando excitação em $633 \mathrm{~nm}$ e puros e mistos usando excitação em $780 \mathrm{~nm}$. Os valores entre parênteses são as intensidades relativas das bandas

Tabela 4.4: Deslocamentos Raman observados em filmes sublimados da $\mathrm{PdPc}$. Os valores entre parênteses são as intensidades relativas das bandas 
Tabela 4.5: Deslocamentos Raman observados em filmes LB da RhPc.

Os valores entre parênteses são as intensidades relativas das bandas

Tabela 4.6: Bandas harmônicas observadas em um filme LB da RhPc

Tabela 4.7: Comparação de resultados de espectroscopia Raman para a $\mathrm{YbPc}_{2}, \mathrm{PdPc}$ e RhPc. Os valores em porcentagem são as intensidades relativas das bandas 


\section{LISTA DE EQUAÇÕES}

PÁGINA

3.1) Equação de medida da pressão de superfície

3.2) Equação de medida da diferença de potencial

3.3) Equação do modelo de Demchak e Fort

3.4) Equação do modelo de Gouy-Chapman

3.5) Equação da medida de potencial de superfície para uma monocamada LB 


\section{RESUMO}

Este trabalho apresenta um estudo sobre síntese, caracterização e propriedades de ftalocianinas metálicas na forma de filmes ultrafinos. Foi obtida mais de uma fração para cada ftalocianina. Para as ftalocianinas de paládio $(\mathrm{PdPc})$ e de ródio $(\mathrm{RhPc})$, apenas uma fração pôde ser totalmente purificada para trabalhos com a técnica Langmuir-Blodgett (LB). As frações de ftalocianina de rutênio (RuPc) não atingiram pureza suficiente para fabricação de filmes de Langmuir e LB. As propriedades das ftalocianinas de ródio e bisftalocianina de itérbio $\left(\mathrm{YbPc}_{2}\right)$, sintetizada em trabalho anterior, foram estudadas na formação de filmes LB. Observou-se forte influência das condições experimentais nos resultados. Para a $\mathrm{YbPc}_{2}$, a posição do sensor de medida de pressão altera a pressão de colapso dos filmes, algo que só é observado em filmes de compostos semi-anfifilicos. O potencial de superficie dos filmes de Langmuir depende da velocidade de compressão, mas tais diferenças não aparecem nos filmes LB depositados. Foi observada uma forte interação química entre a RhPc e o ácido esteárico, o que é atípico para ftalocianinas. Esta interação parece ser bem menos intensa nos filmes LB. As áreas ocupadas por molécula para as bisftalocianinas de itérbio e samário e a ftalocianina de ródio foram 69,60 e $75 \AA^{2}$ e as pressões de colapso 52,54 e $57 \mathrm{mN} / \mathrm{m}$, respectivamente. Esses resultados mostram similaridade nas características das diferentes ftalocianinas. Entretanto, o potencial de superficie foi bem menor para a $\mathrm{RhPc}$, provavelmente devido a uma menor componente de dipolo normal à superfície da água. $\mathrm{O}$ comportamento eletroquímico de filmes $\mathrm{LB}$ da $\mathrm{YbPc}_{2}$ dependeu da espessura dos filmes. Em filmes mais espessos, há maior dificuldade na difusão dos íons, principalmente no processo catódico. Filmes LB da $\mathrm{YbPc}_{2}$ e PdPc apresentaram eletrocromismo, mudando de cor com a aplicação de diferentes potenciais. Em espectroscopia Raman, observou-se que a banda em $675 \mathrm{~cm}^{-1}$ é a de maior intensidade para a $\mathrm{RhPc}$ e $\mathrm{YbPc}_{2}$, quando utilizada a linha de laser em $633 \mathrm{~nm}$. A PdPc tem comportamento distinto apresentando a banda de maior intensidade em $1520 \mathrm{~cm}^{-1}$. Ao analisar estes resultados à luz de dados da literatura, conclui-se que o fator predominante para os espectros Raman é o estado de oxidação. Os metais $\mathrm{Yb}$ e Rh estariam no mesmo estado de oxidação, diferente do $\mathrm{Pd}$. Comparando os resultados de microscopia de força atômica (AFM) e mapeamento Raman para a $\mathrm{YbPc}_{2}$, observou-se que filmes $\mathrm{LB}$ contendo maior porcentagem de $\mathrm{YbPc}_{2}$ são mais homogêneos. 


\begin{abstract}
This work presents the synthesis, characterization and properties of metallic phthalocyanines. For the palladium phthalocyanine $(\mathrm{PdPc})$ and rhodium phthalocyanine ( $\mathrm{RhPc}$ ), only one fraction could be totally purified for work with the Langmuir-Blodgett (LB) technique. The fractions of ruthenium phthalocyanine $(\mathrm{RuPc})$ could not be sufficiently purified for the fabrication of Langmuir and LB films. The film properties of rhodium phthalocyanine and ytterbium bisphthalocyanine $\left(\mathrm{YbPc}_{2}\right)$, synthesized in a previous work, were investigated, which showed results depending on the experimental conditions. For $\mathrm{YbPc}_{2}$, the positioning of the pressure sensor affects the collapse pressure of the Langmuir films. This is only observed in semi-amphiphilic compounds. The surface potential of the Langmuir films depends on the compression speed, but these differences are not observed in LB films. A strong chemical interaction between stearic acid and RhPc was observed, which is unprecedented for phthalocyanines. The interaction seems less intense in LB films than in solution. The areas per molecule in the condensed phase for the ytterbium and samarium bisphthalocyanines and rhodium phthalocyanine were 69,60 and $75 \AA^{2}$ and the collapse pressures were 52,54 and 57 $\mathrm{mN} / \mathrm{m}$, respectively. These results show the similar characteristics of the different phthalocyanines. However, the surface potential was lower for RhPc, probably due to a smaller dipole component normal to the water surface. The electrochemical behavior of $\mathrm{YbPc}_{2} \mathrm{LB}$ films depends on film thickness. In thicker films, ion diffusion is hindered, mainly in the cathodic process. LB films of $\mathrm{YbPc}_{2}$ and $\mathrm{PdPc}$ showed electrochromism, with changes in color upon the application of distinct potentials. In Raman spectroscopy using the $633 \mathrm{~nm}$ laser line, the most intense band occurs at 675 $\mathrm{cm}^{-1}$ for $\mathrm{RhPc}$ and $\mathrm{YbPc}_{2}$. PdPc behaves differently, with the most intense band at $1520 \mathrm{~cm}^{-1}$. Analyzing the results in the light of data in the literature, it was concluded that the dominating factor for the Raman spectra is the oxidation state of the metal. $\mathrm{Yb}$ and $\mathrm{Rh}$ metals are likely to be in the same oxidation state, differently from Pd. Comparing results from atomic force microscopy (AFM) and Raman mapping with LB films from $\mathrm{YbPc}_{2}$ mixed with stearic acid, it was observed that LB films with a larger amount of $\mathrm{YbPc}_{2}$ are more homogeneous.
\end{abstract}




\section{Capítulo I}

\subsection{Introdução}

A busca de novos materiais com propriedades interessantes para uso em dispositivos eletrocrômicos e sensores gasosos tem sido motivação para o estudo de ftalocianinas de vários metais. Neste trabalho de doutorado foram utilizadas ftalocianinas sintetizadas com os metais itérbio, ródio, rutênio e paládio. A maioria das aplicações prevê a preparação dos materiais na forma de filmes. Dentre as várias possibilidades, elegemos a técnica de Langmuir-Blodgett (LB) como a principal, por permitir estudos em nível molecular e alto controle da espessura dos filmes. As ftalocianinas sintetizadas com metais da série de transição como o itérbio formam as bisftalocianinas, isto é, um composto formado por dois anéis ftalocianina, sendo que o metal se encontra entre esses anéis ligado através de oito nitrogênios. Os metais ródio, rutênio e paládio podem chegar ao número de coordenação oito, assim imaginou-se que estes poderiam formar bisftalocianinas. Como será mostrado nesta tese, esta expectativa não se confirmou, e se formaram monoftalocianinas.

As ftalocianinas foram descobertas em 1927 e são estudadas desde essa época. As mais exploradas são as sintetizadas com metais da primeira série de transição, mais fáceis de serem obtidas. Não são conhecidas na literatura bisftalocianinas formadas com os metais ródio, rutênio e paládio, e muito pouco foi estudado com suas monoftalocianinas. Esta foi a motivação para a síntese de várias ftalocianinas no presente projeto. Será apresentado nesse trabalho um estudo sobre propriedades físicas e físico-químicas de filmes finos dessas ftalocianinas. Para a formação desses filmes foram utilizadas além da técnica (LB), as técnicas casting e de sublimação. Com a técnica LB é possivel estudar interações entre as moléculas de ftalocianina umas com as outras e a interação delas com ácido esteárico e estearato de cádmio.

O primeiro passo para analisar filmes LB consiste na investigação das propriedades de formação dos filmes de Langmuir na interface ar/água. Neste trabalho foram empregadas medidas de pressão e potencial de superfície para a análise. 
Os filmes LB depositados sobre substratos sólidos apresentam propriedades como atividade eletroquímica e eletrocrômica. Por isso, estudos eletroquímicos foram realizados, permitindo investigar a interferência da espessura e das moléculas de ácido esteárico e estearato de cádmio na migração de íons no filme durante os processos de oxidação e redução. É possível ainda observar as mudanças de forma eletrocrômica ocorridas nas ftalocianinas com a aplicação de diferentes potenciais.

As espectroscopias de infravermelho e ultravioleta-visível foram utilizadas para caracterização dos compostos obtidos e acompanhamento da purificação dos mesmos. Elas também trazem informações sobre possíveis interações entre as moléculas de ftalocianina e ácido esteárico ou estearato de cádmio nos filmes. Os diferentes estados oxidados e reduzidos das ftalocianinas podem ser acompanhados por espectroscopia ultravioleta-visível.

Uma técnica bastante explorada neste trabalho foi a espectroscopia Raman, inclusive com a possibilidade de mapeamento, que permite obter uma imagem das distribuições dos grupos ativos no infravermelho. $\mathrm{O}$ uso das técnicas foi possível graças a um estágio no laboratório do Prof. Dr. Ricardo Aroca, na Universidade de Windsor, Canadá. Através de espectroscopia Raman foram estudadas as interações intermoleculares nos filmes, inclusive verificando se há interação com o substrato. Uma das grandes vantagens da técnica Raman com amplificação é a possibilidade de trabalhar com moléculas que contenham moléculas de água e a obtenção de espectros com sinais amplificados, permitindo a visualização de sinais em filmes extremamente finos. Isso é possível devido à utilização de substratos de vidro onde previamente são depositadas ilhas de prata. Com essa amplificação, na espectroscopia Raman podem ser observados sinais que não seriam observados sem amplificação devido à baixa intensidade. Com o mapeamento, utilizando a técnica de micro espectroscopia Raman, são obtidas informações sobre diferentes espécies químicas no filme, através da identificação de diferentes fases. Pode-se também observar a existência de aglomerados nos filmes. As técnicas apresentadas foram utilizadas para estudar as várias ftalocianinas sintetizadas, e estudar diferenças e semelhanças entre elas quando sintetizadas utilizando diferentes metais em seu centro.

O Capítulo II apresenta uma breve revisão bibliográfica sobre as ftalocianinas e detalhes dos procedimentos experimentais das sínteses e caracterizações das 
mesmas. O Capítulo III traz uma revisão sobre a técnica LB, e os resultados obtidos através dessa técnica com a bisftalocianina de itérbio e a ftalocianina de ródio. Os resultados de espectroscopia Raman, e uma comparação com medidas de microscopia de força atômica para o caso da $\mathrm{YbPc}_{2}$, são apresentados no Capítulo IV. O Capítulo V apresenta os resultados de voltametria cíclica da bisftalocianina de itérbio e ftalocianina de paládio. A tese é encerrada com uma Conclusão no Capítulo VI.

\subsection{Objetivos do Trabalho de Doutorado}

Os objetivos desse trabalho de doutoramento foram:

1) sintetizar e purificar várias ftalocianinas metálicas para a fabricação de filmes de Langmuir e Langmuir-Blodgett (LB);

2) verificar propriedades especiais desses materiais na forma de filmes finos, principalmente aquelas dependentes da organização molecular;

3) investigar propriedades fundamentais, como as espectroscópicas. Para tanto foram utilizadas as técnicas de espectroscopia infravermelho, ultravioleta-visível e Raman;

4) investigar as propriedades eletroquímicas e eletrocrômicas das ftalocianinas. Para esses estudos foi utilizada a técnica de voltametria cíclica. 


\section{Capítulo II}

Este capítulo descreve as sínteses, purificações e caracterizações das ftalocianinas metálicas. Para obtenção dos compostos utilizados no trabalho, foram necessárias várias tentativas de síntese, com diferentes rotas sintéticas. São descritas aqui as sínteses que levaram à obtenção do produto de interesse, e comentadas as que não trouxeram um resultado satisfatório.

\subsection{Ftalocianinas}

Em 1907, Braun e Tcherniac sintetizaram a primeira ftalocianina. As ftalocianinas são compostos macrocíclicos altamente conjugados, com intensa coloração azul ou verde [1]. Esses compostos podem ser sintetizados substituindo-se os hidrogênios de seu centro por metais que fazem ligações com os nitrogênios. Essas são chamadas de ftalocianinas metálicas. [1]. Em 1930, Linstead e seus colaboradores [1] sintetizaram várias ftalocianinas metálicas, e sugeriram que a ftalocianina consiste de quatro unidades isoindol, interligadas por quatro nitrogênios aza, possuindo um sistema altamente conjugado. Usando difração de Raios-X, Linstead e Robertson mostraram que as estruturas de muitas ftalocianinas metálicas podem ser expressas pelas fórmulas MPc, $M X P c$ e $\mathrm{MX}_{2} \mathrm{Pc}$ para metais bi-, tri-, e tetra- valentes, onde $\mathrm{M}$ é o íon metálico, Pc o ligante ftalocianina e X um outro ligante [1]. Dessa maneira, as ftalocianinas podem ter diferentes formas, sendo que a representação de uma delas se encontra na figura 2.1.

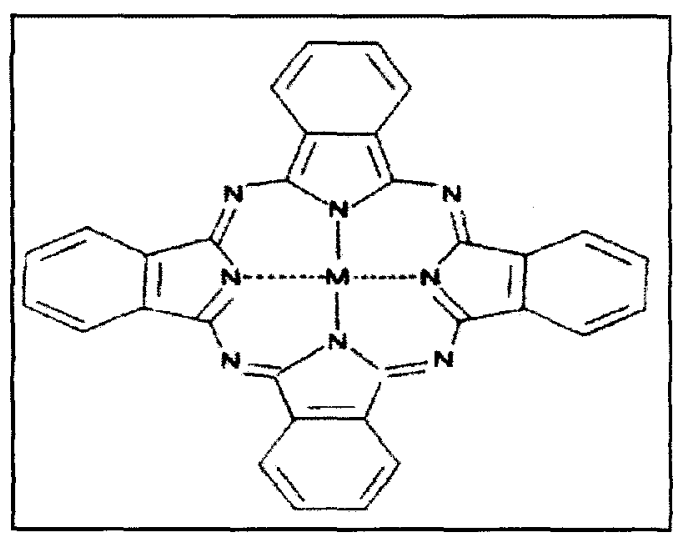

Figura 2.1: Ftalocianina Metálica 
Com o avanço no estudo de ftalocianinas, verificou-se que era possível a síntese de compostos tipo sanduíche com este ligante, sendo denominados bisftalocianinas metálicas. Nestas, geralmente no centro metálico, encontram-se íons da série dos lantanídeos. Estes atingem facilmente número de coordenação oito, um dos requisitos necessários para a formação de bisftalocianinas [1].

Apesar de atualmente serem os lantanídeos os metais mais utilizados para sintetizar as bisftalocianinas, a primeira a ser sintetizada foi a bisftalocianina de estanho $\left(\mathrm{SnPc}_{2}\right)$, por Barret [2] em 1936. As bisftalocianinas podem ser expressas pela fórmula $\mathrm{MPc}_{2}$, sendo $\mathrm{Mo}$ íon metálico central e Pc o ligante ftalocianina. Na figura 2.2 encontra-se uma representação para as bisftalocianinas metálicas.

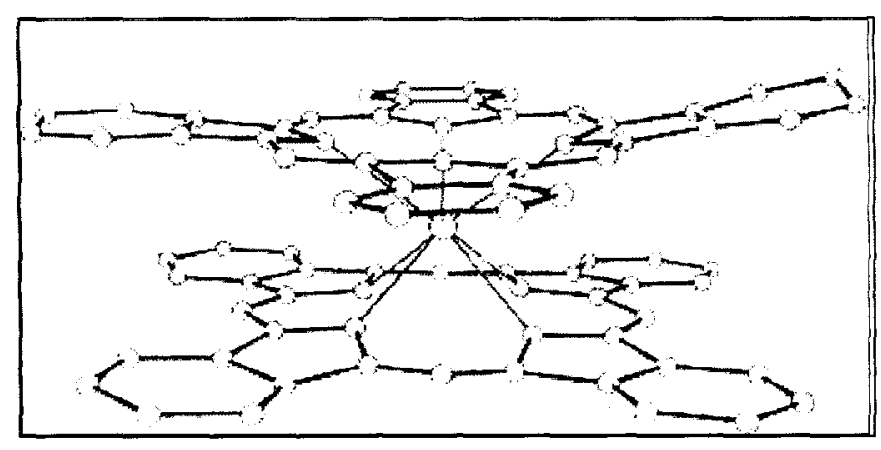

Figura 2.2: Bisftalocianina Metálica

As ftalocianinas possuem um sistema $\pi$ altamente conjugado, alta densidade de empacotamento no estado sólido [3,4], alta estabilidade em solventes orgânicos. Essas propriedades a tornam um material muito atraente para o trabalho com a técnica de formação de filmes finos Langmuir-Blodgett (LB) $[5,6]$, que será descrita no capítulo III.

A síntese de ftalocianinas metálicas sempre apresentou baixo rendimento e uma grande quantidade de subprodutos, tais como a ftalocianina livre, a monoftalocianina e as diferentes formas eletrocrômicas. Um método utilizado para a síntese da ftalocianina livre foi descrito por Tomoda [7]. Os métodos mais conhecidos para síntese de ftalocianinas metálicas são basicamente dois. $\mathrm{O}$ mais antigo, desenvolvido por Kirin (método a) [8], baseia-se no aquecimento a aproximadamente $300^{\circ} \mathrm{C}$ de um sal do metal com ftalonitrila. Essa síntese pode ser representada pelo esquema: 


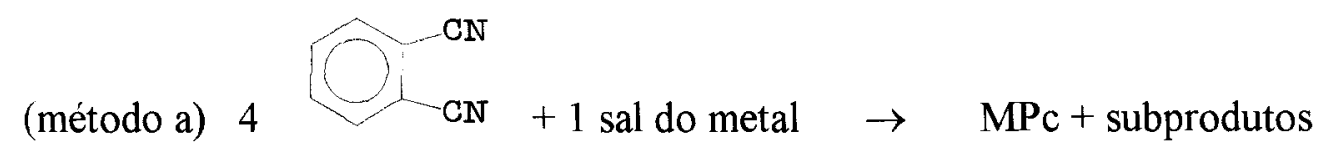

$2 \mathrm{~h}$

De Cian [9] demonstrou que um método alternativo de síntese poderia ser utilizado (b), obtendo-se maiores rendimentos. Esse método baseia-se na reação da ftalonitrila com um sal do metal. Essa reação é realizada sob refluxo em um álcool de cadeia longa, e utiliza 1,8- diazobiciclo [5.4.0] undec-7-ene (DBU) como catalisador. A reação pode ser representada pelo esquema:

\section{DBU}

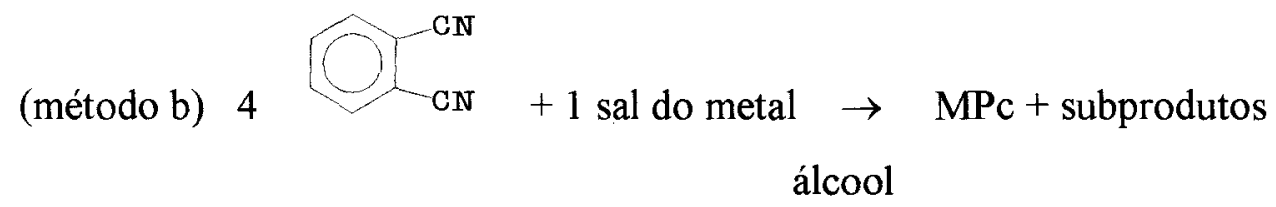

Um outro método, mais recente, é bastante utilizado para a síntese das ftalocianinas de ródio e rutênio [10-14]. Esse método (c) consiste no aquecimento de $o$-cianobenzamida, naftaleno e cloreto do metal, como mostrado a seguir:

\section{$200-300^{\circ} \mathrm{C}$}

12

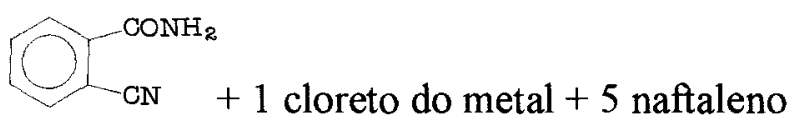

$\rightarrow \quad$ MPc + subprodutos

$1 \mathrm{~h}$

A eficácia do método depende do metal utilizado para a síntese da ftalocianina. Porém, independentemente do método, há necessidade de purificação do produto bruto. Os diversos métodos encontrados na literatura [15] para a purificação de ftalocianinas são:

- dissolução em ácido sulfúrico concentrado, seguida por precipitação em água gelada ou gelo;

- lavagem com vários solventes para a remoção de impurezas;

- métodos de sublimação;

- extração com solventes, seguida da evaporação do mesmo; 
- cromatografia em coluna usando alumina ou sílica gel comum, flash, ou vácuo;

- outros métodos, incluindo cromatografia em camada delgada (CCD) e cromatografia líquida de alta performance (HPLC).

A escolha do método de purificação depende do metal e do tipo de impureza obtido durante a síntese.

As ftalocianinas despertaram interesse devido às várias propriedades e ao alto potencial de aplicações por elas apresentado [15]. Esse tipo de composto tem propriedades elétricas e fotoelétricas, tais como: semicondutividade, fotocondutividade, reatividade fotoquímica, atividade fotossintética e luminescência, as quais são baseadas no sistema altamente conjugado das ftalocianinas metálicas [16]. No início dos estudos com ftalocianinas, a primeira e principal aplicação foi como pigmento [1], pois estes compostos apresentam uma intensa coloração azul ou verde, e possuem alta estabilidade térmica e química.

Uma aplicação de ftalocianinas com grande interesse tecnológico está em dispositivos de sensores de gases, principalmente tóxicos e inflamáveis. A adsorção de certas moléculas gasosas sobre a superficie de filmes de ftalocianinas produz uma significativa mudança nas suas propriedades elétricas. A resposta elétrica das ftalocianinas pode servir como base para um sensor químico para gases. Trabalhos com a ftalocianina de chumbo demonstraram que esta é sensível ao gás $\mathrm{NO}_{2} \mathrm{e} \mathrm{Cl}_{2}$ $[17,18]$. Ftalocianinas de cobre substituídas também são sensíveis ao gás $\mathrm{NO}_{2}[19]$.

As ftalocianinas podem formar filmes LB, cuja condutividade elétrica pode sofrer rápida mudança com a adsorção de gás. Como a condutividade de filmes LB de ftalocianinas é baixa, é necessário um microeletrodo interdigitado para que as medidas elétricas sejam confiáveis [20]. Com a deposição de filmes LB de ftalocianinas nesses microeletrodos interdigitados, podem ser feitas medidas de condutividade elétrica e observadas as mudanças ocorridas por exposição a gases como $\mathrm{NO}$ e $\mathrm{NO}_{2}$ [21]. Rella e colaboradores [22] estudaram as mudanças nas propriedades elétricas da $\mathrm{Cu}(\mathrm{bc}) \mathrm{Pc}$ na presença do gás $\mathrm{NO}_{2}$. CuPc é a ftalocianina de cobre, sendo bc o substituinte tetrakis(n-butoxicarbonil). A condutividade elétrica dos filmes $\mathrm{LB}$ da $\mathrm{Cu}(\mathrm{bc}) \mathrm{Pc}$ muda consideravelmente na presença de pequenas quantidades do gás altamente tóxico $\mathrm{NO}_{2}$ na atmosfera. Souto e colaboradores [23] estudaram as mudanças nas propriedades elétricas e espectroscópicas de filmes da bisftalocianina de itérbio $\left(\mathrm{YbPc}_{2}\right)$, quando expostos a poluentes gasosos comuns 
como o $\mathrm{NO}_{\mathrm{x}}$ e o tabaco (substância presente no cigarro). Para este estudo as monocamadas de $\mathrm{YbPc}_{2}$ foram transferidas para eletrodos interdigitados de ouro através da técnica LB. As medidas, realizadas a diferentes temperaturas, apresentaram uma diminuição na condutividade com o aumento da temperatura. A exposição da amostra ao gás $\mathrm{NO}_{\mathrm{x}}$ causou decréscimo na condutividade, o que também foi observado para a exposição ao tabaco. Richardson e colaboradores [24] estudaram as propriedades espectroscópicas de filmes LB da bisftalocianina de gadolíneo $\left(\mathrm{GdPc}_{2}\right)$ expostos a baixas concentrações de gás cloro. Existe certa dificuldade em trabalhar com vapores do gás cloro devido a este ser corrosivo, podendo deteriorar o filme. Isso não ocorre para as ftalocianinas, que têm excelente estabilidade e não são afetadas pelos vapores de cloro. Pôde-se observar dramáticas mudanças no espectro de absorção do filme na região do visível após a exposição aos vapores do gás cloro durante vinte minutos.

As ftalocianinas exibem diferentes cores, relacionadas às suas formas eletrocrômicas [25,26], o que despertou interesse para utilização em dispositivos eletrocrômicos. As cores podem ser: violeta, azul, verde, laranja e vermelho, das quais as formas conhecidas como azul e verde são as mais estáveis [27].

\subsection{Síntese e Purificação das Ftalocianinas}

As sínteses das ftalocianinas de ródio, rutênio e paládio foram adaptadas de métodos conhecidos na literatura. Devido à dificuldade de obtenção dessas ftalocianinas em quantidades razoáveis e sem muitas impurezas, várias sínteses foram realizadas com diferentes métodos. As ftalocianinas podem ser obtidas nas formas monomérica, dimérica, e de bisftalocianinas. Em uma mesma síntese, as três formas podem ser obtidas, porém pode ser difícil separá-las. Essas diferentes formas das ftalocianinas podem ser distinguidas através dos espectros na região do ultravioleta-visível, já que apresentam diferentes espectros eletrônicos específicos. Nas figuras 2.3 e 2.4 são apresentadas as transições eletrônicas das formas monomérica, dimérica e em uma bisftalocianina [15]. As denominações ${ }^{1} A_{1 \mathrm{~g}},{ }^{1} \mathrm{E}_{\mathrm{u}}$, ${ }^{1} E_{g},(\pi) e_{g},(\pi) b_{2 u},(\pi) a_{2 u}$ e $\pi^{*}\left(e_{g}^{*}\right)$ são representações para os níveis energéticos, sendo que a representação ${ }^{*}$ indica que o orbital é anti-ligante. Observa-se que acontecem 
apenas duas transições para o monômero, uma para a banda $\mathrm{Q}$ e outra para a banda B. Já no dímero, ocorre um desdobramento dos níveis E e com o desdobramento, mais de uma transição pode ocorrer para regiões de maior energia [15].

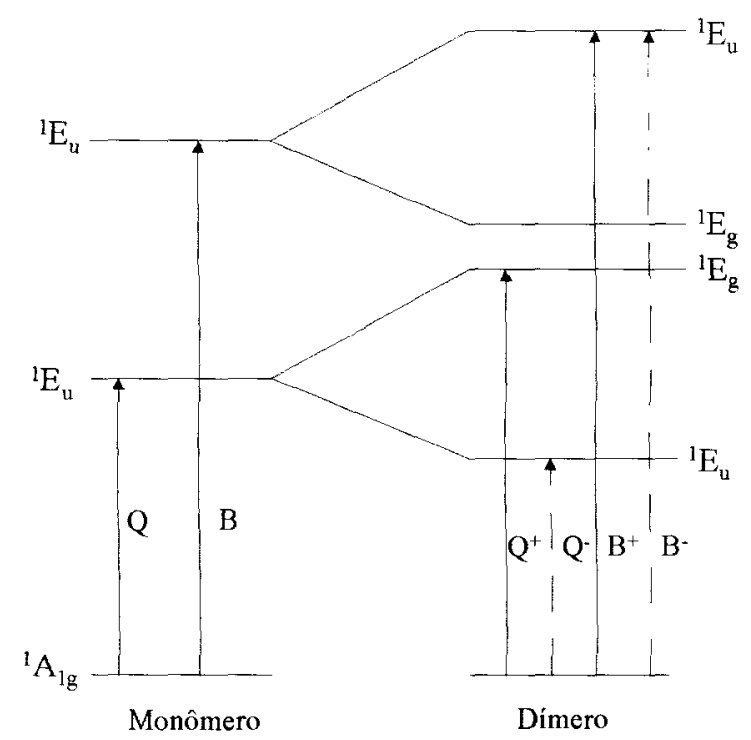

Figura 2.3: Transições eletrônicas para ftalocianinas nas formas de monômero e dímero

No caso das bisftalocianinas, existe maior desdobramento dos níveis energéticos, permitindo mais transições eletrônicas, como pode ser observado na figura 2.4. A banda correspondente à transição $\mathrm{e}_{\mathrm{g}} \rightarrow \mathrm{a}_{2 \mathrm{u}}$ é característica de ftalocianinas na forma eletrocrômica verde [28]. Uma bisftalocianina na forma eletrocrômica azul não apresenta essa transição. 


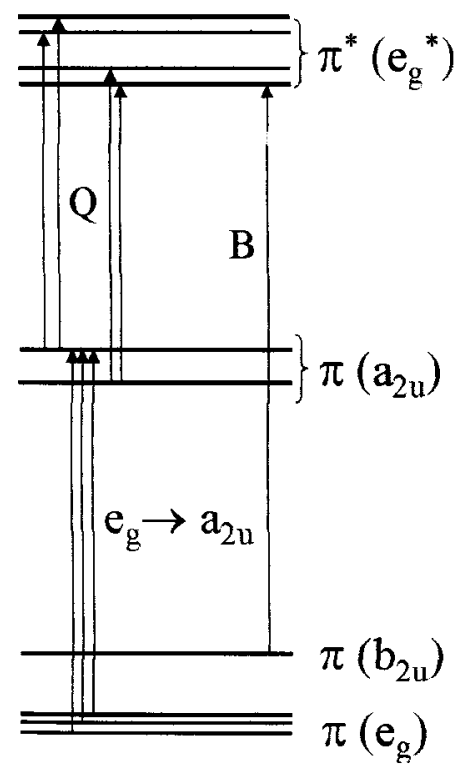

Figura 2.4: Transições eletrônicas para uma bisftalocianina na forma eletrocrômica verde

Para caracterização das frações obtidas nas sínteses das ftalocianinas de ródio, rutênio e paládio, foram utilizadas as técnicas de espectroscopia na região do infravermelho e ultravioleta-visível (UV-vis.). Após a purificação dos compostos foi feita análise elementar de carbono, nitrogênio e hidrogênio. Os espectros na região do ultravioleta-visível foram registrados em um aparelho espectrofotômetro Hitachi, modelo U-2001. Os solventes utilizados foram tolueno, acetonitrila, dimetilformamida e diclorometano para a PdPc e clorofórmio para a RhPc e a RuPc. A região de registro foi de 190 a $1100 \mathrm{~nm}$, utilizando cubeta de quartzo de caminho ótico de $1 \mathrm{~cm}$. A caracterização espectroscópica na região do infravermelho foi realizada em um espectrofotômetro Bomen, modelo MB 102. Foram utilizadas pastilhas de $\mathrm{KBr}$ e a resolução do equipamento foi $4 \mathrm{~cm}^{-1}$. Foi feita correção da linha base em todos os espectros na região do infravermelho apresentados neste capítulo. As atribuições para as bandas encontradas foram tentativas, baseadas em artigos sobre ftalocianinas. $\mathrm{O}$ teor de carbono $(\mathrm{C})$, nitrogênio $(\mathrm{N})$ e hidrogênio $(\mathrm{H})$ foram determinados por análise elementar utilizando-se um analisador Fision, modelo EA 1108 . 


\subsubsection{Síntese e Purificação da Ftalocianina de Paládio (PdPc)}

A ftalocianina de paládio foi sintetizada três vezes, com o objetivo de se obter maiores quantidades de duas das três diferentes frações apresentadas por essa síntese Duas dessas frações, obtidas em quantidade mínima, eram solúveis em solventes orgânicos. Como em nenhuma das três tentativas de síntese foi possível a obtenção de maiores quantidades do composto, alguns trabalhos foram realizados com a fração obtida em maior quantidade. A seguir, é descrita a sintese da PdPc através da qual obteve-se o composto na forma mais pura.

Para a realização dessa síntese, foi seguida a rota sintética do método a, descrito no item 2.1. Foi utilizada proporção molar de reagentes 1:8, reagindo-se $2,299 \mathrm{~g}(20,00 \mathrm{mmol})$ de ftalonitrila e $0,379 \mathrm{~g}(2,50 \mathrm{mmol})$ de cloreto de paládio em um frasco de vidro com saída para gases. Esse frasco foi aquecido em um banho de areia sobre uma placa aquecedora durante 2 horas, a uma temperatura de $300^{\circ} \mathrm{C}$. Após resfriamento do frasco, o mesmo foi quebrado para retirada do sólido formado.

A purificação do produto bruto foi iniciada através de uma extração em soxhlet com etanol. Após a extração, o solvente foi evaporado, obtendo-se um sólido azul. O composto restante no papel de filtro foi submetido a nova extração, desta vez com clorofórmio. Após evaporação do solvente, obteve-se uma fração verde. As duas frações e o composto restante no papel de filtro foram identificados através de espectroscopias na região do infravermelho e do ultravioleta visível. As frações resultantes das extrações em solventes estavam impuras e não havia quantidade suficiente para continuar a purificação. A fração restante no papel de filtro, em maior quantidade, foi seca em estufa a vácuo e submetida novamente ao processo de extração em soxhlet com acetona. A fração restante no papel de filtro foi identificada como pura. Essa fração, porém, era muito pouco solúvel em solventes orgânicos, apresentando alguma solubilidade em tolueno, acetonitrila, dimetilformamida (DMF) e diclorometano. Devido a essa dificuldade de solubilização, as propriedades do PdPc não puderam ser estudadas através da técnica LB. Entretanto, a PdPc foi usada para formação de filmes por sublimação, cujos resultados são apresentados no Capitulo IV.

Os espectros eletrônicos de ftalocianinas na região do infravermelho apresentam bandas típicas referentes às ligações entre os carbonos, carbono com 
nitrogênio e carbono com hidrogênio [3,29-31]. As ligações nitrogênio-metal não são facilmente observadas nos espectros na região do i.v. porque aparecem em regiões abaixo de $300 \mathrm{~cm}^{-1}$. Utilizando pastilhas de $\mathrm{KBr}$, a região de registro ficou entre 400 e $4000 \mathrm{~cm}^{-1}$ não sendo possivel detectar essas bandas.

O espectro na região do i.v. para a PdPc pura é mostrado na figura 2.5 e está de acordo com a literatura. Na tabela 2.1 se encontram as atribuições tentativas para as principais bandas da PdPc após purificação.

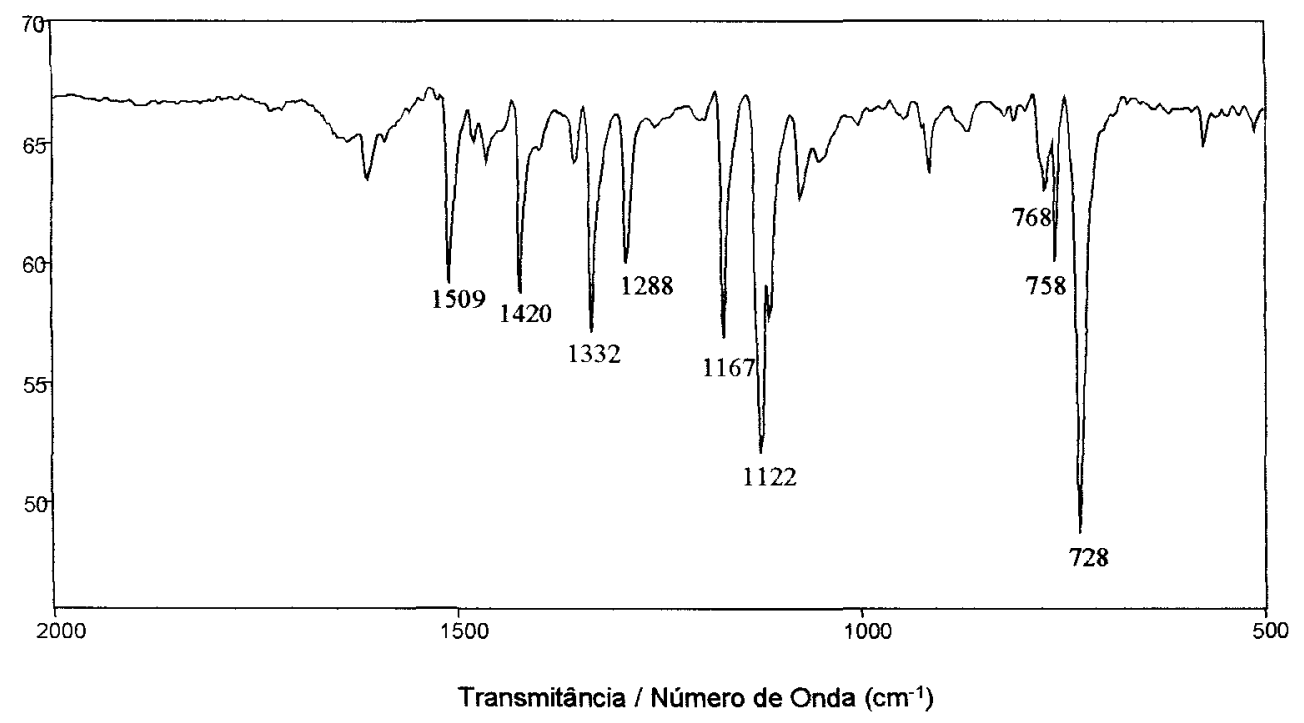

Figura 2.5: Espectro de absorção na região do i.v. da PdPc

Tabela 2.1: Números de onda e atribuições para o espectro i.v. da PdPc

\begin{tabular}{|c|c|}
\hline PdPc & Atribuição Tentativa \\
\hline 728 & Deformação do anel fora do plano \\
\hline 758 & Deformação do anel no plano \\
\hline 768 & Respiração do anel benzênico \\
\hline 1122 & Deformação angular de C-H \\
\hline 1167 & Deformação angular de C-H \\
\hline 1288 & Deformação C-H no plano \\
\hline 1332 & Estiramento isoindol \\
\hline 1420 & Estiramento isoindol \\
\hline 1509 & Estiramento pirrol C $=\mathrm{C}$ \\
\hline
\end{tabular}

Os espectros na região do UV-Vis. para a PdPc nos solventes DMF, tolueno e acetonitrila, apresentados na figura 2.6, são típicos de ftalocianinas na forma de monômero/dímero [15]. Podem ser observadas duas bandas Q, uma em aproximadamente $610 \mathrm{~nm}$ referente à forma dimérica e outra em aproximadamente $660 \mathrm{~nm}$ referente à forma monomérica. A banda $\mathrm{B}$ é observada em aproximadamente 
$330 \mathrm{~nm}$. Sabe-se da literatura que algumas ftalocianinas apresentam bandas em regiões abaixo de $300 \mathrm{~nm}$, denominada banda $\mathrm{N}$ [15]. Utilizando o solvente acetonitrila, foi observada uma banda em $278 \mathrm{~nm}$, que pode ser a banda N. Na figura 2.7, pode-se observar o espectro na região do UV-Vis. da PdPc em diclorometano, típico de ftalocianinas na forma monomérica [15], apresentando a banda Q bem definida em $653 \mathrm{~nm}$. Uma banda de menor intensidade aparece em $590 \mathrm{~nm}$. A banda B foi observada em $335 \mathrm{~nm}$, e não aparece no espectro devido à sua intensidade, maior que o limite de deteç̧ão do equipamento. Nos espectros da figura 2.6, provavelmente a banda em $590 \mathrm{~nm}$ não foi observada devido ao alargamento das bandas Q.

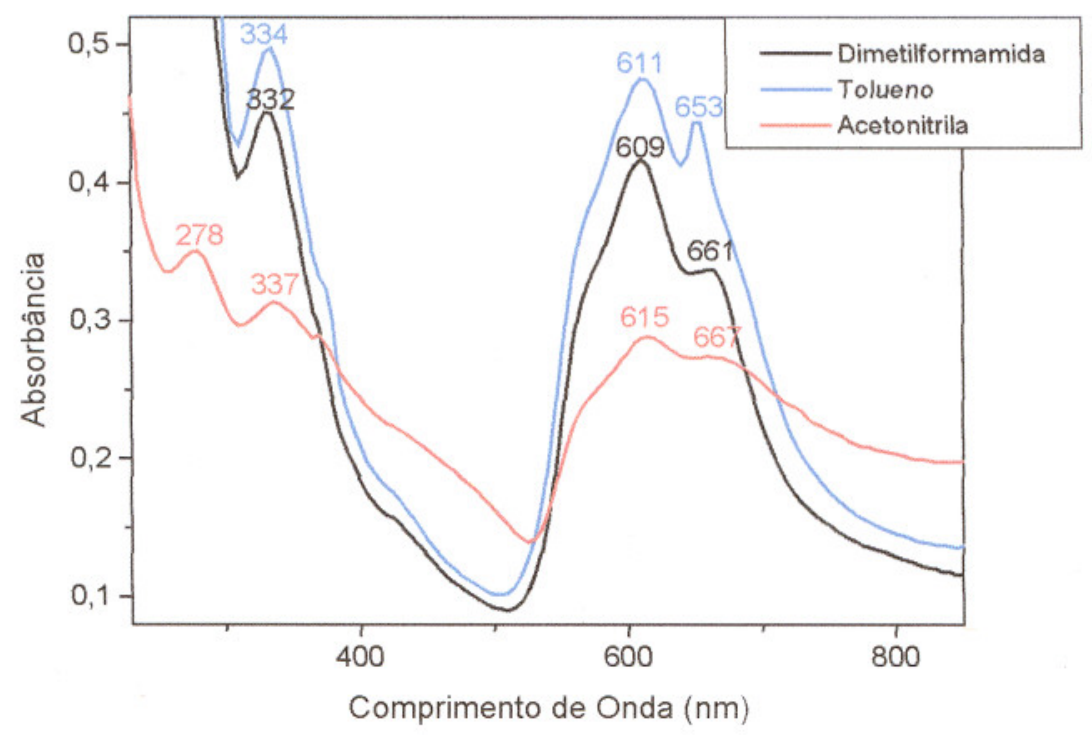

Figura 2.6: Espectro de absorção na região do UV-Vis. da PdPc em diferentes solventes 


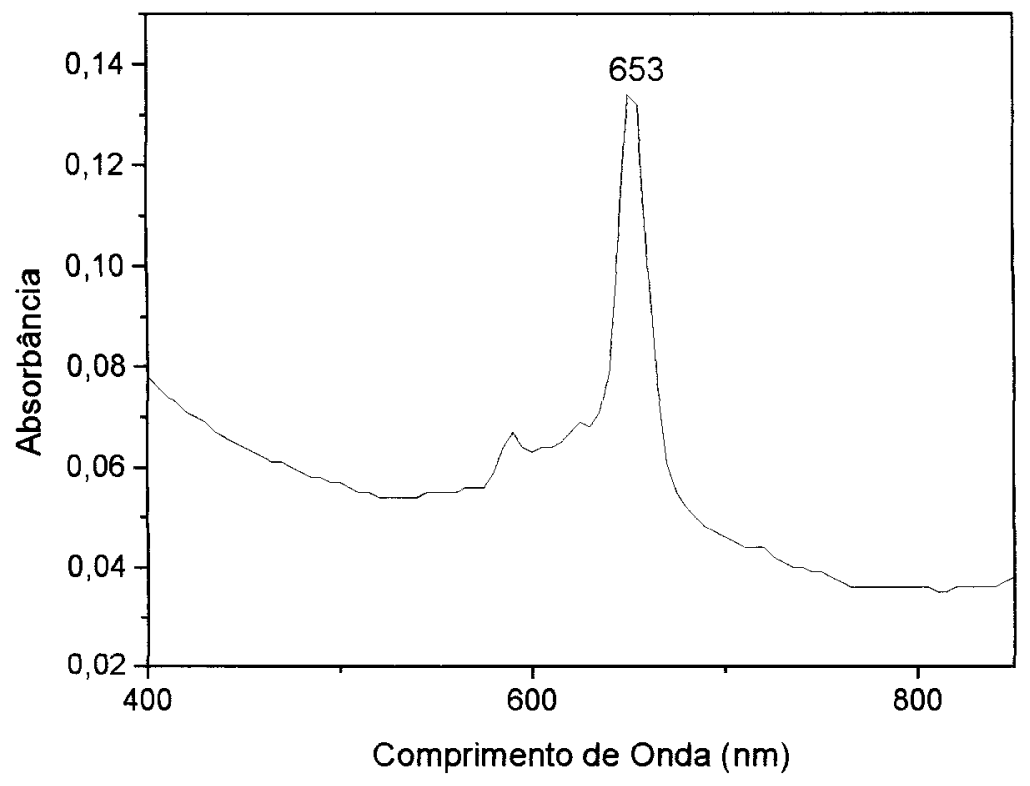

Figura 2.7: Espectro de absorção na região do UV-Vis. da PdPc em diclorometano

Através dos espectros na região do UV-Vis. da PdPc observou-se que duas frações da ftalocianina foram obtidas na síntese. Uma delas dimérica, onde duas PdPc estão ligadas por uma ponte contendo dois $\mathrm{Cl}$, como representado na figura 2.8 . $\mathrm{Na}$ outra, existe apenas um anel $\mathrm{PdPc}$ com um $\mathrm{Cl}$ ligado ao metal. Os solventes DMF, tolueno, acetonitrila, deslocam o equilíbrio para a forma dimérica, porém a monomérica também apresenta solubilidade nesse solvente, sendo que no espectro na região do UV-Vis. são observadas as bandas para as duas formas. Em diclometano, o equilíbrio é deslocado para a forma monomérica, já que observa-se somente a banda referente à esta forma em $653 \mathrm{~nm}$. 


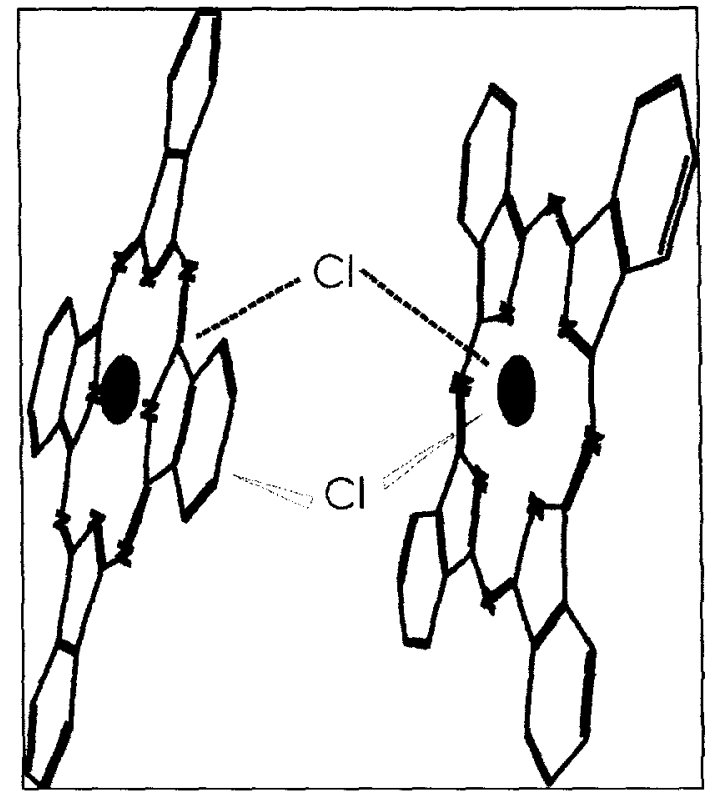

Figura 2.8: Representação da PdPc em forma de dimero

Os resultados da análise elementar apresentaram os dados da tabela 2.2. Os valores teóricos mais próximos dos experimentais indicam que o anel ftalocianina provavelmente contém dois ligantes cloro ligados em ponte, como ilustrado na figura 2.8 .

Tabela 2.2: Resultados de análise elementar para a PdPc

\begin{tabular}{|c|c|c|}
\hline & Teórico (\%) & Experimental (\%) \\
\hline $\mathrm{C}$ & 58,735 & 59,799 \\
\hline $\mathrm{N}$ & 17,123 & 17,648 \\
\hline $\mathrm{H}$ & 2,463 & 2,325 \\
\hline
\end{tabular}

\subsubsection{Síntese e Purificação da Ftalocianina de Ródio (RhPc)}

Para a síntese da $\mathrm{RhPc}$, assim como para a da $\mathrm{PdPc}$, foram necessárias mais de uma síntese para a obtenção do produto de interesse. Duas sínteses foram realizadas através do método a, item 2.1 . Na primeira, o produto obtido degradou-se durante a primeira etapa de purificação. O produto bruto, que apresentava coloração azul, foi aquecido a aproximadamente $250^{\circ} \mathrm{C}$ para a retirada da ftalonitrila (reagente de partida). Observou-se que o sólido, após aquecimento, passou a apresentar uma coloração marrom. A análise por espectroscopia na região do i.v. mostrou que o 
composto havia sofrido degradação, devido à ausência das bandas típicas de ftalocianinas. Na síntese 2, obteve-se três diferentes frações da RhPc, porém, devido à pequena quantidade de material obtido, não foi possível a purificação do produto. Analisando os produtos das sínteses 1 e 2 , observou-se que a adaptação do método de Kirin [8] não era eficiente para a síntese da RhPc. A quantidade de produto obtido era mínima e continha muita impureza. Nova busca na literatura revelou que um outro método de síntese era utilizado para compostos como a RhPc e a RuPc. Foi realizada então uma nova síntese, desta vez utilizando o método c, também apresentado no item 2.1

Para essa síntese reagiu-se $2,00 \mathrm{~g}$ de $o$-cianobenzamida com $0,22 \mathrm{~g}$ de cloreto de ródio e $0,67 \mathrm{~g}$ de naftalina durante 2 horas, a uma temperatura de $290^{\circ} \mathrm{C}$. Após resfriamento, o produto bruto foi submetido à extração em soxhlet com ácido acético por 36 horas. O ácido acético foi evaporado e tanto a fração restante no papel de filtro quanto a restante da extração do ácido acético foram secas em estufa a vácuo por $24 \mathrm{~h}$. O sólido extraído no ácido acético foi submetido novamente em soxhlet com etanol. As frações extraídas no etanol e restante no papel de filtro apresentaram espectros semelhantes mas contendo impurezas. A fração mais adequada para continuidade dos trabalhos foi a restante no papel de filtro, que foi submetida a nova extração em soxhlet com clorofórmio. O material restante no papel de filtro, apesar de conter alguns traços do material de partida (o-cianobenzamida), foi o mais adequado para continuidade dos trabalhos, inclusive os através da técnica LangmuirBlodgett.

As espectroscopias na região do UV-Vis. e do i.v. foram utilizadas para acompanhar as etapas de purificação do composto. Através do espectro de UV-Vis. da RhPc (figura 2.9), observa-se que o composto encontra-se na fase monomérica, apresentando a banda Q em $655 \mathrm{~nm}$ e a banda $\mathrm{B}$ em $345 \mathrm{~nm}$. A RhPc também é um dos casos de ftalocianinas que apresentam a banda $\mathrm{N}$, que foi observada em $280 \mathrm{~nm}$. 


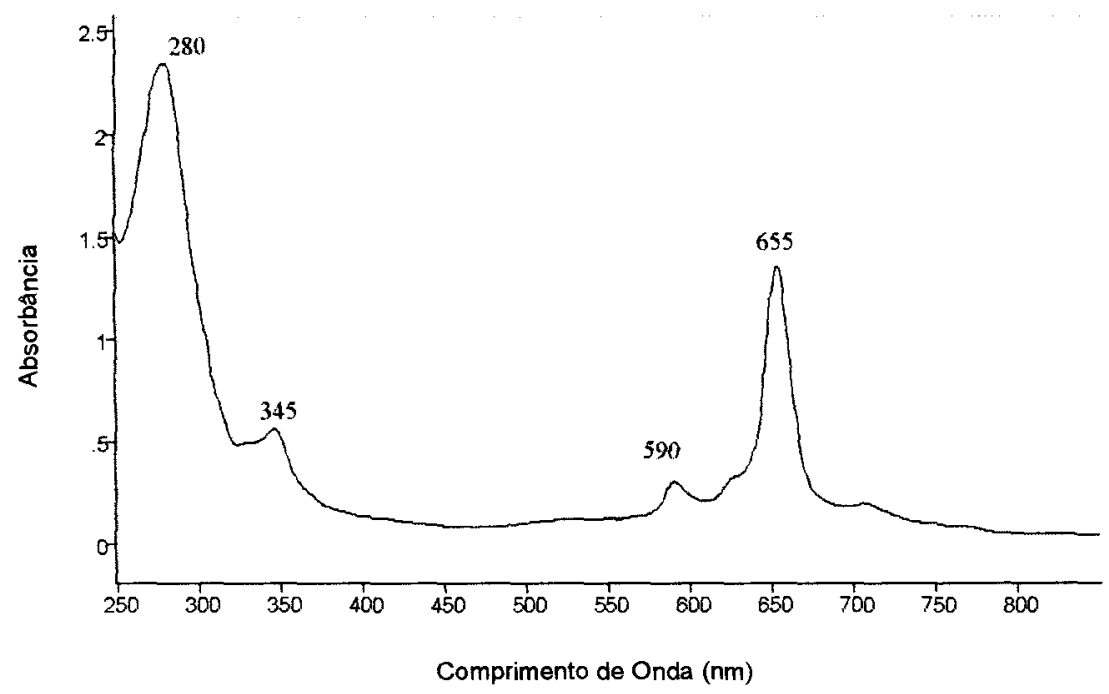

Figura 2.9: Espectro de absorção na região do UV-Vis. da RhPc após purificação (clorofórmio)

O espectro na região do infravermelho da figura 2.10 apresenta a maioria das bandas típicas de Pcs, atribuídas na tabela 2.3. As bandas em 1716 e $2221 \mathrm{~cm}^{-1}$ são típicas do composto de partida $o$-cianobenzamida.

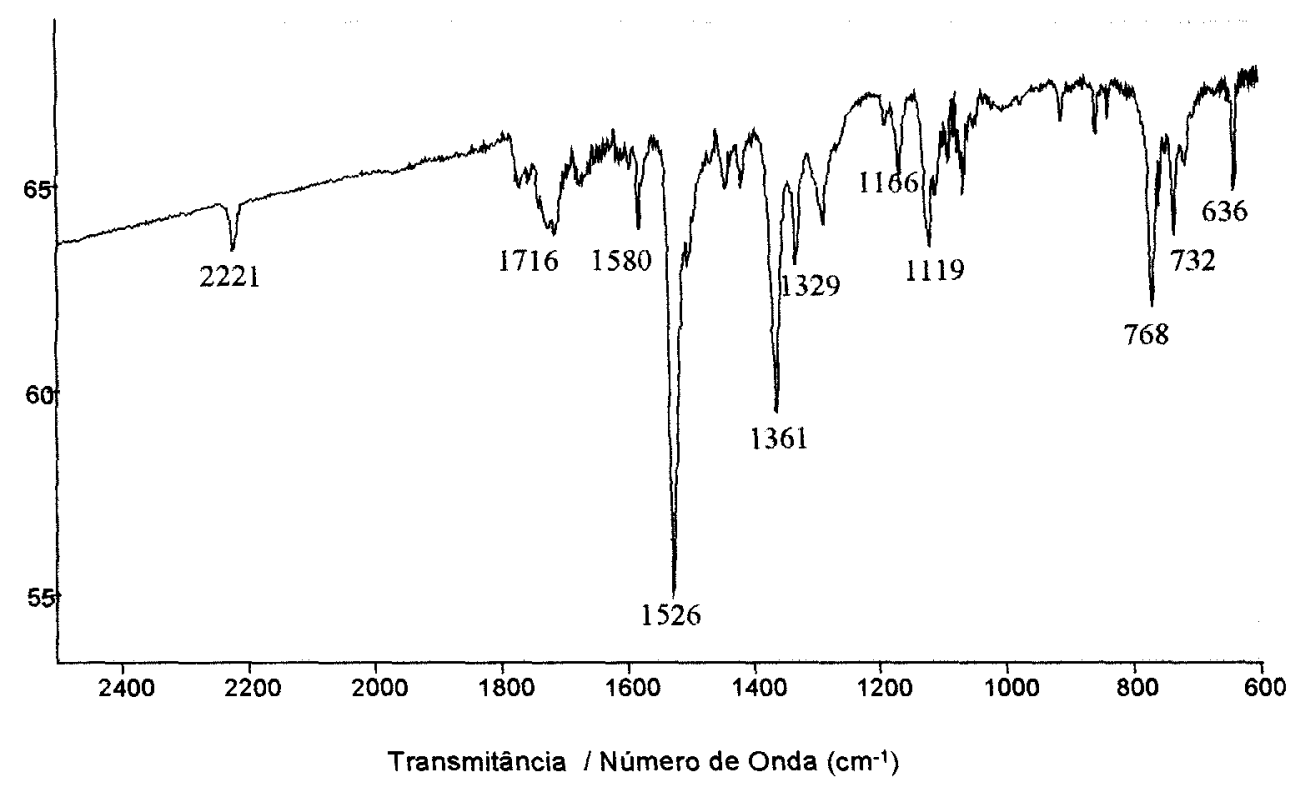

Figura 2.10: Espectro de absorção na região do i.v. da RhPc após purificação 
Tabela 2.3: Números de onda e atribuições para o espectro na região do i.v. da RhPc

\begin{tabular}{|c|c|}
\hline RhPc & Atribuição Tentativa \\
\hline 718 & Deformação do anel fora do plano \\
\hline 732 & Deformação do anel fora do plano \\
\hline 768 & Respiração do anel benzênico \\
\hline 1119 & Deformação angular de C-H \\
\hline 1166 & Deformação angular de C-H \\
\hline 1329 & Estiramento isoindol \\
\hline 1361 & Estiramento isoindol \\
\hline 1526 & Estiramento pirrol C=N \\
\hline 1580 & Estiramento C=C do anel benzênico \\
\hline
\end{tabular}

Os cálculos de análise elementar foram realizados sem considerar o metal, apresentando os resultados da tabela 2.4. Os valores teóricos que mais se aproximaram dos experimentais foram obtidos considerando a presença de uma molécula de $o$-cianobenzamida ligada na molécula de RhPc .

Tabela 2.4: Resultados de análise elementar para a RhPc

\begin{tabular}{|c|c|c|}
\hline & Teórico (\%) & Experimental (\%) \\
\hline $\mathrm{C}$ & 72,94 & 73,27 \\
\hline $\mathrm{N}$ & 21,27 & 20,55 \\
\hline $\mathrm{H}$ & 3,37 & 3,42 \\
\hline
\end{tabular}

\subsubsection{Síntese e Purificação da Ftalocianina de Rutênio (RuPc)}

A ftalocianina de rutênio (RuPc) foi o composto mais difícil de ser sintetizado e, apesar de várias tentativas, não foi obtido o produto com características adequadas para o estudo de suas propriedades. Foram realizadas três sínteses através do método a, item 2.1, porém, todas sem sucesso.

O método c, que utiliza $o$-cianobenzamida como um dos precursores da síntese, utilizado para sintetizar a RhPc foi também empregado em uma nova síntese para a RuPc. Nessa síntese, reagiu-se $2,00 \mathrm{~g}$ de $o$-cianobenzamida com $0,20 \mathrm{~g}$ de 
cloreto de rutênio e $0,80 \mathrm{~g}$ de naftalina durante 2 horas a uma temperatura de $290^{\circ} \mathrm{C}$ (banho de areia). Após resfriamento, o frasco de vidro que continha o produto bruto foi quebrado, e foi iniciada a purificação. Foi feita uma extração em soxhlet com ácido acético por 36 horas. $\mathrm{O}$ ácido acético foi evaporado e tanto a fração restante no papel de filtro quanto a restante da extração do ácido acético foram secas em estufa a vácuo por $24 \mathrm{~h}$. A fração solúvel no ácido acético apresentou bandas não características de ftalocianinas. A fração restante no papel de filtro apresentou um espectro na região do i.v. mais próximo de uma Pc, sendo então realizada uma extração com etanol e clorofórmio. O clorofórmio foi evaporado, obtendo-se uma das frações dessa ftalocianina (figuras 2.11 e 2.12).

O espectro na região do UV-Vis. da figura 2.11 apresenta duas bandas $Q$, indicando a presença de mais de uma forma da ftalocianina metálica. As duas bandas Q são referentes ao dímero $(590 \mathrm{~nm})$ e ao monômero $(646 \mathrm{~nm})$. Como foi comentado para a $\mathrm{RhPc}$, algumas ftalocianinas apresentam bandas em regiões abaixo de $300 \mathrm{~nm}$ [15]. A RuPc, assim como a RhPc, deve ser um desses casos, pois foi observada uma banda em $275 \mathrm{~nm}$.

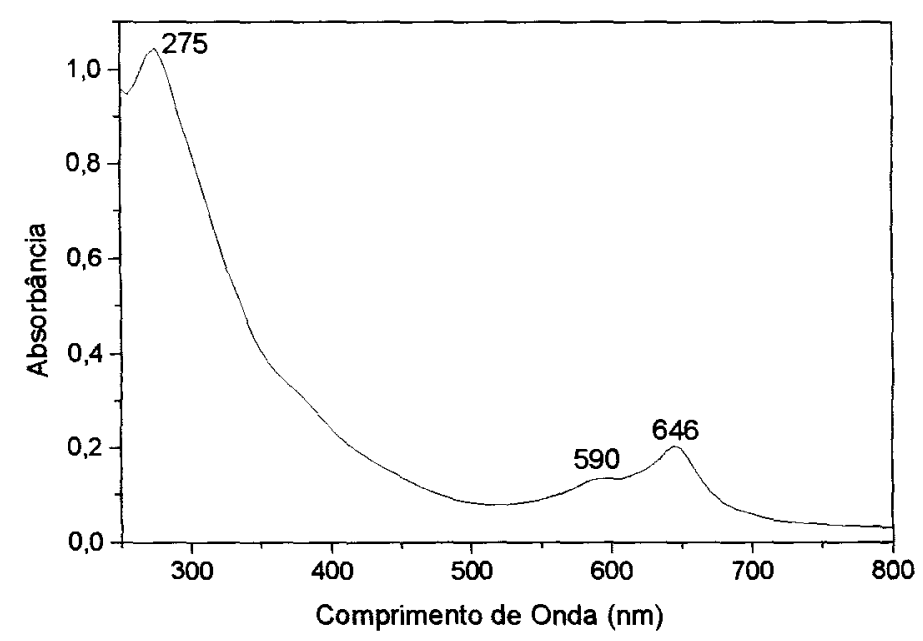

Figura 2.11: Espectro de absorção na região do UV-Vis. da RuPc em clorofórmio (fração solúvel em clorofórmio)

No espectro na região do i.v. da figura 2.12, observa-se a banda em 2225 $\mathrm{cm}^{-1}$, típica do precursor $o$-cianobenzamida e também uma banda $\mathrm{em} 1734 \mathrm{~cm}^{-1}$, que não é típica de ftalocianinas. As demais bandas apresentadas são típicas de Pc e estão de acordo com a literatura [2-5] 


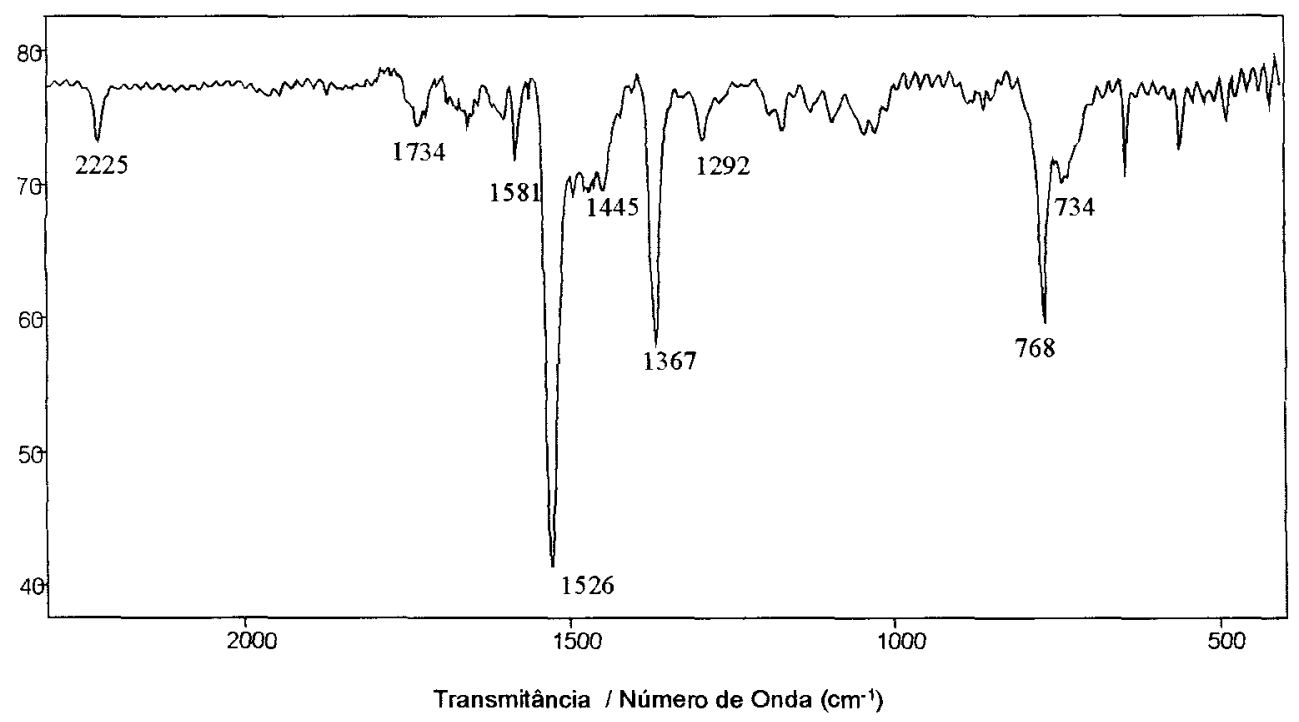

Figura 2.12: Espectro de absorção na região do i.v. da RuPc

(fração solúvel em clorofórmio)

A outra fração obtida foi a restante no papel de filtro após as extrações em etanol e clorofórmio (figuras 2.13 e 2.14). O espectro na região do UV-Vis. da figura 2.13 também parece ser de uma ftalocianina na forma de dímero [1], apresentando duas bandas $\mathrm{Q}$ bastante alargadas. Essa fração do composto pode conter dois anéis ligados por cloros como ocorre na PdPc ou ainda por outros átomos. A banda B aparece em $310 \mathrm{~nm}$.

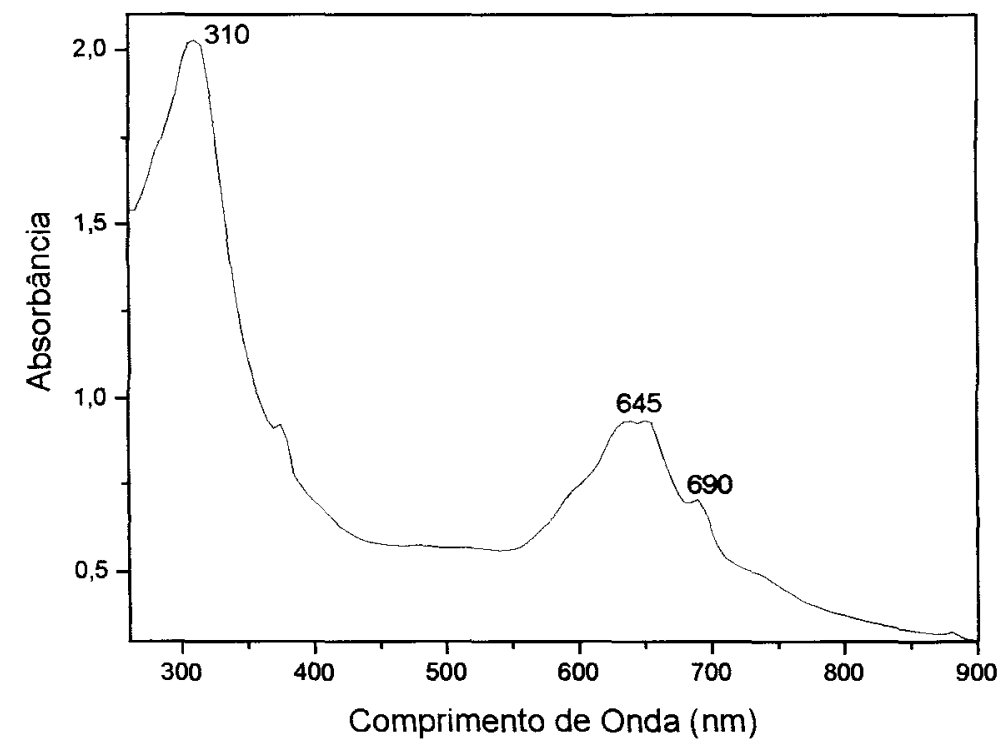

Figura 2.13: Espectro de absorção na região do UV-Vis. da RuPc em clorofórmio (fração restante no papel de filtro) 
No espectro na região do i.v. da figura 2.14 não é observada a banda em $2221 \mathrm{~cm}^{-1}$, típica do precursor usado na síntese (o-cianobenzamida). No entanto, é observada a banda em $1723 \mathrm{~cm}^{-1}$, não típica de $\mathrm{Pc}$, e a região entre 720 e $775 \mathrm{~cm}^{-1}$ apresenta muitas bandas, o que não é comum para as ftalocianinas puras. Apesar de apresentar a maioria das bandas características de Pcs, parece existir ainda mais de uma forma da RuPc, não tendo sido possível isolar as várias frações que podem ter sido obtidas durante a síntese.

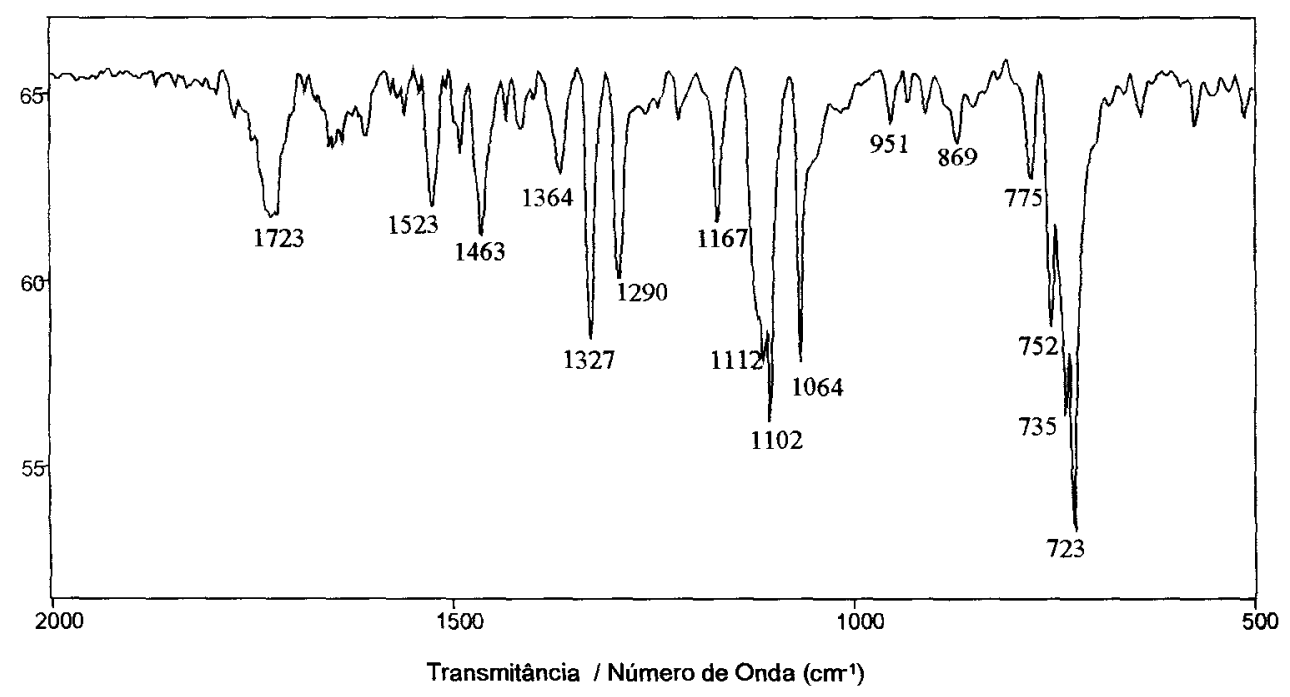

Figura 2.14: Espectro de absorção na região do i.v. da RuPc (fração restante no papel de filtro)

A RuPc não foi utilizada para as medidas do presente trabalho porque, apesar das várias tentativas de purificação, não foi possível a obtenção de uma de suas frações pura.

\subsection{Conclusões}

A rota sintética descrita por Kirin [8] foi utilizada com bons resultados na síntese da PdPc. Apesar da obtenção de três diferentes frações da ftalocianina somente uma foi obtida com a pureza necessária e em quantidade suficiente para continuidade dos trabalhos. A caracterização por espectroscopias na região do UVVis. e infravermelho mostrou que o composto obtido está de acordo com o observado 
na literatura. Da análise elementar, inferiu-se que dois anéis da PdPc estão ligados por uma ponte contendo dois $\mathrm{Cl}$. Foi observado ainda o efeito do solvente sobre o equilíbrio monômero/dímero da PdPc. Dependendo do solvente utilizado, ocorre maior solubilização do monômero ou do dímero. Diclorometano desloca o equílibrio totalmente para o monômero, mas os outros solventes, dimetilformamida, tolueno e acetonitrila, mostram um equilíbrio entre as duas espécies.

Para a síntese da RhPc, o método de Kirin [8] não foi eficiente, sendo utilizado o método c descrito no item 2.1 [10-14], através do qual obteve-se o produto de interesse. Observou-se, através do espectro na região do infravermelho, a presença de resíduos de o-cianobenzamida, o que foi confirmado através dos resultados de análise elementar.

$\mathrm{O}$ método de síntese de Kirin também não apresentou eficiência na síntese da RuPc, sendo utilizado o mesmo método adotado para sintetizar a RhPc. Na síntese da RuPc foram obtidas duas diferentes frações do composto, que puderam ser isoladas, porém, não foi possível a total purificação das mesmas. 


\subsection{Bibliografia}

1. KASUGA, K.; TSUTSUI, M., Coordination Chemistry Reviews, v.32, p.67, 1980.

2. BARRET, P. A.; DENT, C. E.; LINSTEAD, R. P., J. Chem. Soc., p.1719, 1936.

3. BERNO, B.; NARZI, A; AROCA, R., J. Raman Spectroscopy, v.27, p.41, 1996.

4. ROUSSEAU, R.; AROCA, R.; RODRÍGUEZ-MÉNDEZ, M. L., Journal of Molecular Structure, v.49, p.356, 1995.

5. PALACIN S., Advances in Colloid and Interface Science, v.87, p. 165, 2000.

6. NABOK, A. V.; RAY, A. K.; HASSAN, A.K.; TRAVIS, J. R.; COOK, M. J., Supramolecular Science, v.4, p.407, 1997.

7. TOMODA, H.; SAITO, S.; OGAWA, S.; SHIRAISHI, S.; MINATO-KU, S.; MINATO-KU, R., Chemistry Letters, p. 1277, 1980

8. KIRIN, I. S.; MOSKALEV, P. N.; MASKASHEV, Y. A., Russ. J. Inorg. Chem., v.12 (3), p.369, 1967.

9. DE CIAN, A.; MOUSSAVI, M.; FISHER, J.; WEISS, R., Inoganic Chemistry, v.24, p.3162, 1985.

10. DOLPHIN, D.; JAMES, B. R.; MURRAY, A. J. Can. J. Chem., v.58, p.1125, 1980 .

11. FARREL, N. P.; MURRAY, A. J.; THORNBACK, D.; DOLPHIN, H.; JAMES, B. R., Inorganica Chimica Acta, v.28, p.144, 1978.

12. KEEN, I. M.; MALERBI, B. W., J. Inorg. Nucl. Chem., v.27, p.1311, 1965.

13. NYOKONG, T., J. Chem. Soc. Dalton Trans., p. 1359, 1994.

14. ROSSI, G.; GARDINI, M.; PENNESI, G.; ERCOLANI, C.; GOEDKEN, V. L., J. Chem. Soc. Dalton Trans., p. 193, 1989.

15. LEZNOFF, C. C.; LEVER, A. B. P., Phtlalocyanines Properties and Applications, Vol.1, V. C. H. Publishers, New York, 1989.

16. OMIYA, S.; TSUTSUI, M.; MEYER JR., E. F.; BERNAL, I.; CULLEN, D.L., American Chemical Society, v.19, p.134, 1980.

17. COLlinS, R. A.; ABBAS, A. K.; KRIER, A., Thin Solid Films, 239, 268, 1994.

18. SCHOCH JR., K. F.; TEMOFONTE, T. A., Thin Solid Films, 165, 83, 1988. 
19. RELLA, R.; SERRA, A.; SICILIANO, P.; TEPORE, A.; VALLI, L.; ZOCCO, A., Thin Solid Films, v.286, p.256, 1996.

20. AROCA, R.; BOLOURCHI, H.; BATTISTI, D.; NAJAFI, K., Langmuir, v.9, p.3138, 1993

21. MOREIRA, W. C.; AROCA, R., Spectrochimica Acta, v.51A, p.2325, 1995.

22. RELLA, R.; SERRA, A.; SICILIANO, P.; TEPORE, A.; VALLI, L.; ZOCCO, A., Supramolecular Science, v.4, p.461, 1997.

23. SOUTO, J.; RODÍGUEZ-MÉNDEZ, M. L.; DE SAJA-GONZÁLEZ, J.; DE SAJA, J. A, Thin Solid Films, v.284-285, p.888, 1996.

24. RICHARDSON, T; SMITH, V.C.; TOPACLI, A.; JIANG, J.; HUANG, H., Supramolecular Science, v.4, p.465, 1997.

25. CLARISSE, C.; RIOU, M. T., Inorganica Chimica Acta, v. 130, p.139, 1987.

26. CORKER, G. A.; GRANT, B.; CLECAK, N. J., J. Eletrochem. Soc.: ELETROCHEMICAL SCIENCE AND TECHNOLOGY, p. 1340, 1979.

27. KONAMI, H.; HATANO, M.; KOBAYASHI, N.; OSA, T., Chemical Physics Letters, v. 165 N5, p.397, 1990.

28. MENDONÇA, C. R.; GAFFO, L.; MISOGUTI, L.; MOREIRA, W.C.; OLIVEIRA JR., O. N.; ZILIO, S.C., Chemical, Physics Letters, v.323, p.300, 2000

29. KOBAYASHI, T.; KUROKAWA, F.; UYEDA, N.; SUITO, E., Spectrochimica Acta, v.26A, p.1305, 1970.

30. KOBAYASHI, T., Spectrochimica Acta, v.26A, p.1323, 1970.

31. AROCA, R.; CLAVIJO, R. E.; JENNINGS, C. A.; KOVACS, G., J.; DUFF, J. M.; LOUTFY, R. O., Spectrochimica Acta, v.45A, p.957, 1989. 


\section{CAPÍTULO III}

\subsection{Filmes de Langmuir da Bisftalocianina de Itérbio ( $\left.\mathrm{YbPc}_{2}\right)$ e Ftalocianina de Ródio (RhPc)}

Este capítulo descreve a técnica Langmuir-Blodgett (LB) e os trabalhos para formação de filmes de Langmuir e LB. Foram estudadas a bisftalocianina de itérbio e a ftalocianina de ródio. Estão relatadas nesse capitulo a parte experimental, resultados e discussões referentes a essa etapa do trabalho. A bisftalocianina de itérbio foi sintetizada através de uma adaptação do método de Kirin [1] durante o mestrado [2].

\subsection{A Técnica Langmuir-Blodgett (LB)}

A técnica Langmuir-Blodgett (LB) é uma técnica de formação de filmes ultrafinos, os quais são altamente organizados. Esses filmes são formados na interface ar-água, podendo ser depositados em substratos sólidos para posteriores caracterizações [3-5]. A técnica foi desenvolvida em 1915 por Irving Langmuir que fez os primeiros estudos utilizando o ácido esteárico. Em 1919, Katharine Blodgett fez a primeira transferência de filmes para substratos sólidos. Filmes formados na superficie da água são denominados filmes de Langmuir e, após deposição em substratos sólidos, são chamados filmes LB [3].

Um rigoroso sistema de limpeza é necessário para trabalhos com a técnica LB, pois qualquer contaminação pode alterar os resultados devido às pequenas quantidades de material utilizadas para esse tipo de trabalho [6]. A preparação de um filme LB é conduzida em um equipamento chamado cuba de Langmuir (figura 3.1). Esse equipamento consiste de um aparato contendo uma subfase líquida (a) sobre a qual a monocamada é espalhada, barreiras para a compressão do filme (b), um sensor para medir a pressão da superficie (c) e um detector para medir a área da superficie do filme (d). O suporte onde é colocado o substrato para a deposição do filme está representado pela letra e [7]. 


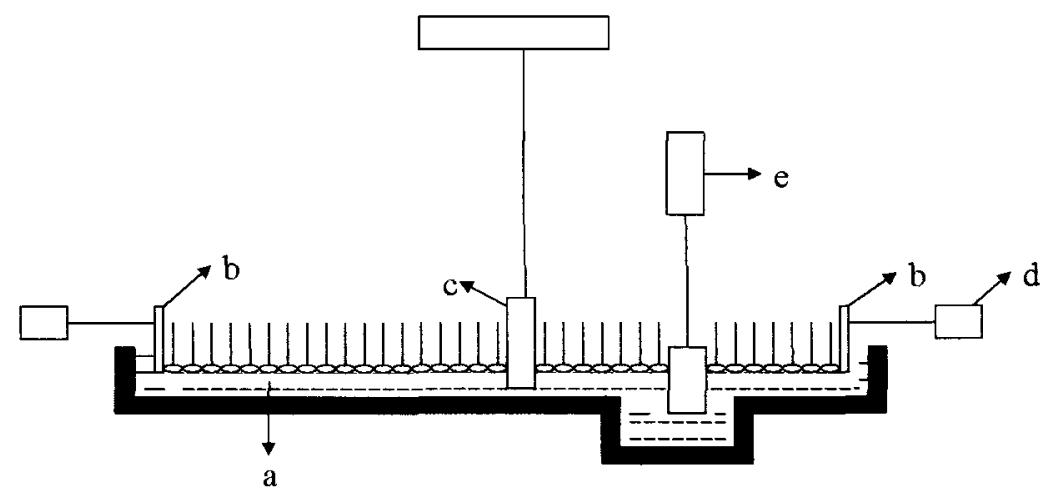

Figura 3.1: Cuba de Langmuir

Em estudos de filmes de Langmuir e Langmuir-Blodgett, é comum a obtenção de dois tipos de isotermas. Uma delas é obtida através de um gráfico da pressão da superfície versus a área ocupada por molécula, representada por $\pi$-A e a outra é obtida através do gráfico de potencial de superficie versus a área ocupada por molécula, representada por $\Delta \mathrm{V}-\mathrm{A}[8]$. $\pi$ é a pressão da superficie, $\Delta \mathrm{V}$ é a variação no potencial de superfície e A, a área ocupada por molécula.

A presença de uma monocamada sobre a superfície da água afeta a tensão de superfície. A medida da pressão de superficie (П) é dada pela equação 3.1 :

$$
\Pi=\gamma_{0}-\gamma
$$

sendo que $\gamma_{0}$ é a tensão de superfície da água pura e $\gamma$ é a tensão de superfície da água contendo a monocamada.

É chamada de potencial de superfície $(\Delta V)$ do filme, a variação que ocorre no potencial Volta quando uma monocamada insolúvel é espalhada sobre uma interface gás-líquido [8]. Este potencial pode ser medido experimentalmente através da medida do potencial entre um eletrodo ionizante colocado sobre a interface ar-água e outro eletrodo colocado dentro da água. $\mathrm{O}$ eletrodo ionizante ioniza o ar que está entre ele e a água, dando uma corrente elétrica caso haja uma diferença de potencial entre a placa e a superfície da água. É aplicado então o método nulo, no qual essa corrente elétrica é cancelada pela aplicação de um potencial de polarização externo até que o potencial entre as placas seja zero. Nessas condições, a voltagem que é aplicada na referência torna-se igual ao potencial de superficie da monocamada [9]. 
Outro método para medida de potencial de superficie é o do capacitor vibrante, também chamado método de Kelvin. A figura 3.2 mostra um esquema do aparato usado para medida do potencial de superficie de uma monocamada. Neste método, a corrente gerada pela diferença de potencial entre a prova de Kelvin e a superficie da água é uma corrente de deslocamento devida à vibração da prova de Kelvin. Esta corrente pode ser escrita como:

$\mathrm{I}=\mathrm{d} / \mathrm{dt}(\mathrm{CV})$

onde $\mathrm{C}$ é a capacitância do capacitor de placas planas e paralelas formado pela placa de Kelvin e a superfície equipotencial da água. A diferença de potencial é representada por V. Esta corrente é detectada como uma diferença de potencial no resistor de carga representado na figura. Analogamente ao método do eletrodo ionizante, emprega-se o método de nulo, onde a corrente elétrica é cancelada pela aplicação de um potencial de polarização externo $\left(\mathrm{V}_{0}\right)$ até que o potencial entre as placas seja zero. Quando $\mathrm{V}_{0}$ for igual à diferença de potencial entre as placas, $\mathrm{V}$, então a corrente será nula, a despeito da vibração de prova de Kelvin.

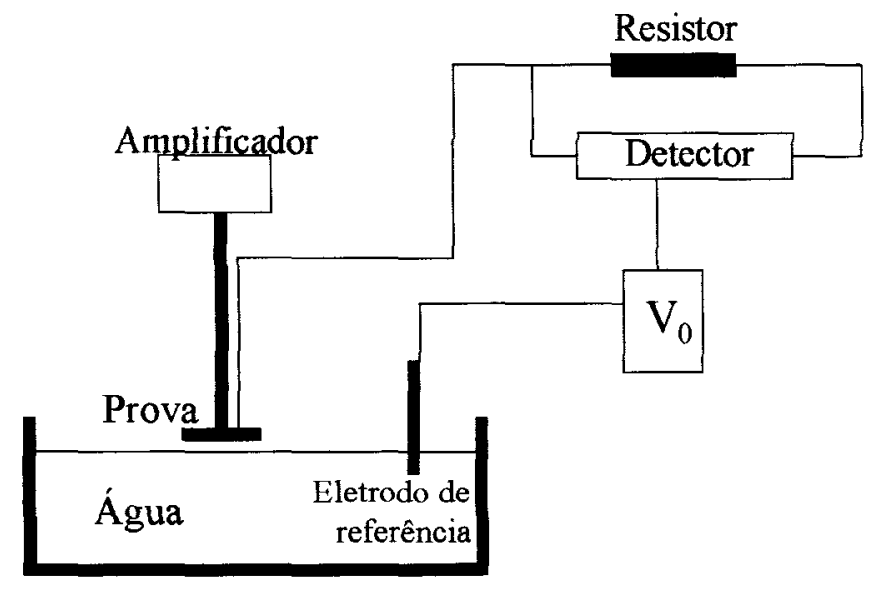

Figura 3.2: Aparato usado para medida do potencial de superfície de uma monocamada

Existem alguns modelos teóricos para interpretar o potencial de superficie de monocamadas. Um deles é o modelo de Helmholtz. Nele, a monocamada é considerada como um arranjo uniforme de dipolos, com cada dipolo contribuindo igualmente para a polarização. A diferença de potencial da monocamada $(\Delta \mathrm{V})$ é dada pela componente da polarização normal ao plano da monocamada $\left(\mathrm{P}_{\perp}\right)$. A diferença 
de potencial pode ser relacionada à de um capacitor de placas paralelas através da equação3.2:

$$
\mathrm{P}_{\perp}=\mu_{\perp} / \mathrm{Ad}=\varepsilon \varepsilon_{0} \Delta \mathrm{V} / \mathrm{d}
$$

onde $\varepsilon$ é a permissividade relativa da monocamada, $\varepsilon_{0}$ é a permissividade no vácuo $\left(\varepsilon_{0}=8,854 \times 10^{-12} \mathrm{Fm}^{-1}\right), \mathrm{d}$ é a espessura do filme (monocamada), $\mu_{\perp}$ é a componente do momento dipolar normal ao plano da monocamada e A é a área média ocupada por cada molécula [10].

O modelo de Helmholtz foi estendido por Davies e Rideal e mais tarde por Demchak e Fort [11], que consideraram a monocamada como um capacitor de três camadas. De acordo com esse modelo, o potencial de superficie da monocamada possui três principais contribuições dipolares, como mostra a equação 3.3 :

$$
\Delta V=1 / A \varepsilon_{0}\left[\mu_{1} / \varepsilon_{1}+\mu_{2} / \varepsilon_{2}+\mu_{3} / \varepsilon_{3}\right]
$$

onde $\mu_{1}$ é a componente normal do momento dipolar devido à reorientação das moléculas de água na presença da monocamada, $\mu_{2}$ é a componente normal do momento dipolar dos grupos hidrofilicos na interface monocamada-água, $\mu_{3}$ é a componente normal do momento dipolar dos grupos hidrofóbicos na interface monocamada-ar. $\varepsilon_{\mathrm{i}}$ são as constantes dielétricas das respectivas regiões nas quais estão os dipolos. É pressuposto que o efeito de diferentes monocamadas na subfase $\mu_{1} / \varepsilon_{1}$ é o mesmo e as constantes dielétricas $\varepsilon_{2}$ e $\varepsilon_{3}$ não são dependentes da natureza das moléculas que formam a monocamada [12]. Se uma monocamada é parcialmente ionizada, ocorre a formação da dupla camada. A contribuição da dupla camada pode ser calculada através da equação 3.4 , de Gouy-Chapman.

$$
\psi_{0}=2 \mathrm{kT} / \mathrm{e} \operatorname{senh}^{-1}\left[\operatorname{e} \alpha / \mathrm{A}\left(\left(5,88 \times 10^{-7}\right) \operatorname{c\varepsilon T}\right)^{1 / 2}\right]
$$

onde $\psi_{0}$ é o potencial da dupla camada, $\alpha$ é o grau de dissociação dos grupos hidrofilicos da monocamada, e é a carga dos prótons, k é a constante de Boltzmann, 
T é a temperatura absoluta, c é a concentração iônica na unidade molar, A é a área ocupada por molécula e $\varepsilon$ é a constante dielétrica da subfase [12].

Uma representação da formação da dupla camada pode ser observada na figura 3.3 .

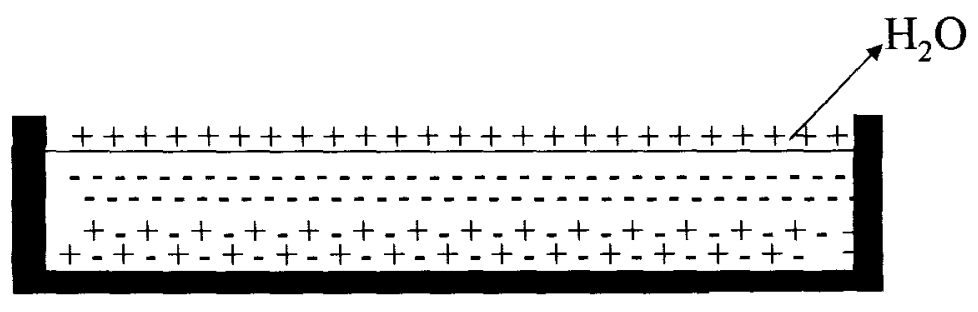

Figura 3.3: Representação da formação de dupla camada

As isotermas de potencial de superfície $(\Delta \mathrm{V}-\mathrm{A})$ proporcionam informações sobre a orientação das moléculas sobre a superficie da água. Também pode ser obtida através dessas medidas, a área crítica. $\mathrm{A}$ área crítica corresponde à saturação na qual domínios se condensam passando a apresentar sinal detectável pelo sistema de medida de potencial. Para compostos simples como o ácido esteárico, esta área crítica pode estar relacionada ao estágio no qual há uma diminuição significativa na constante dielétrica $\varepsilon_{2}$. Para compostos como ftalocianinas, muitas vezes não é possível estabelecer a área crítica. Isso ocorre porque ftalocianinas são compostos mais complexos, sendo muito sensíveis às diferentes condições experimentais. Diferentes quantidades de material espalhado sobre a subfase podem alterar a área crítica, o que torna esse tipo de análise muito impreciso.

A obtenção de isotermas é importante devido às informações que estas proporcionam. As principais informações obtidas através de uma isoterma $\pi$-A são a pressão na qual devem ser depositados os filmes, a área ocupada por molécula e a estabilidade dos filmes formados.

A deposição de uma monocamada molecular sobre um substrato sólido consiste no mergulho ou retirada do substrato na subfase contendo a monocamada. A barreira é deslocada sobre a superficie da subfase, até a obtenção de uma monocamada molecular comprimida. A deposição é feita mantendo a pressão superficial constante, podendo ser iniciada com o substrato submerso antes da formação do filme. Neste caso, ao retirar-se o substrato ocorre a transferência do 
filme, isto é, de uma monocamada molecular. Repetidos mergulhos do substrato resultam na deposição de uma estrutura de multicamadas.

A razão de transferência é usada como uma medida da qualidade da deposição do filme. É definida pela razão da área da monocamada removida da superficie da água pela área do substrato coberta pela monocamada. Uma boa deposição é obtida quando essa razão é igual à unidade. Quando essa razão é igual a um, espera-se que a orientação das moléculas sobre o substrato seja muito similar à orientação destas sobre a superficie da água [3]. Uma boa deposição dependerá não somente da natureza das moléculas formadoras da monocamada, mas também das condições da subfase, como $\mathrm{pH}$, temperatura, velocidade da imersão e retirada do substrato.

\subsection{Filmes de Langmuir da $\mathrm{YbPc}_{2}$}

A bisftalocianina de itérbio foi sintetizada e purificada durante o mestrado [2], quando alguns trabalhos utilizando a técnica LB foram realizados. Em continuação a esse trabalho, experimentos utilizando essa técnica foram realizados com a $\mathrm{YbPc}_{2}$ durante o doutorado. A ftalocianina de ródio, sintetizada durante o doutorado, também foi estudada através dessa técnica. Os resultados obtidos são apresentados a seguir.

\subsubsection{Experimental}

As medidas foram realizadas em uma cuba modelo KSV 5000. A subfase utilizada foi água ultrapura, obtida através do sistema Milli-Q de purificação, com resistividade de $18,2 \mathrm{M} \Omega \mathrm{cm}$. Nos estudos com a $\mathrm{YbPc}_{2}$, o efeito das condições experimentais sobre a formação das isotermas e deposição dos filmes foi investigado variando-se a temperatura da subfase, a posição do sensor que faz a medida de pressão e as quantidades de material espalhado sobre a subfase. Também foram realizados estudos com diferentes velocidades de compressão da barreira e utilizando $\mathrm{NaCl}$ na subfase.

A investigação dos efeitos das condições experimentais foi iniciada com variação de temperatura da subfase. Foram obtidas isotermas $\pi$-A e $\Delta V$-A para a 
$\mathrm{YbPc}_{2}$ a 14 e $22^{\circ} \mathrm{C}$. A solução utilizada foi preparada em tolueno com concentração de $0,1 \mathrm{mg} / \mathrm{mL}$. A velocidade de compressão da barreira foi $10 \mathrm{~mm} / \mathrm{min}$. A quantidade de material espalhada sobre a subfase foi de $800 \mu \mathrm{L}$. Esse experimento foi feito com o sensor de medida de pressão em duas posições, paralela e perpendicular em relação à barreira de compressão. Para a investigação do efeito da concentração sobre a formação da monocamada foram utilizados volumes de 700 , $800,900,1000$ e $1100 \mu \mathrm{L}$, de uma solução de concentração $0,1 \mathrm{mg} / \mathrm{mL}$. A temperatura utilizada para esse experimento foi $22^{\circ} \mathrm{C}$. O efeito das velocidades de compressão da monocamada foi verificado à temperatura de $22^{\circ} \mathrm{C}$, utilizando-se uma solução de mesma concentração das anteriores e quantidade de material espalhado de $800 \mu \mathrm{L}$. As velocidades de compressão utilizadas foram: 1,10 e $100 \mathrm{~mm} / \mathrm{min}$ e as subfases foram água ultrapura com resistividade de $18,2 \mathrm{M} \Omega \mathrm{cm}$ na presença e ausência de $\mathrm{NaCl}(0,001 \mathrm{M})$. Foram medidos os potenciais de filmes LB depositados a partir de diferentes velocidades de compressão da barreira. $O$ equipamento utilizado para estas medidas foi um voltímetro eletrostático Trek 320B.

\subsubsection{Resultados e Discussão}

Há na literatura estudos com a $\mathrm{YbPc}_{2}$ utilizando a técnica LB. Porém, esses estudos foram direcionados para propriedades condutivas, principalmente sensitividade a gases $[13,14,15]$. No presente trabalho foram realizados estudos mais detalhados sobre as alterações que podem ocorrer na formação dos filmes, caso sejam alteradas as condições de sua formação. As ftalocianinas não são compostos anfifilicos tradicionais, não possuindo regiões hidrofilicas e hidrofóbicas bem definidas. Isso faz com que esses compostos sejam muito sensiveis às mudanças nas condições de trabalho com a técnica LB. O experimento com variação na temperatura foi realizado duas vezes nas mesmas condições, alterando-se somente a posição do sensor de pressão. Nas figuras 3.4 e 3.5 podem ser observadas as posições do sensor em relação à barreira de compressão. 


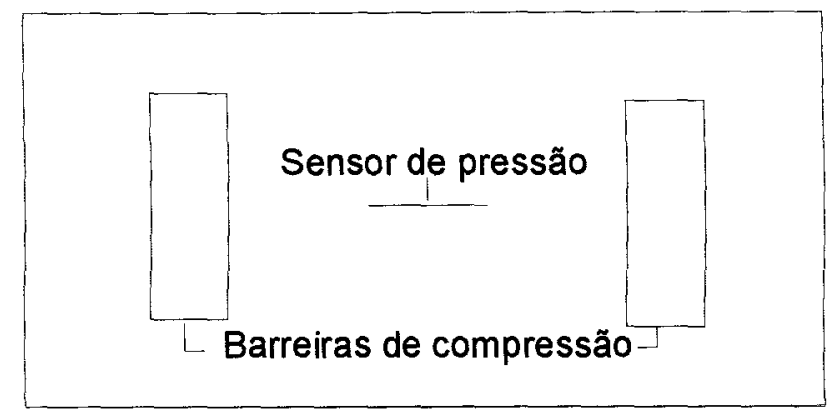

Figura 3.4: Sensor na posição perpendicular

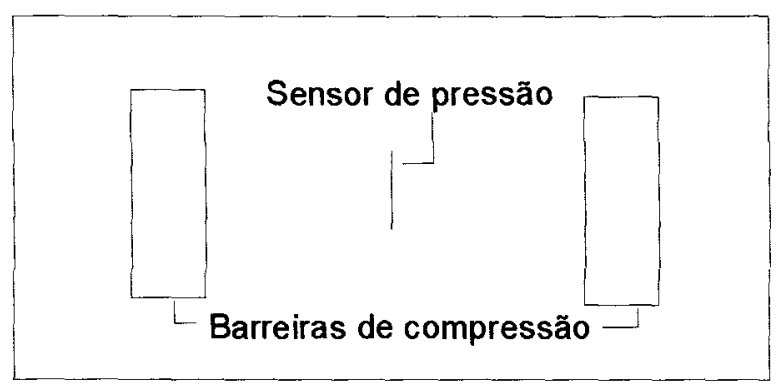

Figura 3.5: Sensor na posição paralela

As isotermas $\pi$-A obtidas com diferentes temperaturas da subfase não apresentaram alterações em relação à área ocupada por molécula e pressão de colapso. Porém, quando foi alterada a posição do sensor de pressão, houve uma mudança considerável na pressão de colapso, como pode ser percebido nas isotermas $\pi$-A das figuras 3.6 e 3.7 .

Observou-se que quando o sensor está na posição paralela em relação às barreiras de compressão, a pressão de colapso foi cerca de $53 \mathrm{mN} / \mathrm{m}$, enquanto que na posição perpendicular, a pressão ficou em torno de $33 \mathrm{mN} / \mathrm{m}$. Com alteração na temperatura não houve mudança significativa. $O$ experimento alterando a posição do sensor foi realizado também com o ácido esteárico (composto anfifílico tradicional), onde nenhuma alteração foi observada. Essas alterações provavelmente estão relacionadas a um artefato experimental. Como as ftalocianinas formas filmes rígidos, ocorre uma inclinação do sensor de medida de pressão, alterando o ângulo formado com a água e assim, os resultados observados. Um comportamento semelhante a este foi observado com monocamadas de ligninas na interface ar-água [16], sendo possível que isso ocorra para compostos macromoleculares ou 
macrocíclicos, ou compostos que formem filmes viscosos. As isotermas das figuras 3.6 e 3.7 não foram alteradas com a mudança de temperatura.

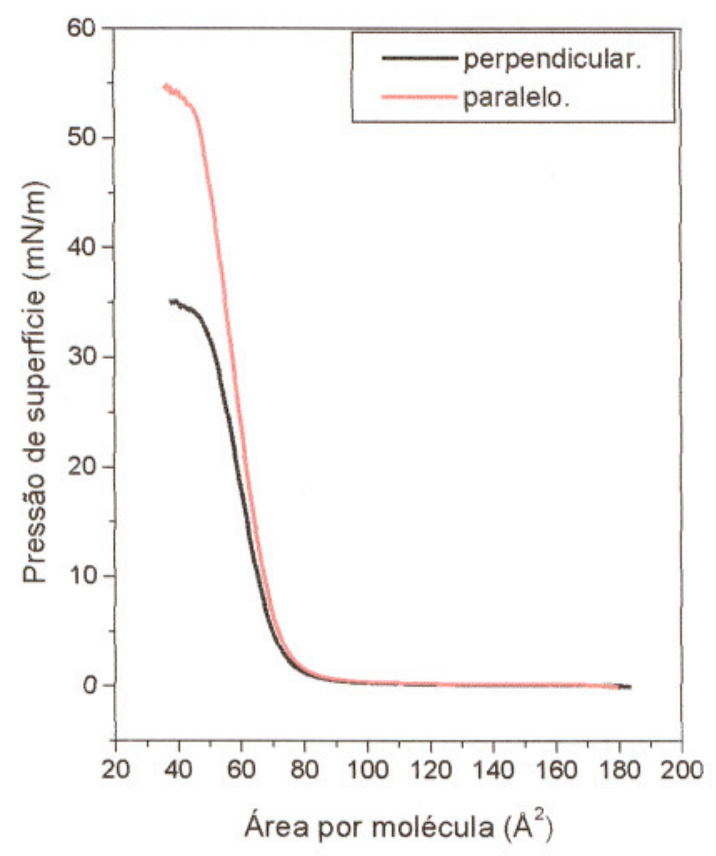

Figura 3.6: Isotermas $\pi$-A para a $\mathrm{YbPc}_{2}$, com o sensor de pressão em diferentes posições, $\mathrm{T}=22^{\circ} \mathrm{C}$, Volume $=800 \mu \mathrm{L}$, Concentração da solução $=0,1$ $\mathrm{mg} / \mathrm{mL}$, Velocidade de compressão $=10 \mathrm{~mm} / \mathrm{min}$

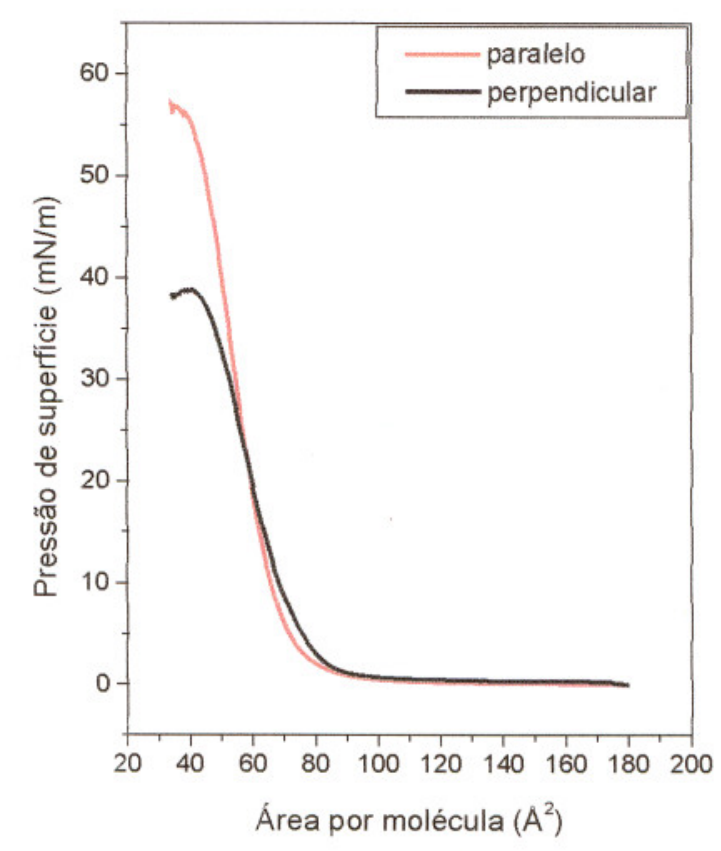

Figura 3.7: Isotermas $\pi$-A para a $\mathrm{YbPc}_{2}$, com o sensor de pressão em diferentes posições, $\mathrm{T}=14^{\circ} \mathrm{C}$, Volume $=800 \mu \mathrm{L}$, Concentração da solução $=0,1$ $\mathrm{mg} / \mathrm{mL}$, Velocidade de compressão $=10 \mathrm{~mm} / \mathrm{min}$ 
As diferenças observadas na medida da pressão advêm de artefatos experimentais. Pois a placa de Wilhelmy (papel de filtro) pode não se manter perpendicular à superfície da água com a compressão, como é suposto no cálculo de $\pi$. Isso geralmente ocorre em filmes mais rígidos, em que visualmente se nota a deflexão da placa com a movimentação das barreiras.

A figura 3.8 apresenta isotermas $\Delta \mathrm{V}$-A para a $\mathrm{YbPc}_{2}$ a temperatura ambiente, com diferentes volumes espalhados sobre a subfase.

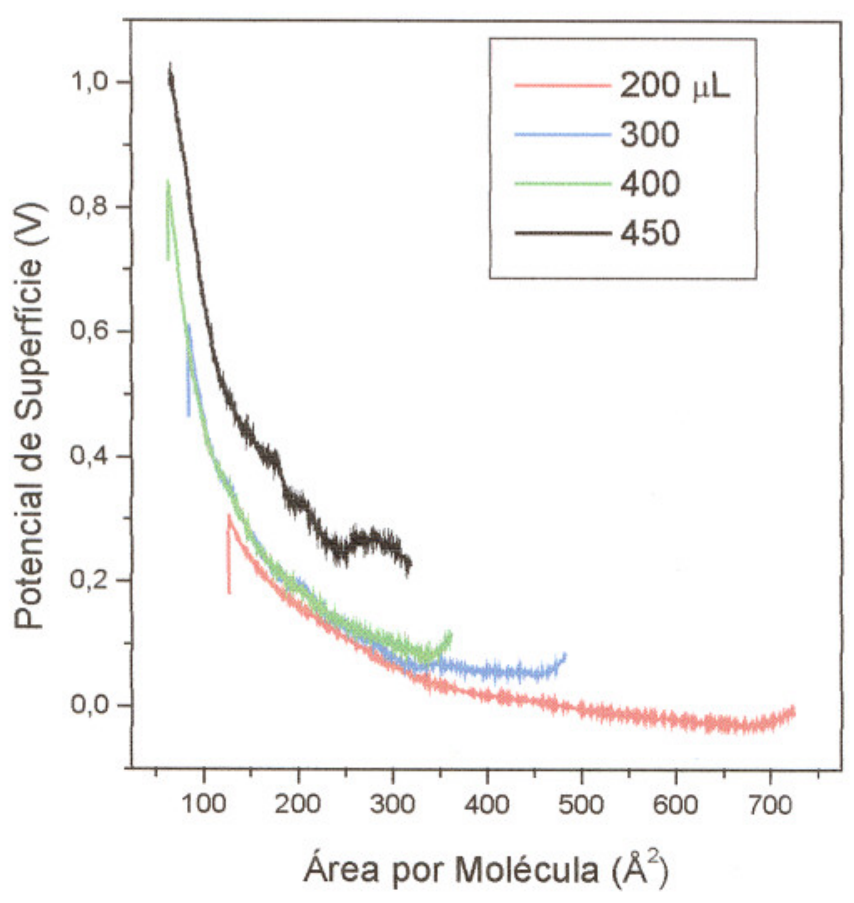

Figura 3.8: Isotermas $\Delta \mathrm{V}$-A para a $\mathrm{YbPc}_{2}$ com diferentes volumes, $\mathrm{T}=22^{\circ} \mathrm{C}$,

Concentração da solução $=0,1 \mathrm{mg} / \mathrm{mL}$

Velocidade de compressão $=10 \mathrm{~mm} / \mathrm{min}$

O tipo de empacotamento das moléculas de ftalocianinas é determinado principalmente pela interação dos anéis ftalocianina com a água e também pelas interações $\pi-\pi$ entre os anéis ftalocianina. Pode-se observar na figura 3.8 que, quando menores volumes de solução são espalhados, o potencial antes do início da compressão atingia zero. Com o aumento na quantidade de volume espalhado, o potencial passa a não atingir zero antes da compressão. Isso é devido à formação de agregados. As isotermas $\Delta \mathrm{V}$-A não foram alteradas com variação da temperatura e 
posição do sensor. Os diferentes comportamentos observados nas curvas $\pi$-A e $\Delta \mathrm{V}$-A para a $\mathrm{YbPc}_{2}$ e $\mathrm{SmPc}_{2}$ [17] serão discutidos de forma mais detalhada no final desse capítulo, juntamente com os resultados da RhPc.

$\mathrm{Na}$ figura 3.9 encontram-se as isotermas $\pi$-A para a $\mathrm{YbPc}_{2}$, alterando-se a quantidade de material espalhado sobre a subfase.

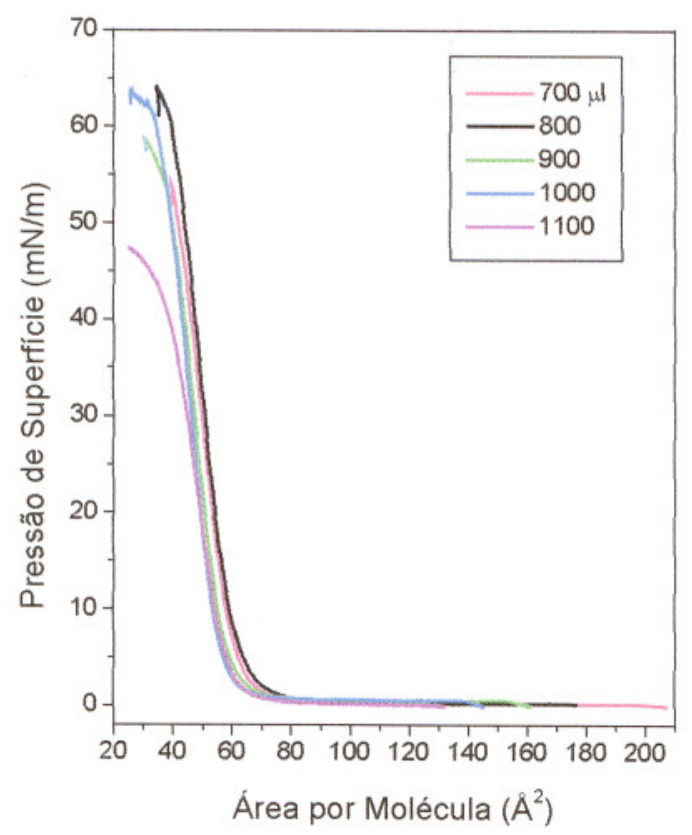

Figura 3.9: Isotermas $\pi$-A para a $\mathrm{YbPc}_{2}$, variando-se a quantidade de material espalhado, $\mathrm{T}=22^{\circ} \mathrm{C}$, Concentração da solução $=0,1 \mathrm{mg} / \mathrm{mL}$, Velocidade de compressão $=10 \mathrm{~mm} / \mathrm{min}$

Nas isotermas obtidas para várias quantidades de material espalhado sobre a subfase, observou-se que os valores de área ocupada por molécula variaram entre 62 e $68 \AA^{2}$. Essa variação não é muito significativa, tendo sido observadas variações semelhantes em outros trabalhos [18]. Menciona-se que para compostos anfifilicos tradicionais, como os ácidos graxos, não há dependência com o volume espalhado. Esta dependência está provavelmente ligada à agregação de compostos macrocíclicos, não sendo estes tipicamente anfifílicos. As variações para a pressão de colapso também não foram relevantes, encontrando-se entre 55 e $64 \mathrm{mN} / \mathrm{m}$, com exceção do volume de 1100 , para o qual a pressão de colapso foi de $40 \mathrm{mN} / \mathrm{m}$. Provavelmente, para este volume o colapso ocorre em menor pressão devido à maior quantidade de material existente. 
Não era esperado que os filmes de Langmuir estivessem ionizados (possuíssem contribuição da dupla camada). Para confirmar esta expectativa, foram realizados experimentos utilizando $\mathrm{NaCl}$ na subfase e diferentes velocidades de compressão. Além disso, pretendia-se verificar se as diferenças observadas no potencial máximo com diferentes velocidades de compressão eram realmente devidas ao tipo de empacotamento das moléculas ou havia interferência da subfase. Esses resultados são mostrados nas figuras 3.10 e 3.11. O máximo potencial de superfície foi menor para menores velocidades de compressão, o que pode ser claramente observado para as monocamadas espalhadas sobre a subfase contendo $\mathrm{NaCl}$. Observou-se que não há contribuição da dupla camada ionizada, pois se houvesse os valores de potencial obtidos com $\mathrm{NaCl}$ seriam bastante diferentes daqueles obtidos sobre água pura, o que não ocorreu. A área crítica encontrada para as isotermas obtidas na presença e na ausência de $\mathrm{NaCl}$ foi de aproximadamente $150 \AA^{2}$, indicando que os arranjos moleculares obtidos em diferentes velocidades de compressão não tinham influência da subfase. Foram encontrados arranjos moleculares distintos possuindo praticamente a mesma área por molécula, mas diferentes componentes normais para o momento dipolar, principalmente na presença de $\mathrm{NaCl}$ na subfase. A diferença principal foi entre as altas velocidades de compressão (10 e $100 \mathrm{~mm} / \mathrm{min})$ e a velocidade mais baixa $(1 \mathrm{~mm} / \mathrm{min})$. As isotermas de pressão de superficie versus área ocupada por molécula não foram alteradas devido à presença de $\mathrm{NaCl}$ na subfase. A obtenção de potenciais diferentes, a despeito de a área por molécula ser a mesma para as três velocidades, indicou que havia dipolos na molécula com grandes contribuições para o potencial de superficie. Pequenas alterações em sua orientação afetam $\Delta \mathrm{V}$ marcadamente. Infelizmente ainda não é possível quantificar as contribuições dos momentos de dipolo de moléculas como $\mathrm{YbPc}_{2}$. É provável que isso se torne possível num futuro próximo, com os pacotes de química quântica disponíveis.

Foi medido o potencial de superficie de filmes LB da $\mathrm{YbPc}_{2}$ (7 monocamadas) depositados após serem comprimidos com diferentes velocidades de compressão. O potencial apresentado foi de $340 \mathrm{mV}$ para os três casos. Isso implica que durante (ou logo após) a transferência do filme para o substrato houve um rearranjo das moléculas de $\mathrm{YbPc}_{2}$, para que todos os filmes fornecessem o mesmo potencial. Tal rearranjo não é surpreendente, pois as diferenças no empacotamento 
eram pequenas, já que a área por molécula era praticamente a mesma para os diferentes rearranjos. O menor potencial de superficie para os filmes LB em comparação com o potencial da monocamada é devido à contribuição negativa da interface filme/substrato, a qual se encontra normalmente entre 100 e $300 \mathrm{mV}$ dependendo do material, como já foi observado para filmes LB poliméricos [19,20]. O potencial de superficie para uma monocamada LB pode ser escrito através da equação 3.5 [21]:

$$
V_{\mathrm{LB}}=\Delta V_{\mathrm{L}}+\varphi+V_{\mathrm{SU}}
$$

Onde $\Delta V_{\mathrm{L}}$ é o potencial de superfície devido aos dipolos, como em uma superfície de monocamada não-ionizada, $\varphi$ é a contribuição das cargas imagens, semelhante à contribuição da dupla-camada em uma monocamada de Langmuir e $V_{\text {SU }}$ é a contribuição da injeção de carga do substrato. Para um filme LB com várias camadas deve ser considerado o tipo de empacotamento, se é ou não centrossimétrico, pois isso pode cancelar a contribuição dos momentos dipolares.

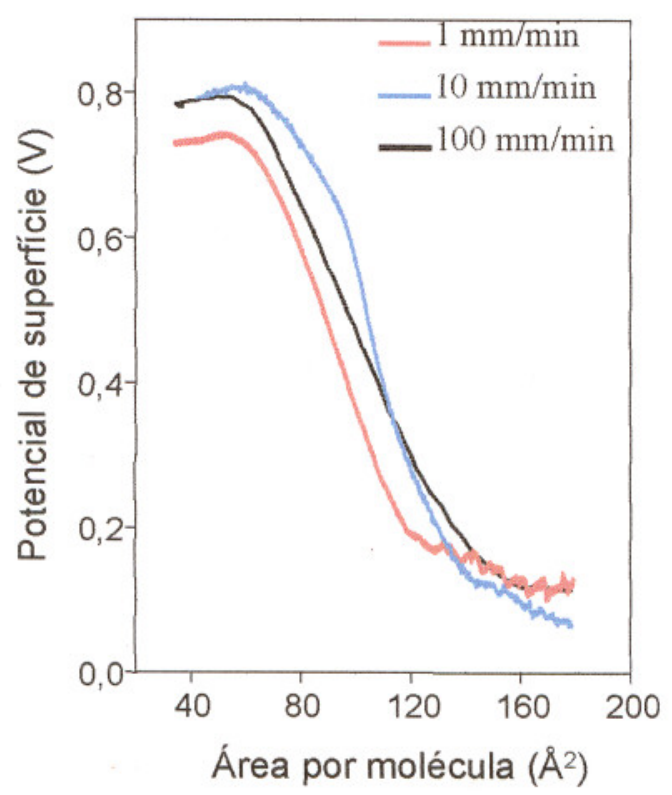

Figura 3.10: Isotermas $\Delta \mathrm{V}-\mathrm{A}$ da $\mathrm{YbPc}_{2}$ em diferentes velocidades na ausência de $\mathrm{NaCl}$ na subfase 


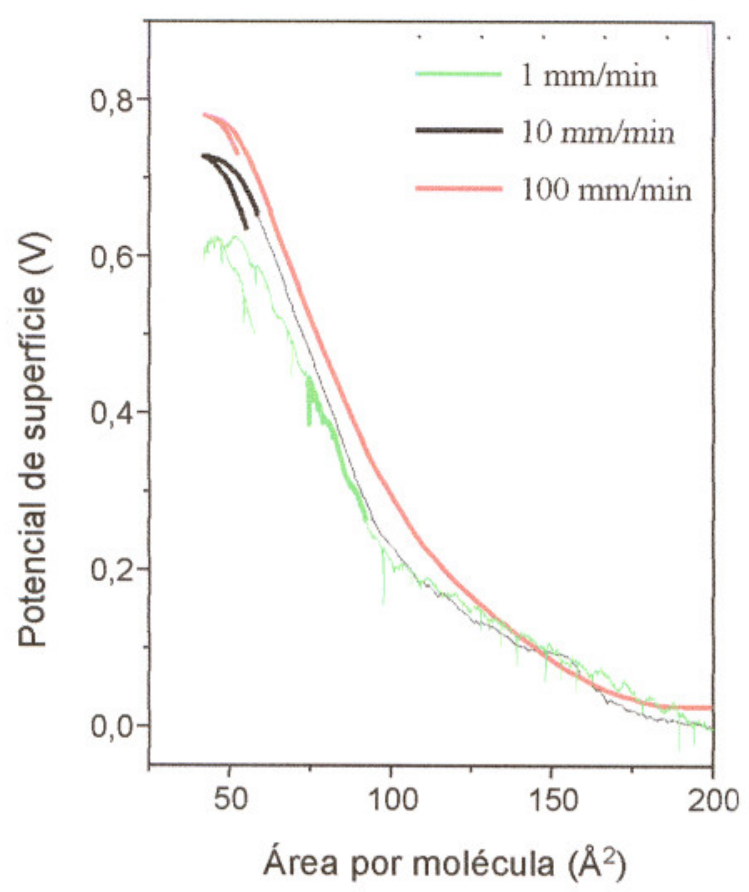

Figura 3.11: Isotermas $\Delta \mathrm{V}-\mathrm{A}$ da $\mathrm{YbPc}_{2}$ em

diferentes velocidades na presença de $\mathrm{NaCl}$ na subfase

\subsection{Filmes de Langmuir da RhPc}

A ftalocianina de ródio, sintetizada durante o doutorado, também foi estudada através da técnica LB. Os resultados obtidos são apresentados a seguir.

\subsubsection{Experimental}

Foram registradas as isotermas $\pi$ - $\mathrm{A}$ e $\Delta \mathrm{V}$-A para a $\mathrm{RhPc}$ pura e isotermas $\pi$ A para uma solução mista RhPc/ácido esteárico [3:1] em massa. A proporção utilizada em massa corresponde a 3,24 moléculas de RhPc para cada molécula de ácido esteárico. As soluções foram preparadas em clorofórmio com concentração de $0,5 \mathrm{mg} / \mathrm{mL}$ para a $\mathrm{RhPc}$ pura e $0,7 \mathrm{mg} / \mathrm{mL}$ para a solução mista. A velocidade de compressão da barreira foi $10 \mathrm{~mm} / \mathrm{min}$. As quantidades de material espalhado sobre a subfase variam de acordo com a concentração das soluções. Para a solução de RhPc pura a quantidade de material espalhada foi de $400 \mu \mathrm{L}$ e para a solução mista $\mathrm{RhPc/ácido} \mathrm{esteárico} \mathrm{a} \mathrm{quantidade} \mathrm{espalhada} \mathrm{variou} \mathrm{devido} \mathrm{à} \mathrm{mudança} \mathrm{na} \mathrm{área}$ ocupada por molécula. A temperatura utilizada para os experimentos foi de $22^{\circ} \mathrm{C}$. 
Os espectros eletrônicos na região do ultravioleta-visivel dos filmes e soluções foram registrados em um espectrofotômetro Hitachi, modelo U-2001. Para as soluções, foi utilizado clorofórmio como solvente. Os filmes puro e misto, foram depositados sobre vidro (35 monocamadas). A região de registro foi de 190 a 1100 $\mathrm{nm}$, utilizando cubeta de quartzo de caminho ótico de $1 \mathrm{~cm}$. A caracterização espectroscópica na região do infravermelho foi realizada em um espectrofotômetro Bomen, modelo MB 102. Para estas medidas foram utilizados filmes LB da RhPc pura e mista com ácido esteárico depositados em silício ( 81 monocamadas). A resolução do equipamento para as medidas na região do infravermelho foi de $4 \mathrm{~cm}^{-1}$.

\subsubsection{Resultados e Discussões}

As isotermas $\pi$-A e $\Delta \mathrm{V}$-A para a RhPc pura em solução de clorofórmio são mostradas na figura 3.11. A área média ocupada por molécula de RhPc é em torno de $75 \AA^{2}$ e a pressão de colapso é aproximadamente $59 \mathrm{mN} / \mathrm{m}$. A área estimada para um anel ftalocianina é cerca de $160 \AA^{2}$ quando esta se encontra em posição horizontal em relação à superficie da água $[15,17]$. Quando as moléculas encontram-se inclinadas, a área é de aproximadamente $68 \AA^{2}$ [18]. A área ocupada por molécula encontrada para a RhPc foi muito próxima do valor para moléculas inclinadas na superficie da água.

A isoterma de potencial de superficie para a RhPc (figura 3.12) apresentou uma região de irregularidade entre 100 e $90 \AA^{2}$, indicando que o filme não é homogêneo. Isotermas de potencial de superficie para outras ftalocianinas como a $\mathrm{SmPc}_{2}$ e a $\mathrm{YbPc}_{2}[17,22]$ mostraram maior homogeneidade dos filmes, já que as curvas de potencial não apresentam essa irregularidade. 


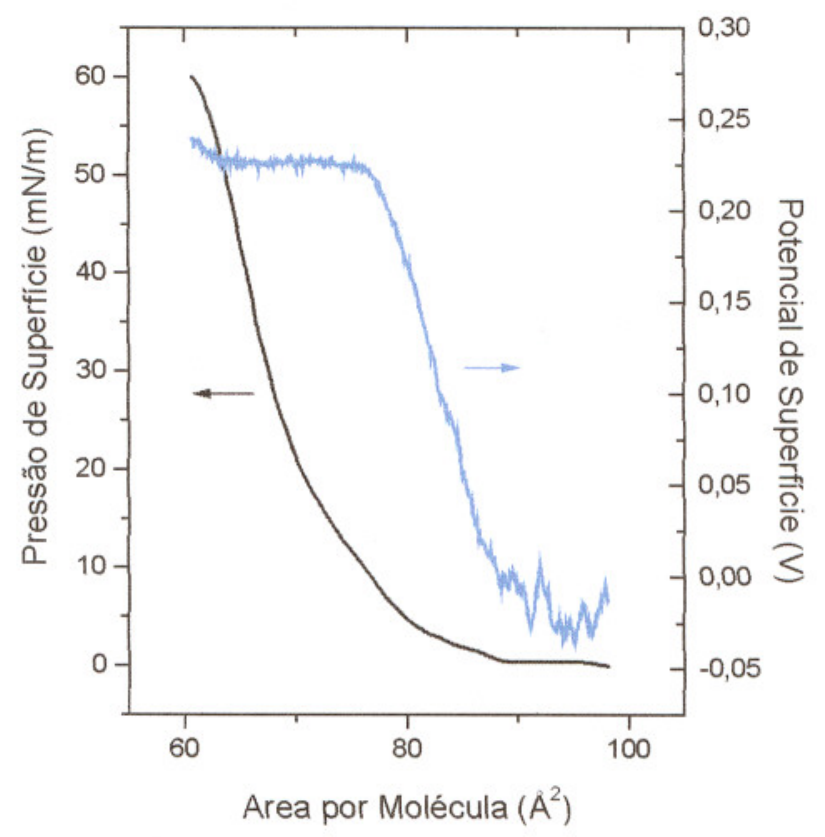

Figura 3.12: Isotermas $\pi$-A e $\Delta \mathrm{V}$-A para a $\mathrm{RhPc}$

Temperatura $=22^{\circ} \mathrm{C}$, Volume $=400 \mu \mathrm{L}$, Concentração da Solução $=0,5 \mathrm{mg} / \mathrm{mL}$, Velocidade de Compressão $=10 \mathrm{~mm} / \mathrm{min}$

As isotermas $\pi$-A de uma solução mista RhPc/ácido esteárico, mostradas na figura 3.13, apresentaram resultados interessantes. A solução mista ao ser preparada apresenta uma coloração azul semelhante à da solução de RhPc puro. Após alguns dias (uma semana aproximadamente) a solução passa a ter uma coloração púrpura. Com a solução recém preparada, é possível a formação de isotermas, porém a área ocupada por molécula muda muito rapidamente. Após uma hora da preparação da solução, a isoterma já apresenta-se diferente daquela obtida imediatamente após a preparação. A área por molécula diminui com o envelhecimento da solução. As isotermas podem ser obtidas com a solução recém-preparada ou após alguns dias quando ocorre mudança na coloração, sendo que a área ocupada por molécula só é reprodutível depois da mudança de cor. Para outros compostos é preferível trabalhar com as soluções recém-preparadas, pois pode haver decomposição. No caso da RhPc é provável que esteja havendo apenas interação química entre o ácido esteárico e a RhPc, já que as ftalocianinas são compostos bastante estáveis e a decomposição é improvável. Na figura 3.13 pode-se observar que a área ocupada por molécula variou de $52 \AA^{2}$ a $40 \AA^{2}$ em quatro dias. Após treze dias ainda houve diminuição na área, mas com certa estabilização. A área ocupada por molécula ficou em torno de $37 \AA^{2}$ 
dezesseis dias após a preparação da solução. A pressão de colapso variou de 32 a 37 $\mathrm{mN} / \mathrm{m}$.

Para a $\mathrm{YbPc}_{2}$ não foi observada interação química com o ácido esteárico quando eram formadas isotermas de soluções mistas, tendo sido surpreendente o resultado de interação observado para a RhPc e o ácido esteárico. Foi preparada uma solução da PdPc com ácido esteárico para observar se havia mudança de coloração e uma possível interação química. Nada foi observado. A cor não foi alterada, mesmo dias após a preparação da solução.

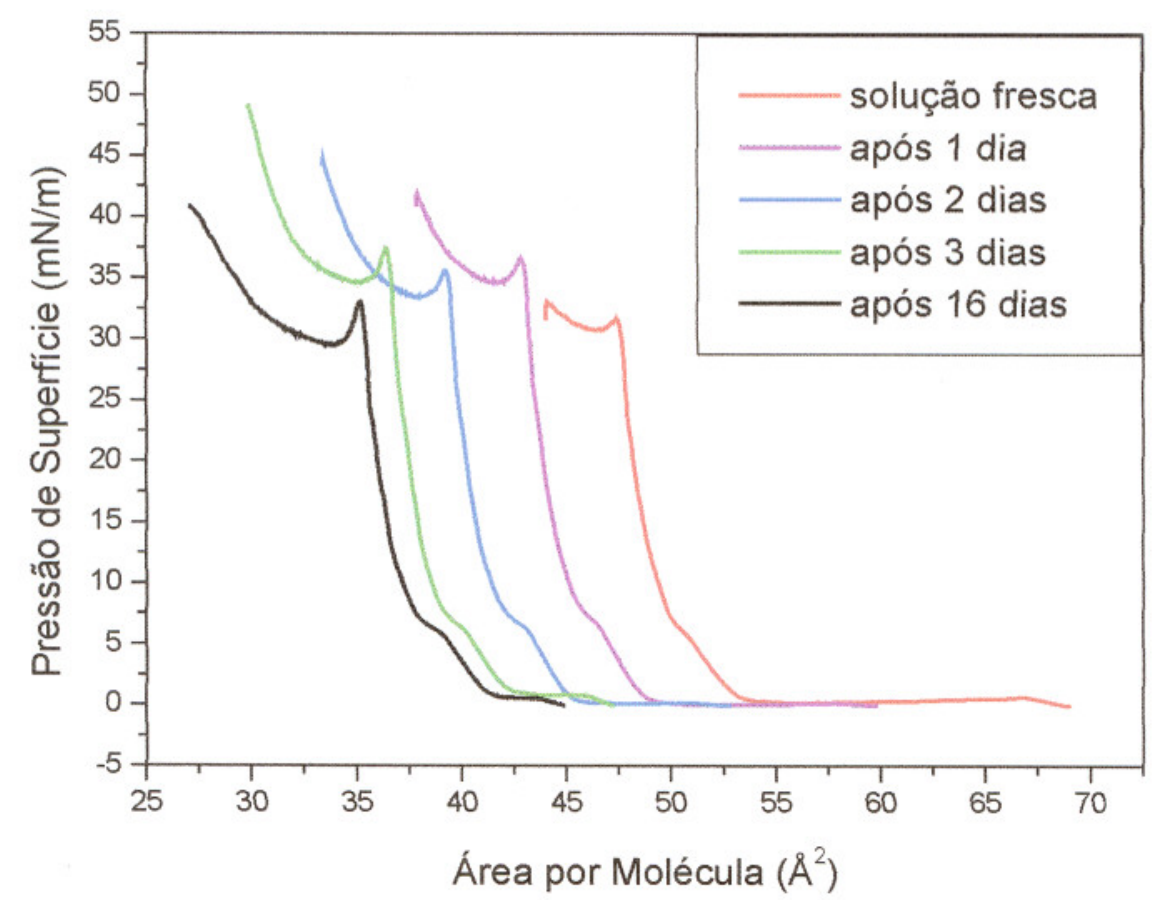

Figura 3.13: Isotermas $\pi$-A para a RhPc/ácido esteárico feitas para a solução recémpreparada e nos dias posteriores, Temperatura $=22^{\circ} \mathrm{C}$, Concentração da Solução $=$ $0,4 \mathrm{mg} / \mathrm{mL}$, Velocidade de Compressão $=10 \mathrm{~mm} / \mathrm{min}$

A figura 3.14 mostra uma isoterma de potencial para uma solução mista da RhPc. O potencial fica em torno de zero até uma área de aproximadamente $110 \AA^{2}$. Até esta área, parece haver uma certa irregularidade na curva que se torna mais homogênea após esse valor. O potencial máximo é em torno de $150 \mathrm{mV}$, menor que para a RhPc pura. 


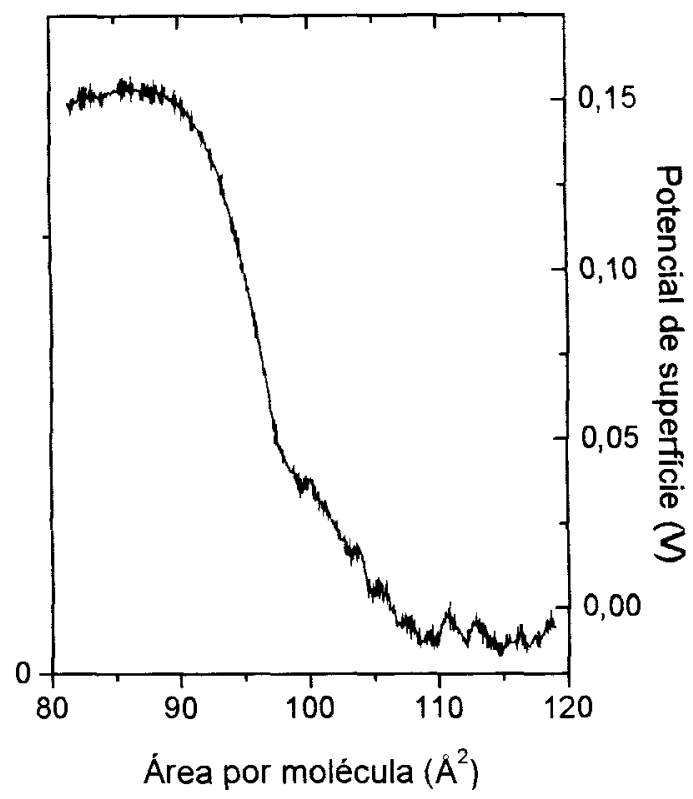

Figura 3.14: Isoterma $\Delta \mathrm{V}$-A para a uma solução de RhPc/ácido esteárico 75/25\%, Temperatura $=22^{\circ} \mathrm{C}$, Volume $=130 \mu \mathrm{L}$, Concentração da Solução $=0,7 \mathrm{mg} / \mathrm{mL}$, Velocidade de Compressão $=10 \mathrm{~mm} / \mathrm{min}$

Os espectros de UV-Vis. para soluções em clorofórmio da RhPc pura e mista com ácido esteárico são mostrados na figura 3.15. O espectro da RhPc pura (solução azul) é semelhante ao mostrado no item 2.2 .2 do capítulo $\Pi$, apresentando as bandas típicas de ftalocianinas metálicas. $O$ espectro de uma solução do composto misto com ácido esteárico apresenta diferenças marcantes em relação ao da RhPc pura. As bandas aparecem em 411, 518 e 708 nm e a solução tem uma coloração púrpura. A mudança na posição das bandas pode indicar ocorrência de interação da RhPc com o ácido esteárico. Casos como este não foram encontrados na literatura de ftalocianinas. 


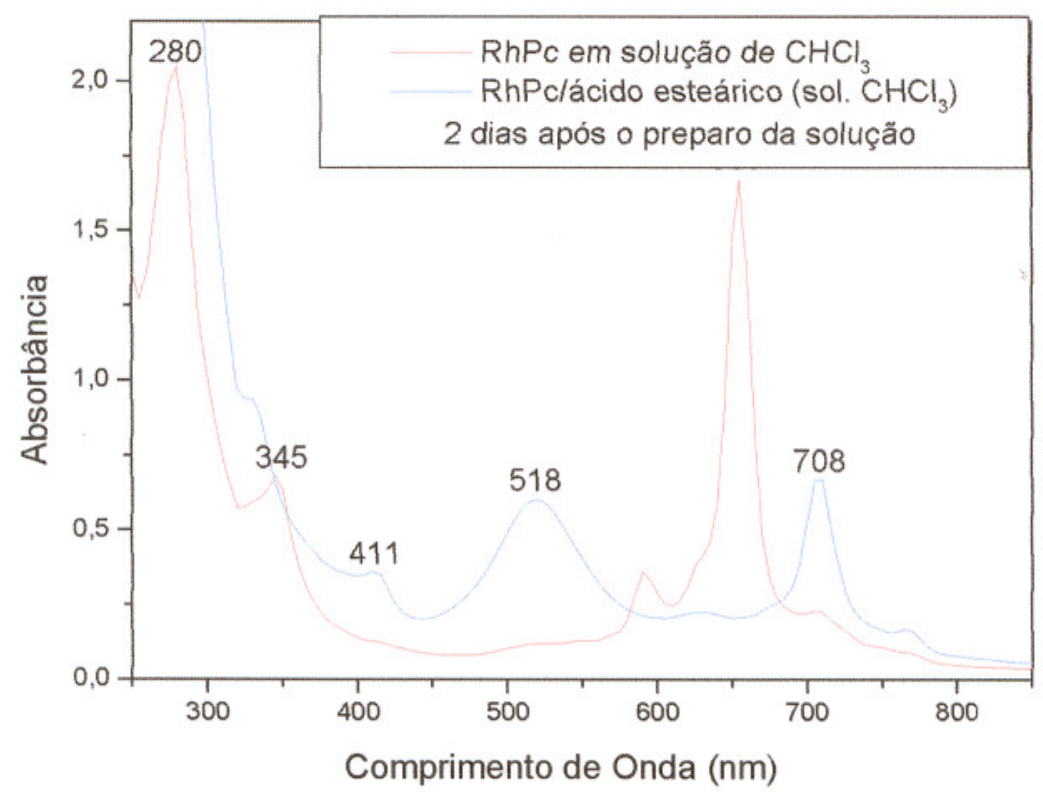

Figura 3.15: Espectro de absorção na região do UV-Vis. de uma solução RhPc/ácido esteárico em clorofórmio e de uma solução da RhPc pura

Foram depositados filmes LB da RhPc pura e mista com ácido esteárico $(25 / 75 \%)$ para medidas espectroscópicas nas regiões do UV-Vis. e do infravermelho na tentativa de explicar o comportamento observado. A deposição dos filmes foi realizada após o envelhecimento da solução. Nos espectros na região do UV-Vis. (figura 3.16) observa-se um deslocamento da banda Q de 668 para $661 \mathrm{~nm}$ do filme da RhPc pura para o filme misto. No espectro do filme misto é observado também um ombro em $729 \mathrm{~nm}$, que pode ser correspondente à banda que aparece no espectro da solução mista em $708 \mathrm{~nm}$. Este comportamento no filme sólido pode ser um indicativo de que esteja ocorrendo uma interação química entre o ácido esteárico e a RhPc. O filme LB da RhPc pura apresenta coloração esverdeada enquanto que o filme LB depositado a partir de uma solução mista (de cor púrpura) apresenta coloração azulada. A proporção de compostos utilizada para formação dos filmes foi $75 \%$ de RhPc e $25 \%$ de ácido esteárico.

A figura 3.17 mostra um esquema representando a ftalocianina de ródio e a bisftalocianina de itérbio. $\mathrm{Na} \mathrm{YbPc}_{2} \mathrm{YbPc}_{2}$ têm-se oito ligações entre o metal e o ligante Pc. Esse é o número de coordenação máximo para o itérbio. $\mathrm{Na} \mathrm{RhPc}$, entretanto, existem posições de coordenação disponíveis para outros ligantes diferentes do anel Pc. Comparando-se com a PdPc, também uma monoftalocianina, 
as posições de coordenação extras podem estar envolvidas na formação de uma espécie dimérica. Provavelmente não ocorre interação da $\mathrm{YbPc}_{2} \operatorname{com} \mathrm{o}$ ácido esteárico (resultados mostrados no capítulo V) devido a não disponibilidade do itérbio para fazer mais ligações. O mesmo deve ocorrer para a PdPc, já que esta forma um dímero, onde o metal Pd se estabiliza fazendo seis ligações. A quantidade de ácido esteárico na solução é pequena em relação à de $\mathrm{RhPc}$, podendo não haver quantidade suficiente para que toda a RhPc interaja, mesmo que fracamente com o ácido esteárico. Dessa forma, provavelmente apenas parte da RhPc presente na solução interage, porém é uma quantidade suficiente para que os espectros de UVVis. da solução e do filme sejam alterados.

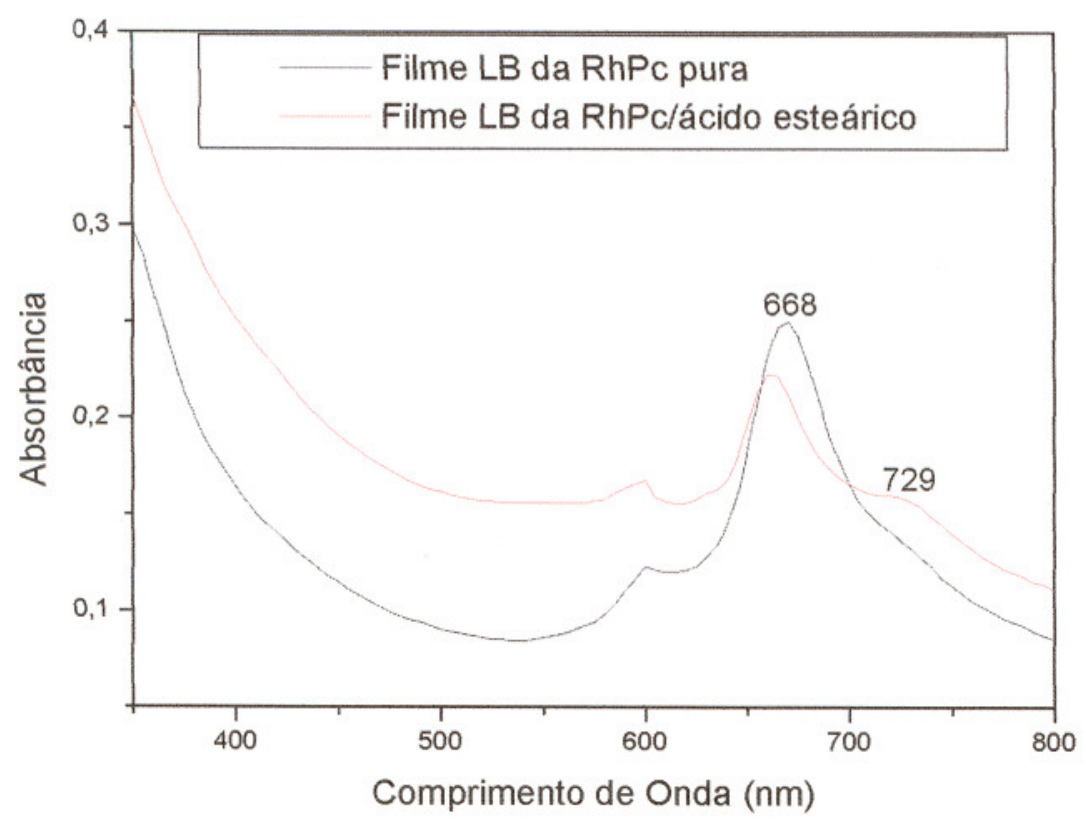

Figura 3.16: Espectro de absorção na região do UV-Vis. de um filme LB da RhPc pura e de um filme misto da RhPc/ácido esteárico
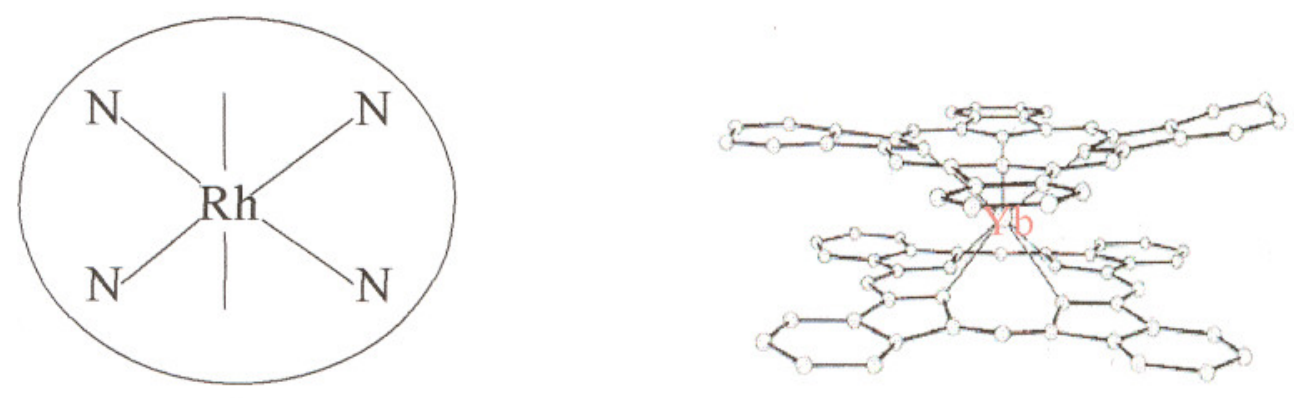

Figura 3.17: Esquema representando como e quantas ligações os metais $\mathrm{Rh}$ e $\mathrm{Yb}$ podem fazer em ftalocianinas metálicas 
$\mathrm{Na}$ tentativa de se investigar a possibilidade de interação entre o ácido esteárico e a RhPc, foram registrados os espectros na região do infravermelho (figura 3.18) para o ácido esteárico (espectro a) e a RhPc em pastilha de $\mathrm{KBr}$ (espectro b), de um filme LB misto RhPc/ácido esteárico (75/25\%) (espectro c) e de um filme LB da RhPc pura (espectro d). Comparando os espectros b e d, são observados mais ruídos no espectro do filme, devido à menor quantidade de material. No espectro da RhPc em pastilha em $\mathrm{KBr}$, aparecem mais bandas na região entre $1000 \mathrm{e} 1300 \mathrm{~cm}^{-1}$, o que pode estar relacionado à quantidade de material ou à orientação da moléculas. As bandas em 1701, 2847 e $2921 \mathrm{~cm}^{-1}$ são do ácido esteárico [23], sendo observadas também no espectro do filme LB misto. O espectro da $\mathrm{RhPc}$ em pastilha de $\mathrm{KBr}$ apresenta as bandas em 1717 e $1525 \mathrm{~cm}^{-1}$, o que dificulta a interpretação dos dados. Se ocorresse interação química entre a RhPc e o ácido esteárico, a banda em 1701 $\mathrm{cm}^{-1}$ deveria desaparecer, surgindo uma outra banda em $1530 \mathrm{~cm}^{-1}$ devido ao carboxilato. Porem não foi possível observar o desaparecimento da banda em 1700 $\mathrm{cm}^{-1}$, nem o deslocamento na posição das bandas para o filme misto. Destes resultados sozinhos, não é possível afirmar se há interação com o ácido esteárico. Devido a dificuldade na interpretação dos espectros, a tabela 3.1 foi construída de modo a serem analisadas as intensidades relativas das bandas. Nesta tabela são mostrados os números de onda dos espectros de i.v. de pastilhas em $\mathrm{KBr}$ do ácido esteárico e da RhPc e de filmes LB da RhPc pura e mista. Analisando as intensidades relativas das bandas, observa-se que para o ácido esteárico a banda mais intensa é em $1700 \mathrm{~cm}^{-1} \mathrm{e}$ a banda em $2923 \mathrm{~cm}^{-1}$ é $84 \%$ da banda mais intensa. Para o filme misto, a banda em $1700 \mathrm{~cm}^{-1}$ diminui de intensidade, passando a ter $34 \%$ da banda mais intensa, que ocorre em $2919 \mathrm{~cm}^{-1}$. Se a banda da RhPc em $1717 \mathrm{~cm}^{-1}$ fosse somada à de $1701 \mathrm{~cm}^{-1}$ do ácido esteárico, a intensidade deveria aumentar em relação à banda em $2919 \mathrm{~cm}^{-1}$. Realmente, observou-se uma diminuição da intensidade relativa da banda em $1701 \mathrm{~cm}^{-1}$ quando comparado a espectro do ácido esteárico em pastilha de $\mathrm{KBr}$, entretanto esta diminuição na intensidade relativa, pode estar também associada ao efeito de orientação no filme LB. Observou-se que para o sistema $\mathrm{YbPc}_{2} /$ ácido esteárico, cujos resultados serão mostrados no Capítulo $\mathrm{V}$, não houve a interação química entre os componentes, a intensidade relativa da banda em $1700 \mathrm{~cm}^{-1}$ também diminui, mas a diminuição de intensidade para este caso não foi tão marcante. Para a RhPc, a interação química pode também ser deduzida pelo aparecimento de uma 
pequena banda no espectro de UV-Vis. do filme misto em $729 \mathrm{~nm}$. De qualquer forma, a interação química entre RhPc e ácido esteárico parece ser mais fraca no filme LB, em comparação com a interação em solução. A dificuldade de análise dos espectros na região do infravermelho pode estar associada à constituição do filme como uma mistura de mais de uma espécie.

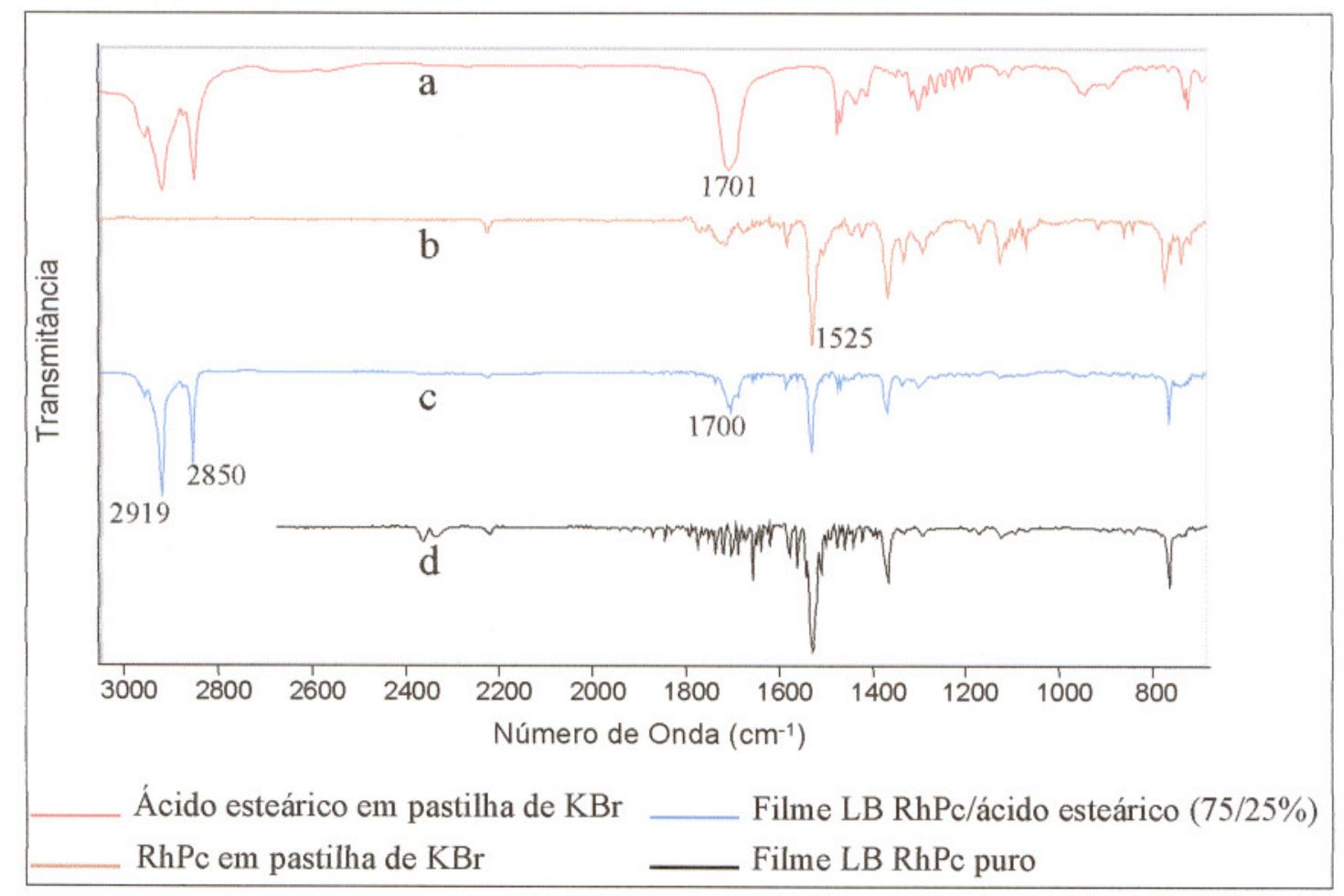

Figura 3.18: Espectro de absorção na região do i.v. de:

(a) ácido esteárico em pastilha de $\mathrm{KBr}$; (b) $\mathrm{RhPc}$ em pastilha de $\mathrm{KBr}$; (c) filme $\mathrm{LB}$ misto RhPc/ácido esteárico (75/25\%); (d) filme LB puro (RhPc) 
Tabela 3.1: Números de onda observados nos espectros de i.v. de pastilhas em $\mathrm{KBr}$ do ácido esteárico e da RhPc e de filmes LB da RhPc pura e mista. Os números entre parênteses indicam as intensidades relativas das bandas.

\begin{tabular}{|c|c|c|c|}
\hline $\begin{array}{c}\text { Ácido esteárico } \\
\text { em pastilha de } \\
\mathrm{KBr}\end{array}$ & $\begin{array}{c}\text { RhPc em } \\
\text { pastilha de } \\
\mathrm{KBr} \\
\end{array}$ & $\begin{array}{l}\text { Filme LB da RhPc } \\
\text { (81 monocamadas) }\end{array}$ & $\begin{array}{c}\text { Filme LB da } \\
\text { RhPc/ácido esteárico } \\
\text { (81 monocamadas) }\end{array}$ \\
\hline \multirow[t]{2}{*}{$550(8)$} & & $555(11)$ & \\
\hline & $639(26)$ & $639(13)$ & \\
\hline \multicolumn{4}{|l|}{$684(10)$} \\
\hline \multirow[t]{8}{*}{$723(32)$} & $719(17)$ & & \\
\hline & $735(27)$ & & \\
\hline & & & $745(12)$ \\
\hline & & $759(9)$ & \\
\hline & $763(23)$ & $762(43)$ & $762(6)$ \\
\hline & $770(37)$ & & \\
\hline & $840(8)$ & $838(4)$ & \\
\hline & $857(11)$ & $858(3)$ & \\
\hline \multicolumn{4}{|l|}{$892(17)$} \\
\hline & $912(8)$ & & \\
\hline \multicolumn{4}{|l|}{$944(24)$} \\
\hline & $1068(15)$ & $1068(3)$ & \\
\hline \multirow[t]{4}{*}{$1117(1)$} & $1110(18)$ & $1116(6)$ & $1108(3)$ \\
\hline & $1123(26)$ & & \\
\hline & $1168(19)$ & & \\
\hline & $1188(6)$ & $1191(2)$ & \\
\hline \multirow[t]{4}{*}{$1293(27)$} & $1290(23)$ & $1291(5)$ & $1297(12)$ \\
\hline & $1331(17)$ & & \\
\hline & $1332(31)$ & & $1333(11)$ \\
\hline & $1363(68)$ & $1366(45)$ & $1366(14)$ \\
\hline \multicolumn{4}{|l|}{$1407(22)$} \\
\hline & $1418(13)$ & & \\
\hline $1435(32)$ & $1442(13)$ & & \\
\hline \multirow[t]{5}{*}{$1468(53)$} & & & $1460(7)$ \\
\hline & $1508(32)$ & & \\
\hline & $1525(100)$ & $1526(100)$ & $1527(82)$ \\
\hline & $1579(20)$ & & $1579(12)$ \\
\hline & & $1599(7)$ & \\
\hline \multirow[t]{5}{*}{$1701(100)$} & & & $1700(34)$ \\
\hline & 1717 (19) & & \\
\hline & $1769(8)$ & & \\
\hline & $2222(12)$ & $2222(6)$ & $2222(5)$ \\
\hline & & $2348(14)$ & \\
\hline $2847(73)$ & & & $2850(92)$ \\
\hline $2923(84)$ & & & $2919(100)$ \\
\hline
\end{tabular}


A seguir são mostradas, na figura 3.19, isotermas $\pi$-A para a $\mathrm{YbPc}_{2}, \mathrm{RhPc}^{\mathrm{e}}$ $\mathrm{SmPc}_{2}$ colocadas em mesma escala para uma melhor comparação dos resultados.

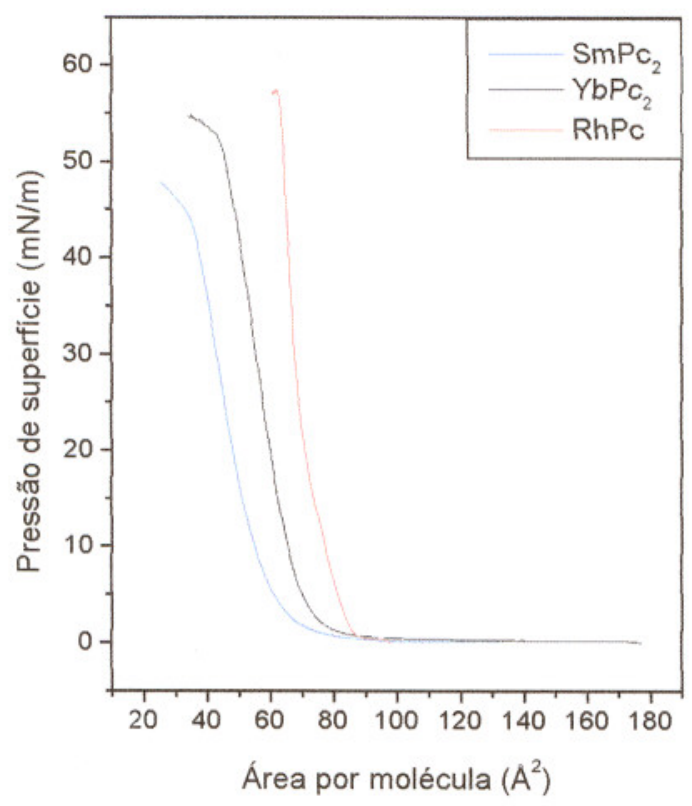

Figura 3.19: Isotermas $\pi-\mathrm{A}$ para a $\mathrm{SmPc}_{2}, \mathrm{YbPc}_{2}$ e $\mathrm{RhPc}$

Temperatura $=22^{\circ} \mathrm{C}$, Velocidade de Compressão $=10 \mathrm{~mm} / \mathrm{min}$

A tabela 3.2 apresenta alguns resultados importantes para a $\mathrm{YbPc}_{2}, \mathrm{SmPc}_{2}$ [2] e RhPc. Tendo em vista que as ftalocianinas são compostos não anfifílicos, a variação nas áreas não é surpreendente. Monocamadas com menores áreas por molécula são consideradas mais condensadas. A $\mathrm{SmPc}_{2}$ pode ser mais condensada que a $\mathrm{YbPc}_{2}$, que por sua vez pode ser mais condensada que a RhPc. Isso confirma que as ftalocianinas estudadas possuem diferentes tipos de empacotamento. Compostos mais condensados possuem menores pressões de colapso. As pressões de colapso foram $57 \mathrm{mN} / \mathrm{m}$ para a $\mathrm{RhPc}, 52 \mathrm{mN} / \mathrm{m}$ para a $\mathrm{YbPc}_{2}$ e $44 \mathrm{mN} / \mathrm{m}$ para a $\mathrm{SmPc}_{2}$, confirmando que a $\mathrm{SmPc}_{2}$ é a mais condensada. 
Tabela 3.2: Dados obtidos das isotermas $\pi$-A e $\Delta \mathrm{V}-\mathrm{A}$ para $\mathrm{YbPc}_{2}, \mathrm{SmPc}_{2}$ e $\mathrm{RhPc}$

\begin{tabular}{|l|c|c|c|}
\hline & $\begin{array}{c}\mathbf{S m P c}_{2} \\
(0,1 \mathrm{mg} / \mathrm{mL})\end{array}$ & $\begin{array}{c}\mathbf{Y b P c}_{\mathbf{2}} \\
(0,1 \mathrm{mg} / \mathrm{mL})\end{array}$ & $\begin{array}{c}\text { RhPc } \\
(0,5 \mathrm{mg} / \mathrm{mL})\end{array}$ \\
\hline Volume espalhado & $700 \mu \mathrm{L}$ & $700 \mu \mathrm{L}$ & $400 \mu \mathrm{L}$ \\
\hline Área por molécula & $60 \AA^{2}$ & $69 \AA^{2}$ & $75 \AA^{2}$ \\
\hline Pressão de colapso & $44 \mathrm{mN} / \mathrm{m}$ & $52 \mathrm{mN} / \mathrm{m}$ & $57 \mathrm{mN} / \mathrm{m}$ \\
\hline Máximo potencial & 470 & 770 & $220 \mathrm{mV}$ \\
\hline
\end{tabular}

A figura 3.20 mostra um esquema das moléculas ftalocianina na posição horizontal em relação à superfície da água e da molécula sofrendo inclinação até atingir uma posição onde elas não sofrerão mais rearranjo. Como dito anteriormente, a área calculada para moléculas de ftalocianinas, quando estas se encontram em posição horizontal com a superfície da água, é de aproximadamente $160 \AA^{2}$, e que quando as moléculas estão inclinadas em relação à superfície da água, a área ocupada é em torno de $65 \AA^{2}[13,15,18]$. Isso indica que as bisftalocianinas de itérbio e samário e a ftalocianina de ródio se encontram posicionadas quase perpendicularmente à superfície da água. Como ocupam áreas ligeiramente diferentes uma da outra, provavelmente estão em ângulos de inclinação diferentes, como ilustram as posições de 1 a 5 na figura 3.20. Moléculas que ocupam menores áreas estão mais inclinadas (posição 5) que moléculas que ocupam maiores áreas (posições 3 e 4).

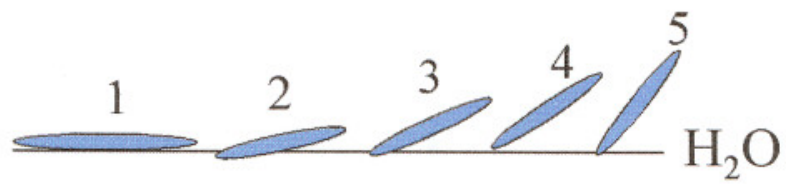

Figura 3.20: Representação de uma molécula ftalocianina em diferentes posições em relação à superfície da água: 1) horizontal; 2, 3 e 4) sofrendo inclinação; 5) inclinada (saturação)

A figura 3.21 mostra uma curva de compressibilidade para a $\mathrm{YbPc}_{2}$. Observou-se que a compressibilidade é alta para grandes áreas por molécula e diminui com a compressão da monocamada. Em menores áreas, a monocamada se torna mais rígida, diminuindo a compressibilidade. 


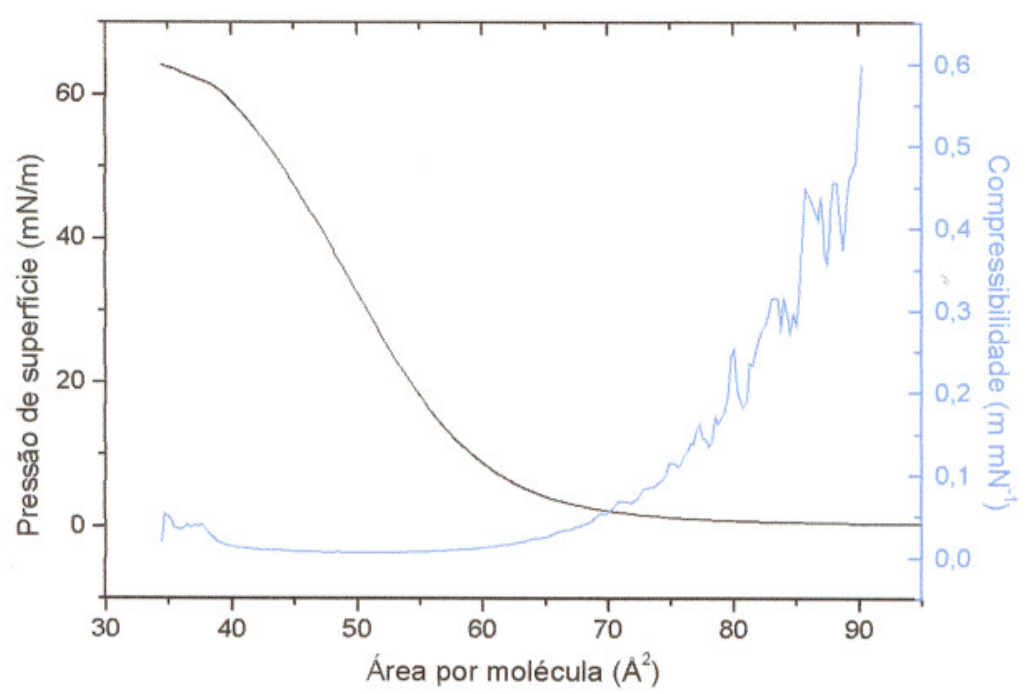

Figura 3.21: Curva de compressibilidade para a $\mathrm{YbPc}_{2}$

A figura 3.22 mostra que a compressibilidade da RhPc também é maior para grandes áreas por molécula, diminuindo com a compressão da monocamada. Numa área de aproximadamente $75 \AA^{2}$, ocorre um pequeno aumento na compressibilidade, voltando a diminuir em $70 \AA^{2}$, o que pode indicar uma mudança de fase. Comparando as curvas para os dois compostos, observa-se que a compressibilidade para a $\mathrm{YbPc}_{2}$ é $0,6 \mathrm{~m} \mathrm{mN}^{-1}$ enquanto que para a $\mathrm{RhPc}$ é $0,02 \mathrm{~m} \mathrm{mN}^{-1}$ em grandes áreas por molécula.

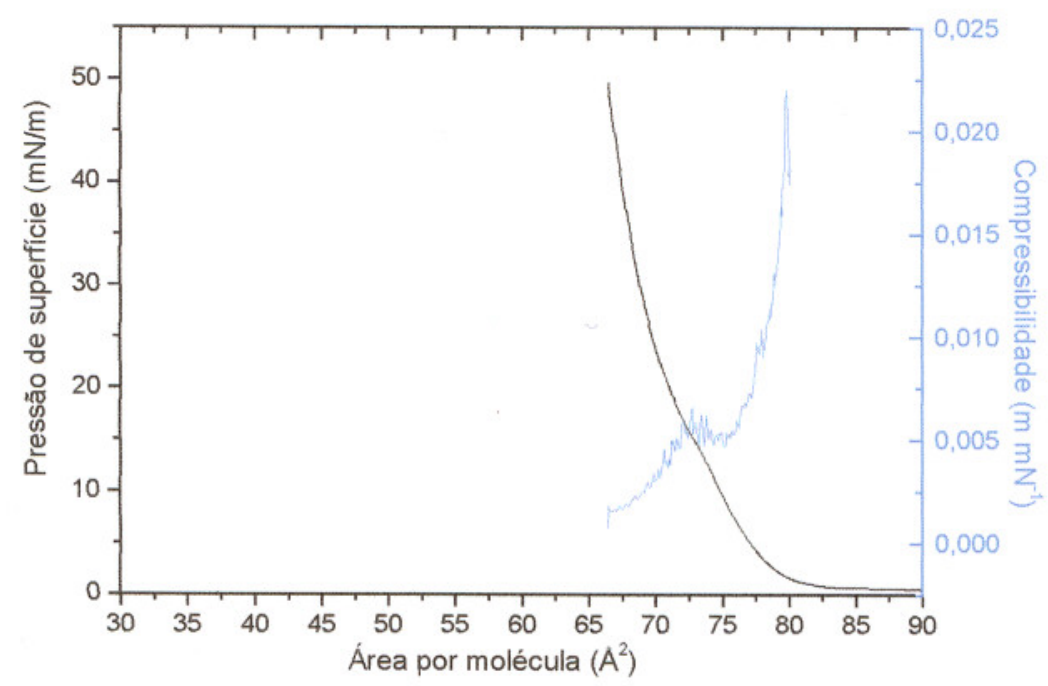

Figura 3.22: Curva de compressibilidade para a $\mathrm{RhPc}$

As isotermas de potencial de superfície para a $\mathrm{YbPc}_{2}, \mathrm{SmPc}_{2}$ e $\mathrm{RhPc}$ em mesma escala são mostradas na figura 3.23. 


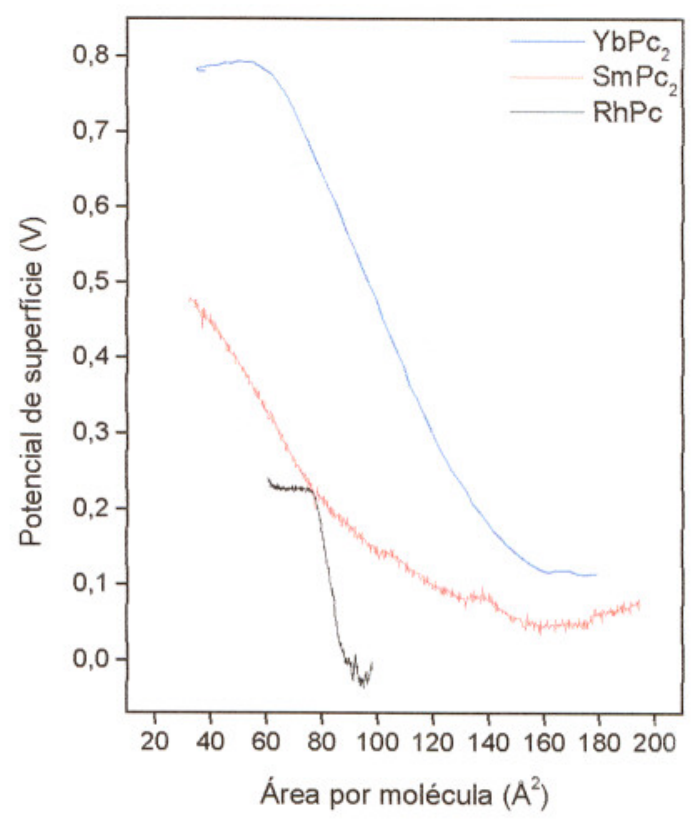

Figura 3.23: Isotermas $\Delta \mathrm{V}-\mathrm{A}$ para a $\mathrm{YbPc}_{2}, \mathrm{RhPc}$ e $\mathrm{SmPc}_{2}$,

Temperatura $=22^{\circ} \mathrm{C}$, Velocidade de Compressão $=10 \mathrm{~mm} / \mathrm{min}$

As isotermas $\Delta \mathrm{V}$-A para a $\mathrm{YbPc}_{2}$ e $\mathrm{SmPc}_{2}$ apresentam formatos semelhantes, porém a inclinação e o potencial de saturação são bastante diferentes [2]. O potencial inicial da $\mathrm{YbPc}_{2}$ se encontra em $115 \mathrm{mV}$ antes do início da compressão, passando a aumentar assim que é iniciada a compressão (numa área de aproximadamente 160 $\AA^{2}$ ). A quantidade de material espalhada foi de $700 \mu \mathrm{L}$. A área em que o potencial aumenta depende da quantidade de material espalhado, como pode ser observado na figura 3.8. Espalhando menor quantidade de material $(200 \mu \mathrm{L})$, o potencial começa a aumentar numa área próxima a $400 \AA^{2}$. A SmPc $\mathrm{S}_{2}$ também tem um potencial inicial não nulo $(70 \mathrm{mV})$ que passa a aumentar numa área de $150 \AA^{2}$ após o início da compressão. A saturação é atingida em $770 \mathrm{mV}$ para a $\mathrm{YbPc}_{2}$ e em $470 \mathrm{mV}$ para a $\mathrm{SmPc}_{2}$ [2]. A RhPc possui um comportamento bastante distinto das bisftalocianinas de itérbio e samário. O potencial inicial é em torno de zero, possuindo uma região de irregularidade entre 90 e $110 \AA^{2}$. O potencial aumenta acentuadamente a partir do término dessa região irregular, atingindo a saturação em aproximadamente $220 \mathrm{mV}$. Esse valor de saturação é bastante baixo se comparado com a $\mathrm{YbPc}_{2}$ e a $\mathrm{SmPc}_{2}$ [2]. Essa diferença pode estar relacionada às diferentes polarizabilidades dos metais nos anéis ftalocianina. Nota-se que não é possível estabelecer uma área crítica para os compostos estudados devido às mudanças com as condições experimentais. 


\subsection{Conclusões}

As características de filmes de Langmuir da $\mathrm{YbPc}_{2}$ e $\mathrm{RhPc}$ foram investigadas, utilizando isotermas de pressão e de potencial de superficie. Para a $\mathrm{YbPc}_{2}$ foi analisada a influência de diferentes condições experimentais como velocidade de compressão da barreira, volume espalhado sobre a subfase, posição do sensor de medida de pressão e temperatura da subfase. A área por molécula decresce quando maiores volumes de solução são espalhados, o que é devido à formação de aglomerados sobre a subfase. A posição do sensor de Wilhelmy que mede a pressão afeta as isotermas de pressão, o que não ocorre para compostos anfifílicos tradicionais. Não foram observadas mudanças significativas com alteração da temperatura. A variação na velocidade de compressão da barreira afetou as isotermas de potencial de superfície e pressão de colapso, porém a área ocupada por molécula permaneceu a mesma. Os valores de potencial de superficie dependem da velocidade de compressão. Porém, o potencial dos filmes após a deposição independe da velocidade utilizada para compressão da monocamada antes da deposição do filme. Isso indica que independentemente da velocidade de compressão, o empacotamento no filme LB é o mesmo. As diferenças de comportamento para as várias quantidades de material espalhado sobre a subfase já eram esperadas, tendo sido observadas variações semelhantes em outro trabalho com compostos não anfifilicos [18].

Nos estudos com a RhPc, não foram analisadas diferentes condições experimentais, devido às alterações observadas na solução do composto com ácido esteárico. Observou-se que há interação entre a RhPc e o ácido esteárico, sendo que a coloração da solução muda de azul para púrpura após alguns dias de sua preparação. A área por molécula encontrada para a RhPc pura foi de $75 \AA^{2}$, enquanto que para a solução mista foi $37 \AA^{2}$ (área por molécula de ácido esteárico). A área por molécula da solução mista varia nos primeiros dias após a preparação da solução devido à interação entre o ácido esteárico e a RhPc. Houve uma pequena alteração nos espectros de UV-Vis. dos filmes LB da RhPc pura e mista, sugerindo a existência de interação química no filme. A interação em solução é mais forte. A comparação dos espectros de i.v. do filme misto, e da RhPc e ácido esteárico em pastilha de $\mathrm{KBr}$, mostrou a diminuição na intensidade da banda em $1700 \mathrm{~cm}^{-1}$, indicando que pode estar havendo interação química. 


\subsection{Bibliografia}

1. KIRIN, I. S.; MOSKALEV, P. N.; MASKASHEV, Y. A., Russ. J. Inorg. Chem., v.12 (3), p.369, 1967.

2. GAFFO L. Síntese, Caracterização e Formação de Filmes Langmuir-Blodgett das Bisftalocianinas de Itérbio e Samário. São Carlos. 1998. Dissertação (Mestrado)Departamento de Química, Universidade Federal de São Carlos.

3. ROBERTS, G., Langmuir-Blodgett Films, Plenum Press, New York, 1990.

4. PETTY, M.C., Thin Solid Films, v.210/211, p.417, 1992.

5. ROBERTS, G. G., Advances in Physics, v.34(4), p.475, 1985.

6. OLIVEIRA JR., O. N, Brazilian Journal of Physics, v.22 N2, p.60, 1992.

7. OLIVEIRA JR., O. N.; TAYLOR, D. M., Ciência Hoje, v.12, p.19, 1990.

8. PETTY, M. C., Langmuir-Blodgett Films: an Introduction, Cambridge University Press, New York, 1996.

9. OLIVEIRA JR., O. N., Electrical Properties of Langmuir Monolayers and Deposited Langmuir-Blodgett Films. Bangor. 1990. Tese (Doutorado)-School of Electronic Engineering Science, University of Wales.

10. GAINES JR., G. L., Insoluble Monolayers at Liquid-Gas Interfaces, Interscience, New York, 1996

11. DEMCHAK, R. J.; FORT, T. J., Jr., J. Colloid Interface Sci., v.46, p.191, 1974.

12. OLIVEIRA JR., O. N.; BONARDI, C., Langmuir, v. 13, p.5920, 1997.

13. SOUTO, J.; RODÍGUEZ-MÉNDEZ, M. L.; DE SAJA-GONZÁLEZ, J.; DE SAJA, J. A, Thin Solid Films, v.284-285, p.888, 1996.

14. RICKWOOD, K. R.; LOVETT, D. R.; LUCKAS, B.; SILVER, J., J. Mater. Chem., v.5(5), p.725., 1995.

15. CLAVIJO, R. E.; BATTISTI, D.; AROCA, R.; KOVACS, G. J.; JENNINGS, C. A., Langmuir, v.8, p.113, 1992.

16. CONSTANTINO, C. J. L.; DHANABALAN, A.; OLIVEIRA JR., O. N., Review of Scientific Instruments, v.70 (9), p.3674, 1999.

17. GAFFO, L.; DHANABALAN, A.; MOREIRA, W.C.; OLIVEIRA JR., O.N., Synthetic Metals, v.102, p.1456, 1999. 
18. GOBERNADO-MITRE, M. I.; AROCA, R.; DE SAJA, J. A., Langmuir, v.11, p.547, 1995.

19. CONSTANTINO, C. J. L.; JULIANI, L. P.; BOTARO, V. R.; BALOGH, D. T.; PEREIRA, M. R.; TICIANELLI, E. A.; CURVELO, A. A. S.; OLIVEIRA JR., O.N., Thin Solid Films, v.284, p.191, 1996.

20. DHANABALAN, A.; MELLO, S.V.; OLIVEIRA JR., O.N., Macromolecules, v.31, p. 1827, 1998.

21. CONSTANTINO, C. J. L.; DHANABALAN, A.; OLIVEIRA JR., O.N., Colloids and Surfaces $A$, in press.

22. DHANABALAN, A.; GAFFO, L.; BARROS, A. M.; MOREIRA, W. C.; OLIVEIRA JR., O. N., Langmuir, v. 15, p.3944, 1999.

23. SCHMELZER, M.; ROTH, S.; NIESERT, C. P.; EFFENBERGER, F.; LI, R., Thin Solid Films, v.235, p.210, 1993. 


\section{Capítulo IV}

\subsection{Espectroscopia Raman das Ftalocianinas}

Nesse capítulo foram estudados filmes $\mathrm{LB}$ da $\mathrm{YbPc}_{2}$ e da $\mathrm{RhPc}$ e filmes evaporados da PdPc. Os filmes da PdPc não foram produzidos na forma de filmes LB devido a sua insolubilidade em solventes orgânicos. Antes da apresentação dos resultados serão abordados tópicos fundamentais de espectroscopia Raman, incluindo as técnicas específicas para amplificação do sinal para filmes finos.

Serão mostrados também nesse capítulo resultados de Microscopia de Força Atômica (AFM), que foram comparados com resultados de mapeamento Raman. Observou-se, fazendo a comparação entre ambos, que o comportamento encontrado para a escala micrométrica (Raman) pode ser extrapolado para a escala nanométrica (AFM).

\subsection{Espectroscopia Raman}

Previsto teoricamente em 1923 por Smekal, o efeito Raman foi descoberto experimentalmente por Raman em 1928. Uma obra fundamental sobre a teoria do efeito Raman foi publicada por Placzek em 1934. A espectroscopia Raman já era usada por químicos em 1940 para obtenção de informações relativas à simetria molecular e às ligações químicas. Até 1950 havia uma certa limitação da técnica para estudar substâncias coloridas e fotossensíveis, devido à utilização da radiação em $435,8 \mathrm{~nm}$, de arcos de mercúrio. Porém, uma fonte desenvolvida por Stammreich e colaboradores no Laboratório de Espectroscopia Molecular da Universidade de São Paulo, utilizando descarga em hélio, permitiu o estudo de substâncias coloridas e fotossensíveis. Essa fonte utilizava radiações em 587,6; 667,8 e 706,5 nm [1].

Os lasers de $\mathrm{Ar}^{+}$e de $\mathrm{Kr}^{+}$, desenvolvidos no final da década de 60, tornaram as técnicas anteriores obsoletas. Surgiram novas possibilidades com o estudo do efeito Raman ressonante e efeito Raman intensificado em superficie (SERS). No espalhamento Raman uma radiação, geralmente no visível ou ultravioleta, interage com a molécula e é espalhada com frequência ligeiramente modificada. A variação 
de frequência é correspondente à diferença de energia entre dois estados vibracionais. A obtenção de um espectro Raman é devida ao espalhamento inelástico de uma radiação monocromática incidente em uma molécula. A molécula pode passar de um estado vibracional para outro, porém o fenômeno é fisicamente diferente da absorção da radiação e espera-se que as regras de seleção sejam diferentes das consideradas na espectroscopia de infravermelho. Na espectroscopia de infravermelho, é considerada a variação do momento dipolar intrínseco com a vibração, já no efeito Raman a atividade está ligada ao momento de dipolo induzido na molécula pelo campo elétrico da radiação [1].

Pelo modelo clássico, o vetor de momento de dipolo induzido oscila com sobreposição de frequências, podendo ser escrito $P=\alpha E$, sendo:

$\alpha$ - polarizabilidade da molécula

E - o vetor do campo elétrico da radiação incidente

$\alpha$ - pode ser escrito, num desenvolvimento em série da coordenada interna q, que define as posições relativas entre dois átomos ligados química ou fisicamente. $\alpha=\alpha_{0}+(\mathrm{d} \alpha / \mathrm{dq})_{0} \mathrm{q}+\ldots$

Supondo que a coordenada q e o campo $\mathbf{E}$ sejam descritos por:

$\mathrm{q}=\mathrm{q}_{0} \cos \left(2 \pi v_{\mathrm{v}} \mathrm{t}\right) \quad$ e $\quad \mathbf{E}=\mathbf{E}_{0} \cos \left(2 \pi v_{0} \mathrm{t}\right)$ sendo $v_{\mathrm{v}}$ e $v_{0}$, respectivamente, a frequência vibracional da ligação e a da radiação incidente, o momento de dipolo induzido ficará:

$$
P=\alpha_{0} E_{0} \cos \left(2 \pi v_{0} t\right)+(d \alpha / d q) q_{0} E_{0} \cos \left(2 \pi v_{0} t\right) \cos \left(2 \pi v_{v} t\right)
$$

Podem ser desprezados termos de ordem mais alta para pequena variação da coordenada q. Considerando que $\cos (a) \cos (b)=1 / 2[\cos (a+b)+\cos (a-b)]$, tem-se:

$P=\alpha_{0} E_{0} \cos \left(2 \pi v_{0} t\right)+1 / 2(d \alpha / d q) q_{0} E_{0}\left\{\cos \left[2 \pi\left(v_{0}+v_{v}\right) t\right]+\cos \left[2 \pi\left(v_{0}-v_{v}\right) t\right]\right\}$

No primeiro termo somente a frequência da radiação incidente $\mathrm{e}$ correspondente ao espalhamento Rayleigh (espalhamento elástico) está presente. No segundo termo aparecem as radiações espalhadas com frequência $v_{0}-v_{\mathrm{v}}$ (espalhamento Raman Stokes) e $v_{0}+v_{v}$ (espalhamento Raman anti-Stokes). Esses 
dois últimos termos terão contribuição somente se $(\mathrm{d} \alpha / \mathrm{dq})_{0}$ for diferente de zero, isto é, deve haver variação da polarizabilidade com o pequeno deslocamento da coordenada q em torno da posição de equilíbrio.

Tanto moléculas diatômicas heteronucleares como homonucleares apresentam atividade Raman, porque para ambas há variação da polarizabilidade com a vibração. No espectro tem-se simetricamente em relação à linha Rayleigh (em escala de $\mathrm{cm}^{-1}$ ) uma banda do lado de frequências mais baixas (Stokes), e uma do lado de frequências mais altas (anti-Stokes). No espalhamento Raman Stokes a molécula no estado fundamental sofre colisão com o fóton de energia $h v_{0}$, passando para um estado intermediário, e decaindo para um estado vibracionalmente excitado, de energia $e_{v}$; o fóton espalhado, $h v_{0}-e_{v}$, tem energia menor do que o incidente. No espalhamento Rayleigh, ocorre a interação do fóton com a molécula e esta volta ao mesmo nível de energia inicial, sendo o fóton espalhado sem modificação de frequência. No espalhamento Raman anti-Stokes o fóton já encontra a molécula num estado vibracional excitado intermediário e após a interação a molécula decai para o estado vibracional fundamental. A diferença é cedida ao fóton, sendo este espalhado com energia $h v_{0}+e_{v}$. Na figura 4.1 podem ser observados os esquemas dos mecanismos de espalhamento, úteis para visualizar o espalhamento Raman. Mostrase que, além do estado inicial e final da molécula, também existe o estado intermediário. Na realidade, após a colisão do fóton com a molécula, este é aniquilado e a molécula sofre uma perturbação em todos seus estados de energia [1].

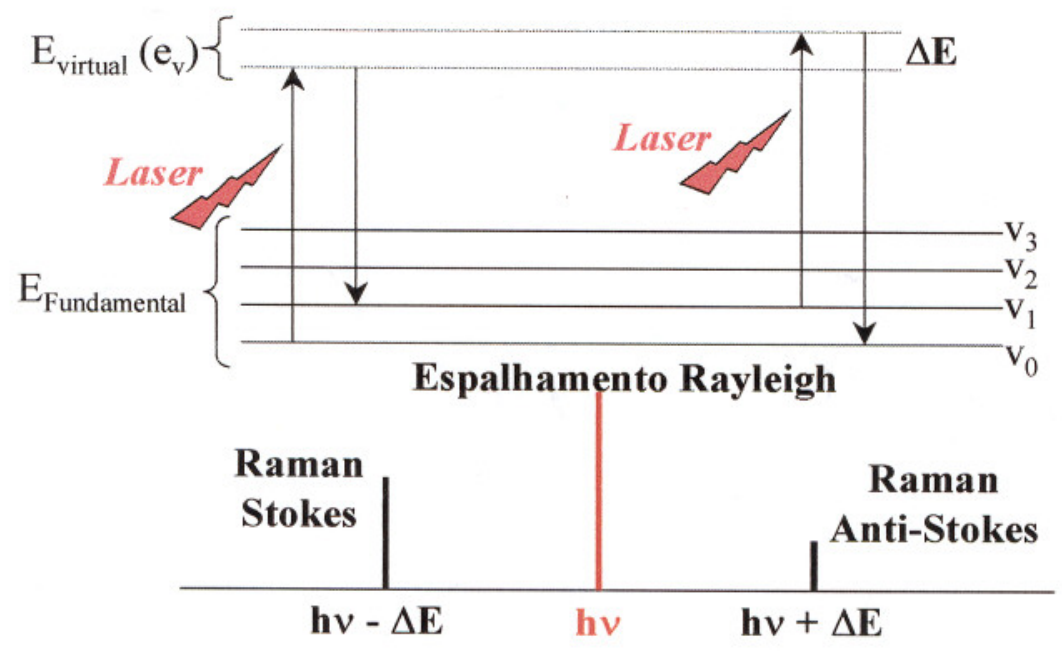

Figura 4.1: Esquemas dos mecanismos de espalhamento 
Quando a radiação incidente é altamente absorvida pelo material sob estudo, as funções de onda cujos autovalores estão próximos ao nível intermediário, no esquema da figura 4.1, terão contribuição preponderante. A consequência disso é a intensificação do espectro, que pode atingir um fator da ordem de $10^{5}$. Somente alguns modos vibracionais sofrem essa intensificação no caso de moléculas poliatômicas. Esses modos serão aqueles para os quais a coordenada interna de equilíbrio é substancialmente diferente no estado eletrônico fundamental e no estado excitado. Tal fenômeno é conhecido como efeito Raman ressonante (RRS). Se a radiação do laser excitante não for absorvida pelo filme, ocorre o espalhamento Raman comum (RS) [1]. A figura 4.2 apresenta um esquema onde são mostrados os efeitos Raman comum e Raman ressonante.

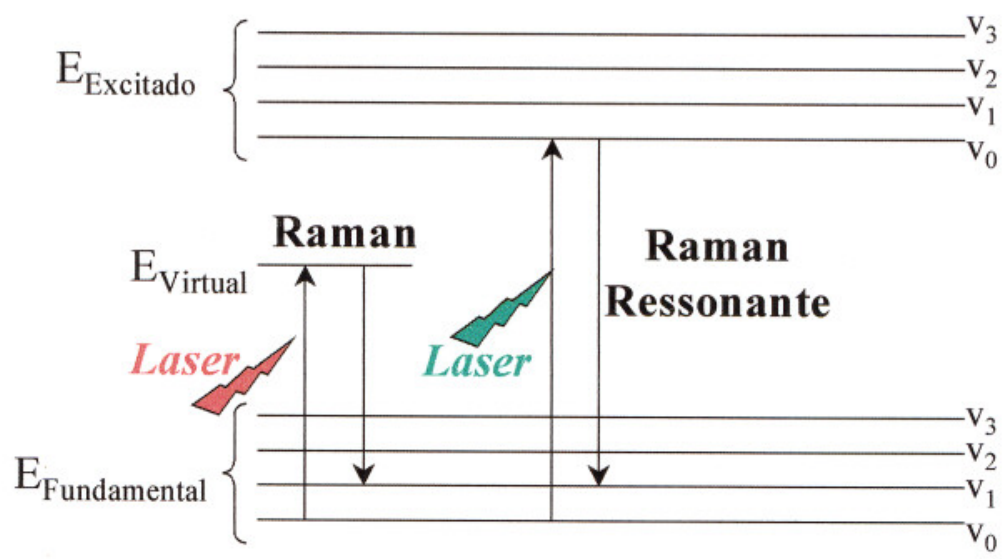

Figura 4.2: Esquemas dos mecanismos de espalhamento Raman e Raman ressonante

Além do Raman ressonante, existe também o Raman amplificado em superfície (SERS). Neste caso, ilhas metálicas (ouro, prata, cobre) são previamente depositadas sobre um substrato (vidro), e sobre essas ilhas metálicas é depositado o composto a ser estudado. São depositadas ilhas metálicas para a obtenção de uma superfície rugosa. A rugosidade é importante para que seja explorada a natureza fractal da superfície. Filmes com pequena fractalidade não têm grande atividade de SERS [2]. A absorção dessas ilhas metálicas é chamada de plasmon. Para uma máxima intensificação eletromagnética, a linha de laser deve estar em ressonância com a absorção do metal (plasmon) e para uma máxima intensificação química, a banda de absorção do metal deve coincidir com a banda de absorção do complexo. Quando ambas absorções estão na mesma região espectral, uma dupla ressonância 
(linha de laser em ressonância com o plasmon e com a absorção eletrônica do composto) deve produzir uma intensidade muito grande nos sinais de Raman. A combinação do espalhamento Raman amplificado em superfície (SERS) com o efeito Raman ressonante (RRS) é obtida pelo uso de moléculas que normalmente absorvem no visível (pigmentos) adsorvidas fisicamente sobre partículas metálicas com espectros de absorção similar. Os dois efeitos se multiplicam nessa técnica, chamada de SERRS [3].

Durante o trabalho de doutorado foram realizados estudos com ftalocianinas metálicas utilizando espectroscopia Raman. Esses resultados são mostrados a seguir.

\subsection{Resultados de Espectroscopia Raman para a Bisftalocianina de Itérbio $\left(\mathbf{Y b P c}_{2}\right)$}

\subsubsection{Experimental}

Para estudar a $\mathrm{YbPc}_{2}$ utilizando espectroscopia Raman, foram preparados filmes LB do composto em uma cuba de Langmuir LB Lauda equipada com um dispositivo controlado eletronicamente, Lauda Filme FL-1. A subfase utilizada foi água ultrapura $(18,2 \mathrm{M} \Omega \mathrm{cm})$ à temperatura ambiente. Foram depositados filmes LB puros e mistos da $\mathrm{YbPc}_{2}$ nas proporções 25/75\% e 75/25\% $\mathrm{YbPc}_{2}$ /ácido esteárico, espalhando-se soluções obtidas pela dissolução dos compostos em clorofórmio com uma concentração de $0.1 \mathrm{mg} / \mathrm{mL}$ na subfase. Os filmes LB foram transferidos para substratos de vidro (Corning 7059) e para os mesmos substratos (vidro) cobertos com $6 \mathrm{~nm}$ de prata. A deposição da prata sobre os substratos de vidro foi realizada em uma evaporadora a vácuo Balzers equipada com uma bomba de vácuo Edwards E2M2, que funcionava como um precursor para a bomba de difusão Edwards. Esferas de prata foram termicamente evaporadas para o substrato pré-aquecido à $200^{\circ} \mathrm{C}$ utilizando uma pressão de $10^{-6}$ Torr. $\mathrm{O}$ aquecimento do substrato é para que a prata seja evaporada ocupando toda a área do substrato. Sem o aquecimento toda a prata poderia ficar concentrada em uma só parte do substrato. A espessura da prata depositada foi de $6 \mathrm{~nm}$. A deposição dos filmes LB foi de uma monocamada em cada

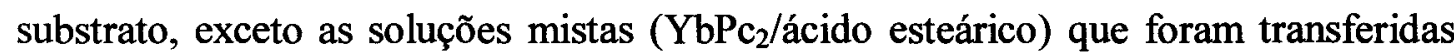
também para substratos de mica (cinco monocamadas). 
O espalhamento Raman ressonante amplificado em superficie (SERRS), Raman ressonante (RRS) e mapeamento para filmes LB foram obtidos com um Microscópio Raman da Renishaw Research, sistema RM2000. O RM2000 usa uma lente Leica (série DMLM). Duas linhas de laser foram usadas para excitação do espalhamento de luz, 633 e $780 \mathrm{~nm}$. Para os mapeamentos foi utilizada linha de laser $633 \mathrm{~nm}$. A área mapeada foi de 40 por $40 \mu \mathrm{m}$. Os dados foram adquiridos e analisados usando o software WiRE para Windows e o software Galactic Industries GRAMS $/ 32^{\mathrm{TM}} \mathrm{C}$, incluindo pacote 3D.

Os espectros UV-Visível dos filmes e da solução foram obtidos em um espectrofotômetro Varian Cary 50 Scan. Medidas de Microscopia de Força Atômica (AFM) foram obtidas em um microscópio Digital Nanoscope IIIA, usando modo de contato interminente (tapping).

\subsubsection{Resultados e Discussão}

A figura 4.3 mostra o espectro de absorção na região do UV-Vis. da $\mathrm{YbPc}_{2}$ em solução de clorofórmio, que é similar aos espectros de ftalocianinas metálicas da literatura [4]. O espectro mostra uma banda ao redor de $650 \mathrm{~nm}$, denominada banda $\mathrm{Q}$, atribuída a transições dos orbitais $\pi\left(\mathrm{a}_{2 \mathrm{u}}\right)$ para os orbitais $\pi^{*}\left(\mathrm{e}_{\mathrm{g}}{ }^{*}\right)$. A banda em torno de $460 \mathrm{~nm}$ corresponde a transições do nível $\pi\left(\mathrm{e}_{\mathrm{g}}\right)$ para o $\pi\left(\mathrm{a}_{2 \mathrm{u}}\right)$, e a banda $\mathrm{B}$ (Soret) que aparece na região do ultravioleta $(320 \mathrm{~nm})$ é atribuída às transições entre os níveis $\pi\left(\mathrm{b}_{2 u}\right)$ e $\pi^{*}\left(\mathrm{e}_{\mathrm{g}}{ }^{*}\right)$ [5]. Essas transições podem ser observadas no Capítulo II, figura 2.4.

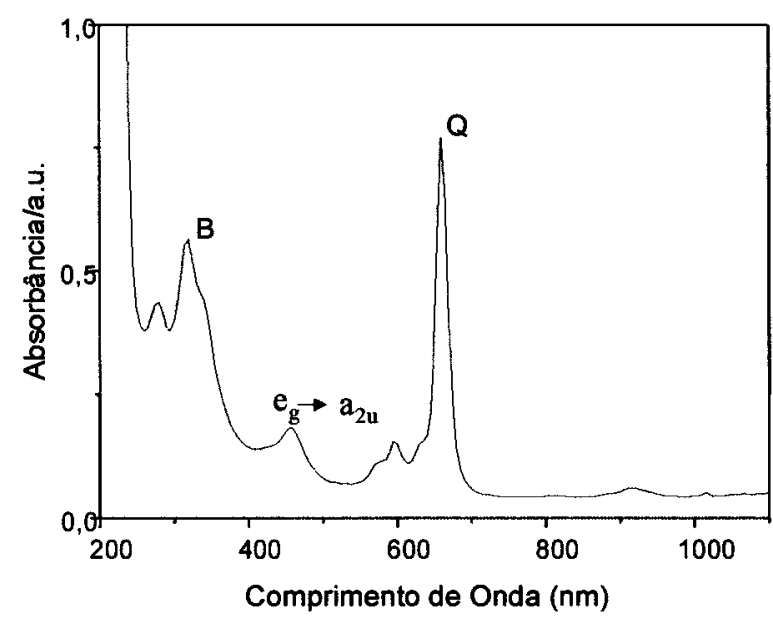

Figura 4.3: Espectro de absorção na região do UV-Vis. da $\mathrm{YbPc}_{2}$ em clorofórmio 
Da figura 4.4 observa-se que o laser $633 \mathrm{~nm}$ está em ressonância com o espectro de absorção da $\mathrm{YbPc}_{2}$, uma condição necessária para se obter o espectro Raman ressonante em superfície (RRS). Na mesma figura é mostrado o espectro de absorção do filme $\mathrm{LB}$ da $\mathrm{YbPc}_{2}$ sobre vidro, em solução de clorofórmio e o espectro do plasmon das ilhas de prata. As bandas observadas nesses espectros são consistentes com a literatura [4].

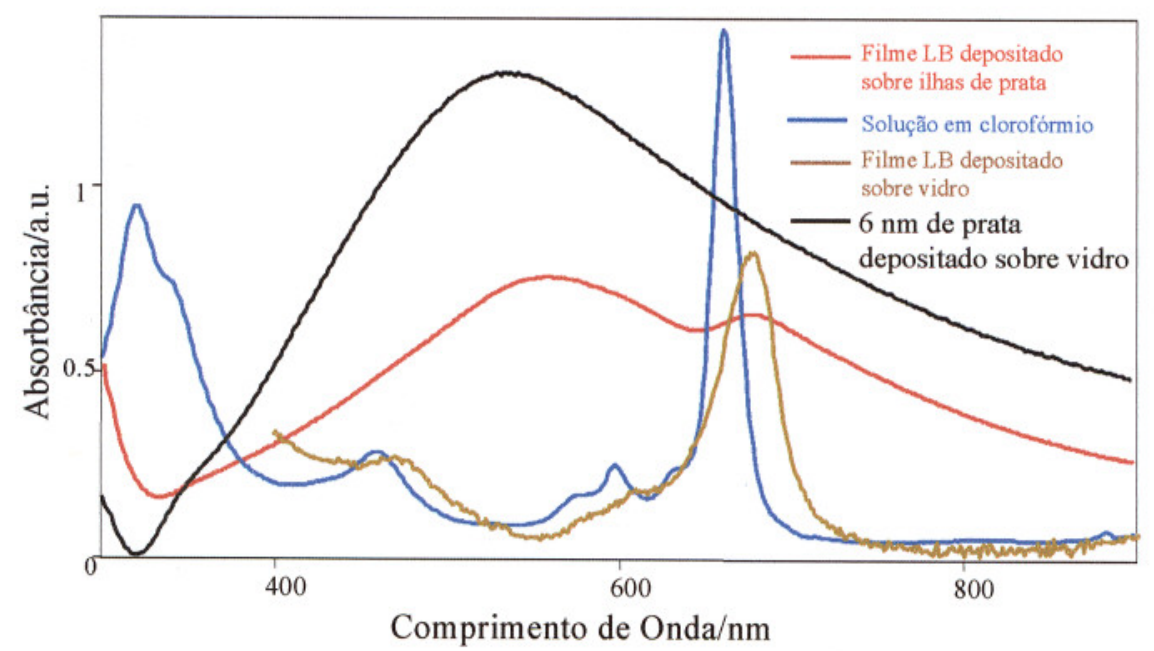

Figura 4.4: Espectros de absorção na região do UV-Vis. para a $\mathrm{YbPc}_{2}$ em: solução de clorofórmio, filme LB depositado sobre vidro, filme LB depositado sobre ilhas de prata e prata depositada sobre vidro

Os efeitos de Raman ressonante (RRS) e espalhamento Raman ressonante amplificado em superfície (SERRS) utilizando excitação em $633 \mathrm{~nm}$ para filmes LB da $\mathrm{YbPc}_{2}$ (1 monocamada) são apresentados na figura 4.5. Os espectros são semelhantes, porém a intensidade dos sinais para SERRS é muito maior que para RRS. Isso ocorre devido ao efeito de amplificação dos sinais proporcionado pelas ilhas de prata. 


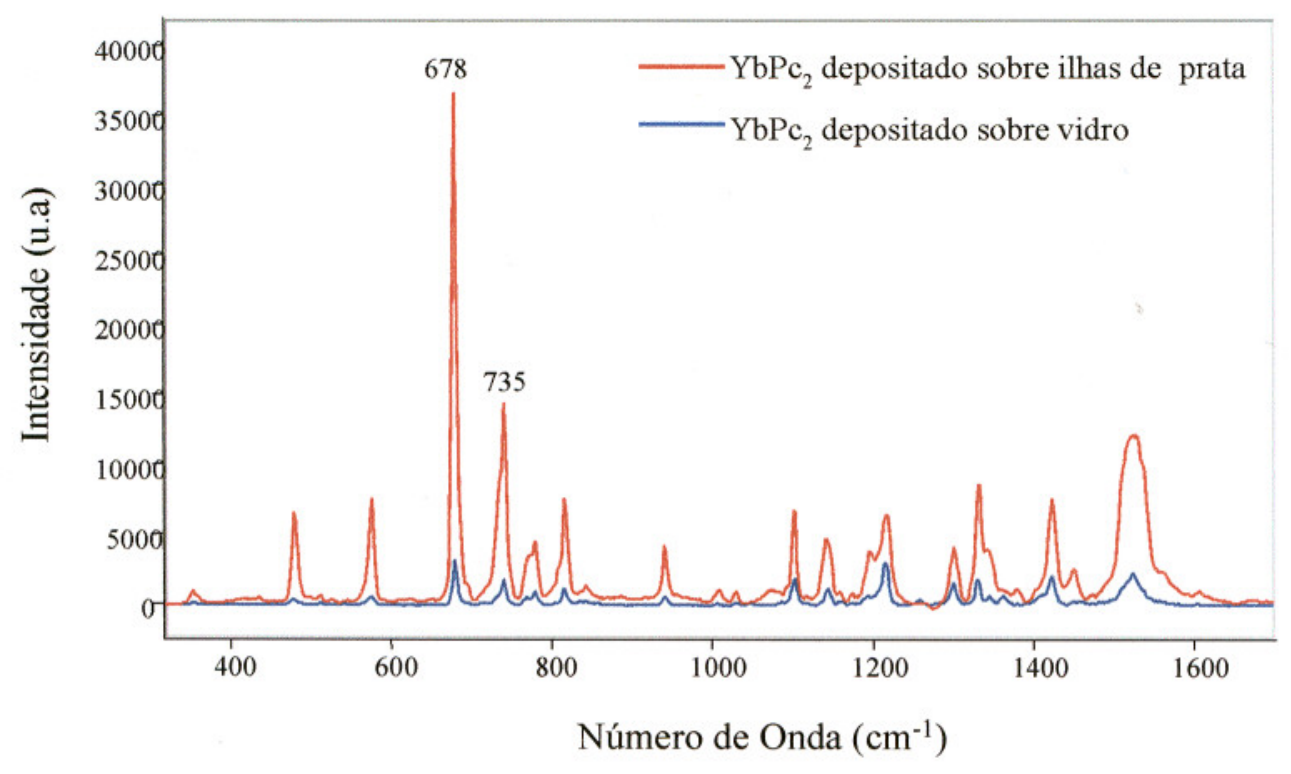

Figura 4.5: Espectros RRS e SERRS (excitação em $633 \mathrm{~nm}$ ) de um filme LB da $\mathrm{YbPc}_{2}$ puro depositado sobre vidro e ilhas de prata

Na figura 4.6 são apresentados os espectros RRS para cinco monocamadas depositadas em mica dos filmes mistos $\mathrm{YbPc}_{2} /$ ácido esteárico nas proporções $25 / 75 \%$ e $75 / 25 \%$. A intensidade dos sinais é praticamente a mesma para ambas as proporções. Na figura 4.7 são apresentados os espectros RRS e SERRS para uma monocamada do filme misto $\mathrm{YbPc}_{2}$ /ácido esteárico 25/75\%. Os sinais de SERRS são mais intensos que RRS devido à amplificação provocada pelas ilhas de prata. A intensidade dos sinais no espectro da $\mathrm{YbPc}_{2}$ /ácido esteárico 25/75\% depositado em ilhas de prata (figura 4.7) é muito semelhante à intensidade dos espectros da figura 4.6. Os sinais do material depositado sobre ilhas de prata deveriam ser maiores que os sinais do material depositado sobre mica. Porém, a quantidade de material depositado sobre mica é maior ( 5 monocamadas), o que também provoca aumento na intensidade. 


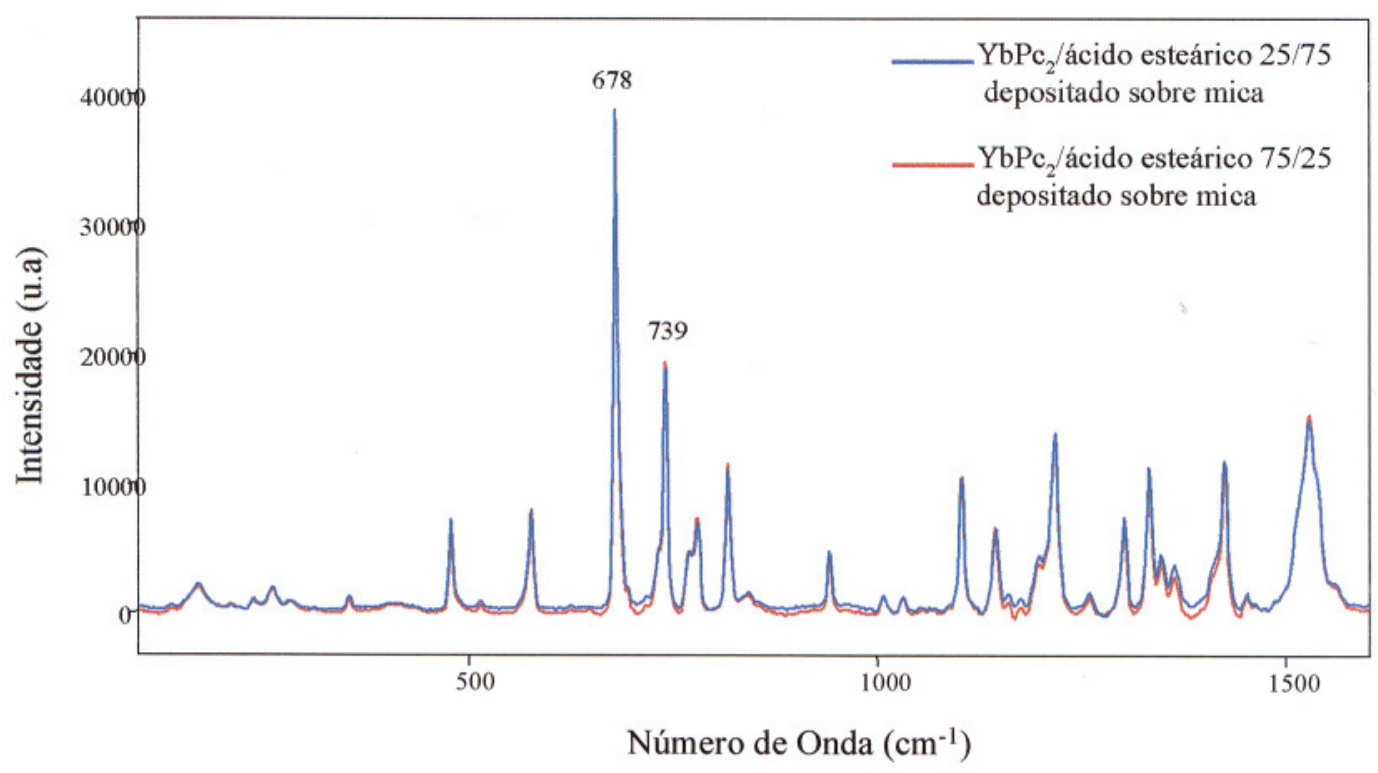

Figura 4.6: Espectro RRS (excitação em $633 \mathrm{~nm}$ ) de filmes LB sobre mica nas proporções: 25/75\% e 75/25\% $\mathrm{YbPc}_{2}$ /ácido esteárico

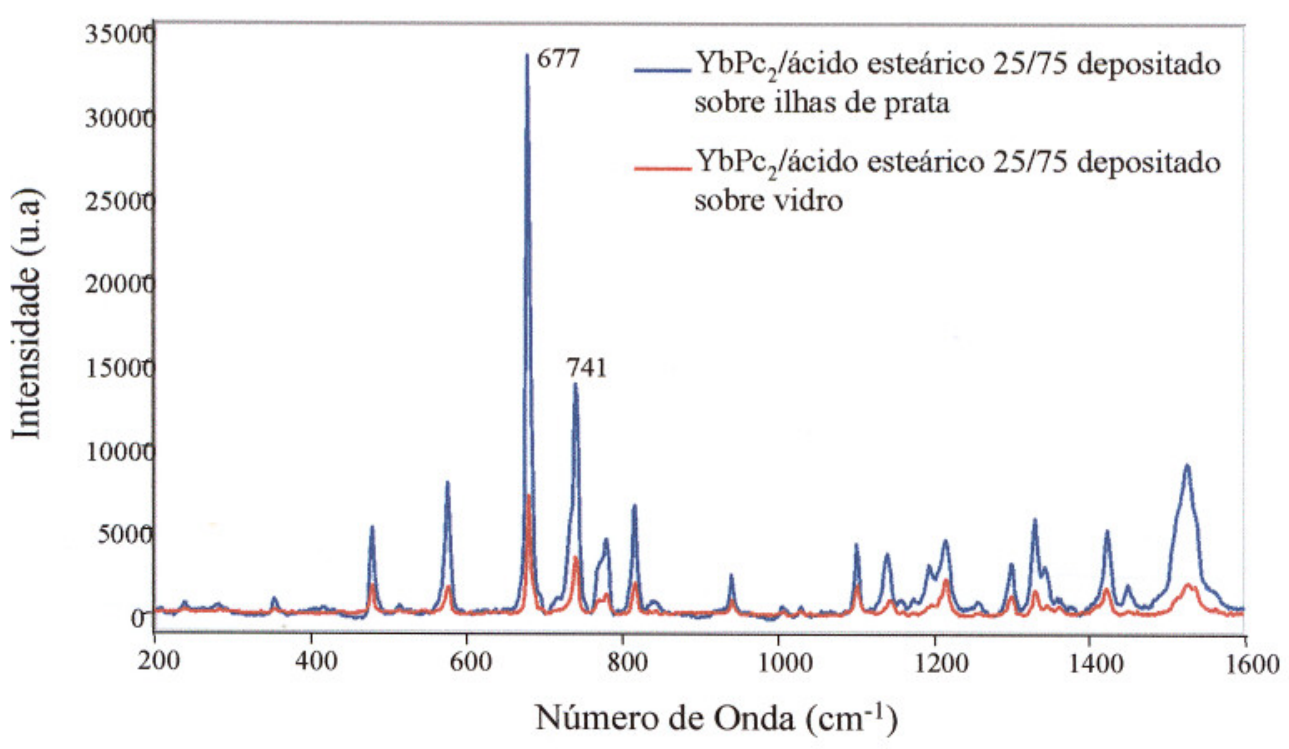

Figura 4.7: Espectro RRS e SERRS (excitação em $633 \mathrm{~nm}$ ) para filmes LB do $\mathrm{YbPc}_{2} /$ ácido esteárico $(25 \% / 75 \%)$ depositados sobre vidro e ilhas de prata

Na tabela 4.1 estão listados os deslocamentos Raman dos espectros de RRS e SERRS para filmes mistos da $\mathrm{YbPc}_{2}$ utilizando linha de laser $633 \mathrm{~nm}$, e suas principais atribuições [6,7]. As intensidades relativas das bandas estão indicadas entre parênteses. 
Tabela 4.1: Deslocamentos Raman em filmes $\mathrm{LB}$ mistos da $\mathrm{YbPc}_{2}$ usando excitação em $633 \mathrm{~nm}$. Os valores entre parênteses são as intensidades relativas das bandas.

\begin{tabular}{|c|c|c|c|}
\hline $\begin{array}{c}\text { RRS } \\
5 \text { camadas } \\
\text { mica } \\
\text { YbPc } 275 \%\end{array}$ & $\begin{array}{c}\text { RRS } \\
1 \text { camada em } \\
\text { vidro } \\
\text { YbPc }_{2} 25 \% \\
\end{array}$ & $\begin{array}{c}\text { SERRS } \\
1 \text { camada em } \\
\text { ilhas de prata } \\
\text { YbPc }_{2} 25 \%\end{array}$ & Atribuições Tentativas \\
\hline $478(25)$ & $480(24)$ & $479(16)$ & Deformação do anel pirrol \\
\hline $575(21)$ & $577(21)$ & $576(24)$ & Benzeno radial \\
\hline $678(100)$ & $681(100)$ & $680(100)$ & Respiração do anel Pc \\
\hline $740(52)$ & $741(45)$ & $740(36)$ & Deformação do anel no plano \\
\hline $769(13)$ & & & Anel Pc \\
\hline $779(16)$ & $777(13)$ & $776(13)$ & Respiração do anel benzênico \\
\hline $816(27)$ & $818(25)$ & $816(19)$ & Deformação angular de C-C-C \\
\hline $839(2)$ & & $841(2)$ & $\begin{array}{c}\text { Deformação do anel fora do } \\
\text { plano }\end{array}$ \\
\hline $940(11)$ & $942(11)$ & $941(3)$ & \\
\hline $1008(3)$ & & $1007(1)$ & Deformação angular de C-H \\
\hline $1030(3)$ & & $1030(1)$ & Deformação angular de C-H \\
\hline $1102(23)$ & $1103(23)$ & $1102(12)$ & Deformação angular de C-H \\
\hline $1144(14)$ & $1145(11)$ & $1141(11)$ & Estiramento pirrol \\
\hline $1158(1)$ & & & Deformação angular de C-H \\
\hline $1198(10)$ & & $1197(7)$ & Deformação angular de C-H \\
\hline & $1203(8)$ & & \\
\hline $1216(24)$ & $1217(26)$ & $1216(13)$ & Deformação do anel no plano \\
\hline $1258(2)$ & & $1258(4)$ & Deformação angular de C-H \\
\hline $1299(15)$ & $1301(15)$ & $1300(9)$ & Deformação do anel no plano \\
\hline $1331(21)$ & $1332(20)$ & $1331(17)$ & Estiramento pirrol \\
\hline $1346(10)$ & $1347(7)$ & $1344(8)$ & \\
\hline $1362(5)$ & $1363(6)$ & & Estiramento isoindol \\
\hline $1415(8)$ & & & Estiramento isoindol \\
\hline $1423(17)$ & $1422(19)$ & $1424(14)$ & Estiramento isoindol \\
\hline $1451(3)$ & & $1451(4)$ & Estiramento isoindol \\
\hline $1528(37)$ & $1529(25)$ & $1525(26)$ & Estiramento pirrol $\mathrm{C}=\mathrm{N}$ \\
\hline
\end{tabular}

Os dados da tabela 4.1 indicam que não há deslocamento nas bandas observadas em virtude da alteração dos substratos. Para o material depositado em vidro observam-se menos bandas que para o material depositado em ilhas de prata ou mica. Isso é devido à amplificação dos sinais para o material depositado sobre ilhas de prata, permitindo a observação de mais bandas. No caso da mica, observam-se mais bandas devido à maior quantidade de material depositado (5 monocamadas). Para os três espectros a banda de maior intensidade apareceu em torno de $680 \mathrm{~cm}^{-1}$, atribuída à respiração do anel ftalocianina. A banda de maior intensidade continuou sendo a mesma para o composto depositado sobre ilhas de prata e não houve 
deslocamento nas posições das bandas, indicando a ausência de interação química entre a $\mathrm{YbPc}_{2}$ e a prata.

As bandas harmônicas correspondem a transições de níveis vibracionais de energia cuja diferença entre níveis de energia é o dobro da diferença de energia de alguma transição envolvendo os modos normais de vibração. Essas bandas podem dar informações sobre as transições dos modos vibracionais que não aparecem nos modos normais. Podem dar também informações sobre o estado fundamental e o estado excitado. Nos filmes de $\mathrm{YbPc}_{2}$ puros e $\mathrm{YbPc}_{2}$ com ácido esteárico na proporção 25/75\% depositados sobre prata foi possível observar, utilizando a linha de laser $633 \mathrm{~nm}$, o aparecimento de bandas harmônicas. Na tabela 4.2 estão listados os números de onda e as atribuições das bandas harmônicas dos espectros SERRS da figura 4.8. Dividindo-se o valor de deslocamento Raman das bandas harmônicas por dois, obtêm-se valores de deslocamento observados no espectro. A atribuição para banda harmônica será a mesma do valor dela dividido por dois.

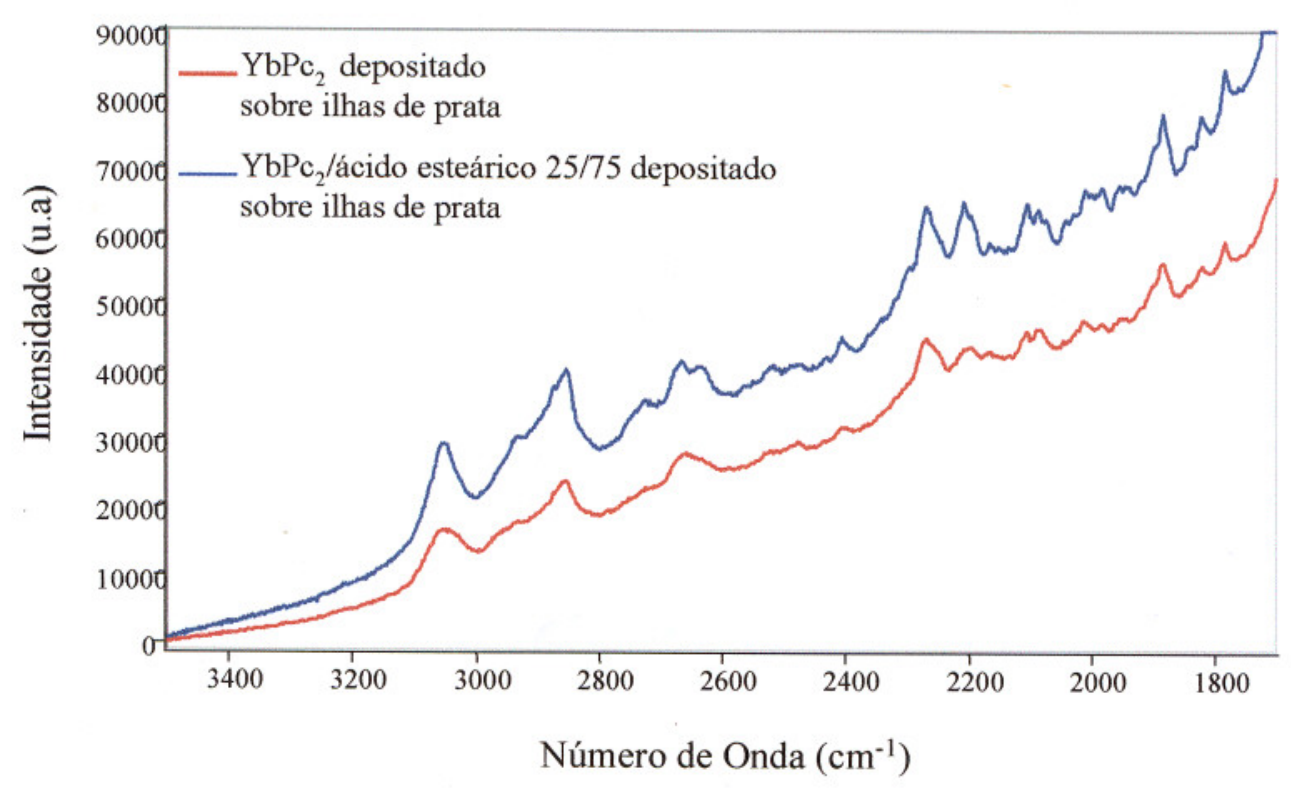

Figura 4.8: Espectro SERRS (excitação $633 \mathrm{~nm}$ ) para filmes LB da $\mathrm{YbPc}_{2}$ puro e misto depositados sobre ilhas de prata (bandas harmônicas) 
Tabela 4.2: Bandas harmônicas para filmes LB puros e mistos da $\mathrm{YbPc}_{2}$ usando excitação em $633 \mathrm{~nm}$

\begin{tabular}{|c|c|c|}
\hline $\begin{array}{l}\mathrm{YbPc}_{2} \\
\text { puro } \\
\left(\mathrm{cm}^{-1}\right)\end{array}$ & $\begin{array}{c}\text { YbPc }_{2} / a ́ c . e s t e a ́ \text { rico } \\
25 / 75 \\
\left(\mathrm{~cm}^{-1}\right)\end{array}$ & Atribuições Tentativas \\
\hline 2011 & 2009 & Deformação angular de C-H \\
\hline 2083 & 2083 & Deformação angular de C-H \\
\hline 2196 & 2203 & Deformação angular de C-H \\
\hline 2270 & 2265 & Pirrol \\
\hline 2665 & 2670 & Estiramento pirrol C-C-C \\
\hline 2854 & 2854 & Estiramento isoindol \\
\hline 3051 & 3053 & Estiramento pirrol $\mathrm{C}=\mathrm{N}$ \\
\hline
\end{tabular}

Também foram realizadas medidas com a linha de laser $780 \mathrm{~nm}$. Como pode ser observado na figura 4.4, esse laser não está em ressonância com o espectro de absorção da $\mathrm{YbPc}_{2}$, sendo obtidos assim espectros SERS. A figura 4.9 mostra espectros SERS com excitação em $780 \mathrm{~nm}$ para filmes LB da $\mathrm{YbPc}_{2}$ e da $\mathrm{YbPc}_{2} /$ ácido esteárico $(25 \% / 75 \%)$ contendo 1 monocamada.

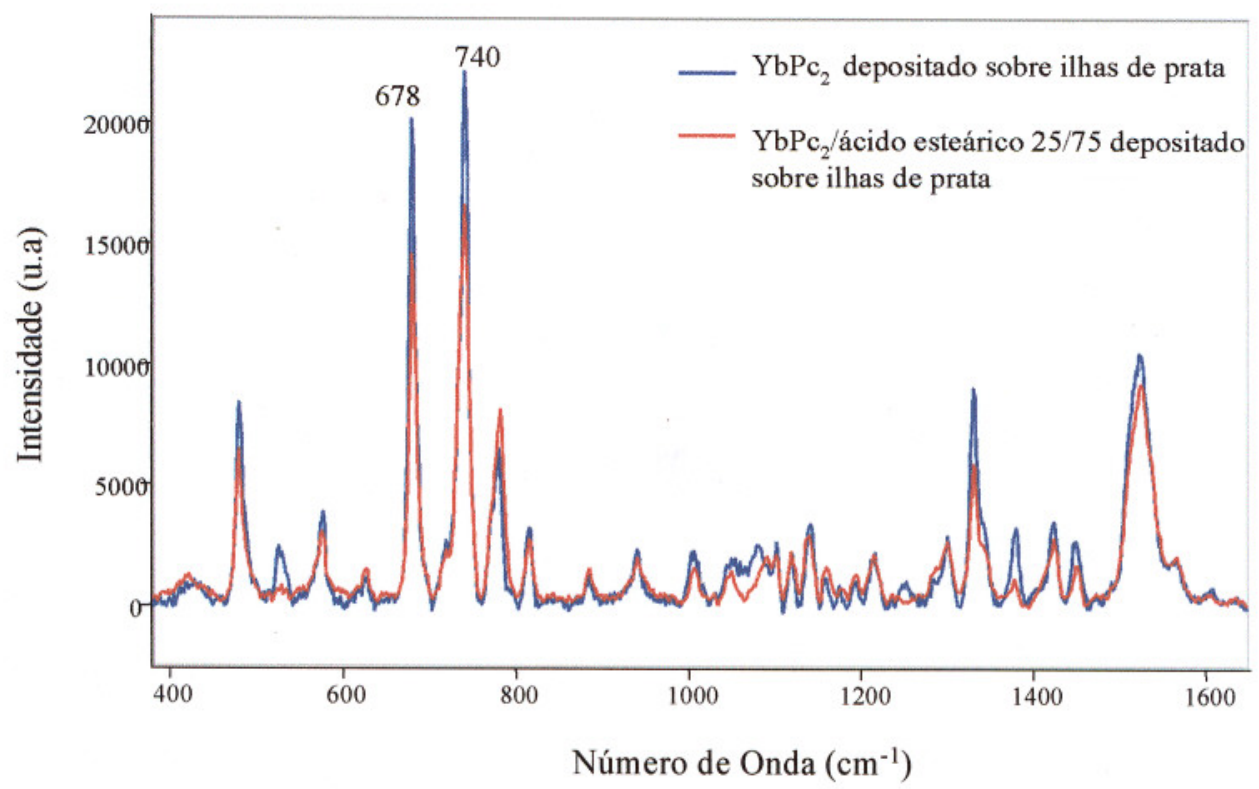

Figura 4.9: Espectro SERS (excitação 780 nm)

para filmes LB da $\mathrm{YbPc}_{2}$ puro e misto depositados sobre ilhas de prata 
Os espectros são semelhantes, sendo que na maioria das bandas as intensidades dos sinais são maiores para o composto puro. Com a linha de laser em $780 \mathrm{~nm}$ não foram observados sinais para os filmes depositados sobre vidro. Comparando os espectros obtidos com a utilização das linhas de laser, 633 e $780 \mathrm{~nm}$, nota-se que a maioria das bandas foi encontrada em ambos os espectros. Utilizando a linha de laser em $780 \mathrm{~nm}$, mais bandas foram observadas, porém com mais ruídos. A banda de maior intensidade muda dependendo da linha de laser. Com a linha de laser em $633 \mathrm{~nm}$, a banda de maior intensidade relativa é em $680 \mathrm{~cm}^{-1}$, já para a linha de laser $780 \mathrm{~nm}$ a banda de maior intensidade relativa passa a ser em $740 \mathrm{~cm}^{-1}$. Utilizando a linha de laser em $633 \mathrm{~nm}$, ocorre a intensificação dos sinais causada pela prata e a intensificação causada devido à ressonância do laser. A banda em 680 $\mathrm{cm}^{-1}$ aumenta de intensidade porque é correspondente às vibrações do anel macrocíclico, onde ocorrem as transições eletrônicas. Ao utilizar a linha de laser em $780 \mathrm{~nm}$, não há intensificação por ressonância, assim a banda em $680 \mathrm{~cm}^{-1}$ não é aumentada. As intensidades das bandas permanecem como seriam sem intensificação por ressonância, e nesse caso, a banda em $740 \mathrm{~cm}^{-1}$ é a mais intensa. As intensidades das bandas também podem ser diferentes porque as ilhas de prata absorvem a luz das linhas de laser 633 e $780 \mathrm{~nm}$ de forma diferenciada. Assim, os campos elétricos são criados com diferentes intensidades em diferentes direções ao redor das ilhas de prata, alterando as intensidades.

Na tabela 4.3 estão listados os deslocamentos Raman dos espectros de RRS e SERRS (figura 4.5) e SERS (figura 4.9) para filmes puros e mistos da $\mathrm{YbPc}_{2}$ utilizando linhas de laser em 633 e $780 \mathrm{~nm}$, e suas principais atribuições [6,7]. Os números indicados entre parênteses são as intensidades relativas das bandas.

Tomando os dados das tabelas 4.1 e 4.3, para filmes puros e mistos utilizando as linhas de laser (633 e $780 \mathrm{~nm}$ ), observa-se que as bandas são praticamente as mesmas para filmes puros $\left(\mathrm{YbPc}_{2}\right)$ e filmes mistos. Isso era esperado porque não há interação química entre o ácido esteárico e a $\mathrm{YbPc}_{2}$. 
Tabela 4.3: Deslocamentos Raman observados em filmes $\mathrm{LB}$ da $\mathrm{YbPc}_{2}$ puros usando excitação em $633 \mathrm{~nm}$ e puros e mistos usando excitação em $780 \mathrm{~nm}$. Os valores entre parênteses são as intensidades relativas das bandas.

\begin{tabular}{|c|c|c|c|c|}
\hline $\begin{array}{c}\text { SERRS/633 } \\
\text { 1 camada } \\
\text { YbPc2 sobre } \\
\text { ilhas de } \\
\text { prata }\end{array}$ & $\begin{array}{c}\text { RRS/633 } \\
\text { 1 camada } \\
\text { YbPc } \\
\text { sobre } \\
\text { vidro }\end{array}$ & $\begin{array}{c}\text { SERS/780 } \\
\text { 1 camada } \\
\text { YbPc2 sobre } \\
\text { ilhas de } \\
\text { prata }\end{array}$ & $\begin{array}{c}\text { SERS/780 } \\
\text { 1 camada } \\
\text { YbPc } 2 \text { ác. } \\
\text { est. 25/75\% }\end{array}$ & Atribuiçães Tentativas \\
\hline $482(19)$ & $480(10)$ & $482(38)$ & $481(37)$ & Deformação do anel pirrol \\
\hline $577(20)$ & $577(17)$ & $576(18)$ & $575(16)$ & Benzeno radial \\
\hline & & $627(6)$ & $626(7)$ & \\
\hline $680(100)$ & $681(100)$ & $681(92)$ & $681(89)$ & Respiração do anel Pc \\
\hline & & & $727(13)$ & Deformação do anel fora do \\
plano
\end{tabular}

Foi explorada também a possibilidade de usar microscopia Raman a fim de obter uma imagem das ligações químicas dos filmes LB de $\mathrm{YbPc}_{2}$. O objetivo foi verificar a separação de fases entre os dois componentes, e também a homogeneidade da deposição. A resolução da microscopia Raman é em escala micrométrica. Foram 
realizadas, então, medidas de microscopia de força atômica (AFM) para comparar imagens em escalas diferentes, uma vez que nas imagens de AFM atinge-se resolução nanométrica. Foram utilizados filmes LB mistos ( $\mathrm{YbPc}_{2} /$ ácido esteárico: $25 / 75 \%$ e 75/25\%), depositados sobre mica, contendo 5 monocamadas. No mapeamento Raman, uma área do filme de 40 por $40 \mu \mathrm{m}$ foi mapeada. Para se obter esse mapeamento, são feitos espectros nessa área de 3 em $3 \mu \mathrm{m}$, obtendo-se assim imagens semelhantes às das figuras 4.10 e 4.11. Estas figuras 3D trazem uma série de espectros obtidos em diferentes pontos da amostra, à medida que se faz o mapeamento. As principais bandas são escolhidas e tratadas através de um programa de computador obtendo-se as imagens da figura 4.12.

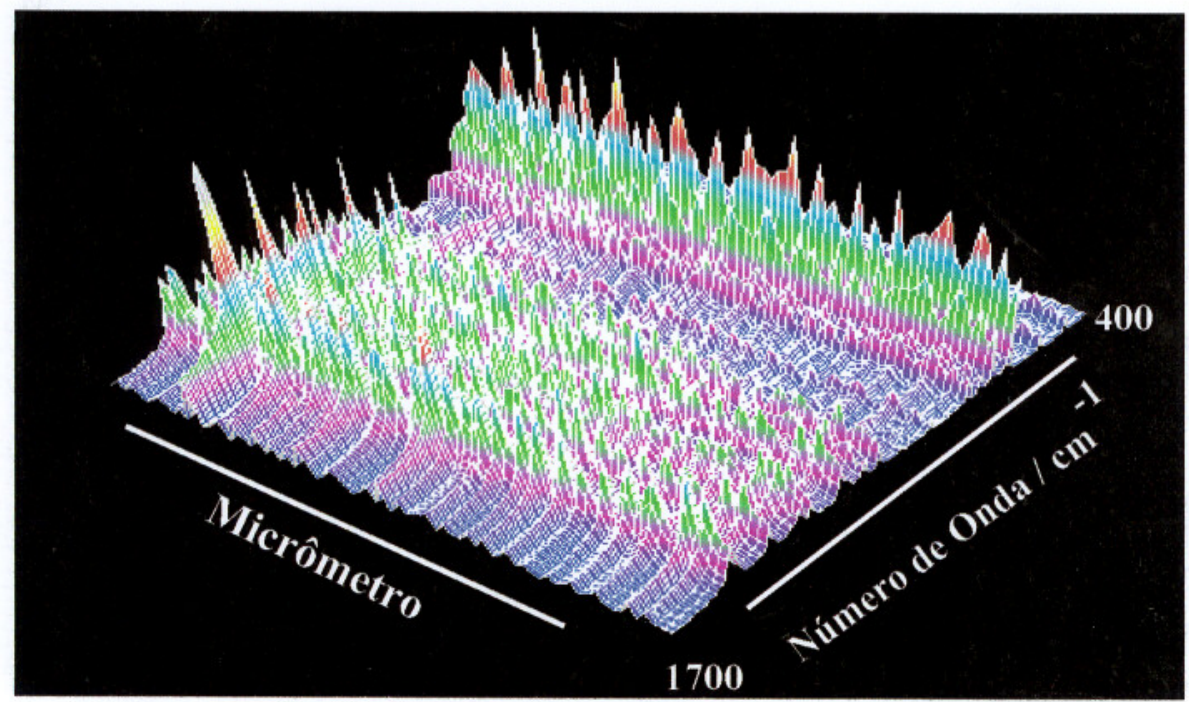

Figura 4.10: Mapeamento Raman $\mathrm{YbPc}_{2} /$ ácido esteárico 25/75\%

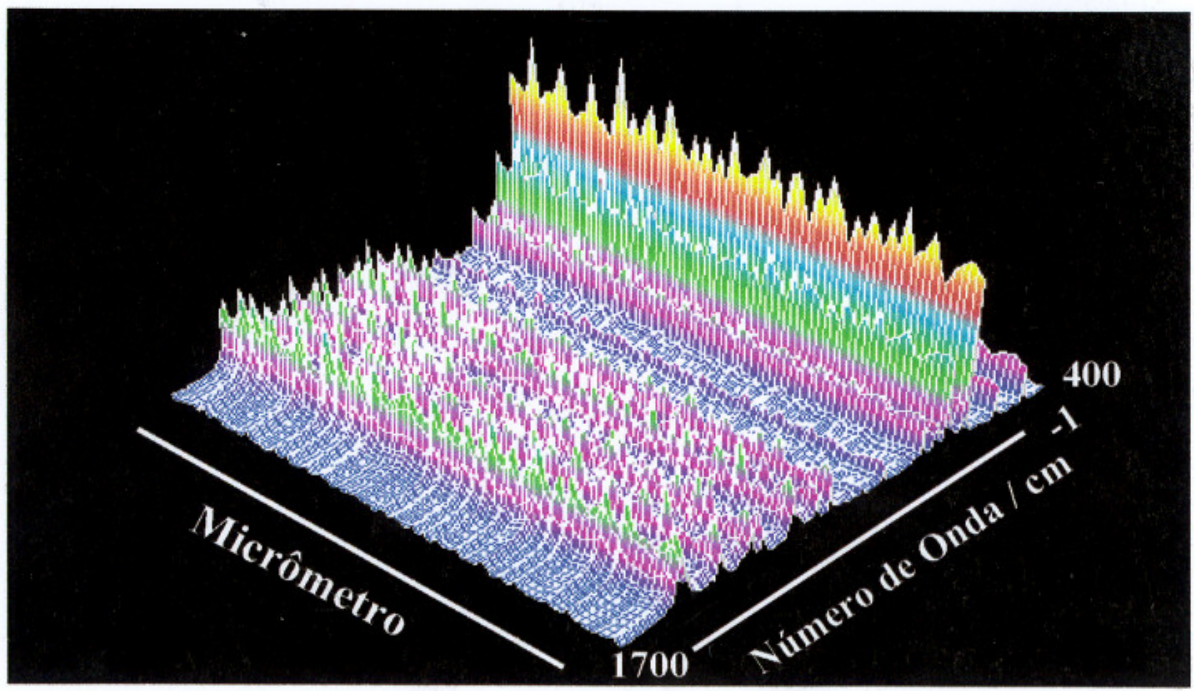

Figura 4.11: Mapeamento Raman $\mathrm{YbPc}_{2} /$ ácido esteárico 75/25\% 


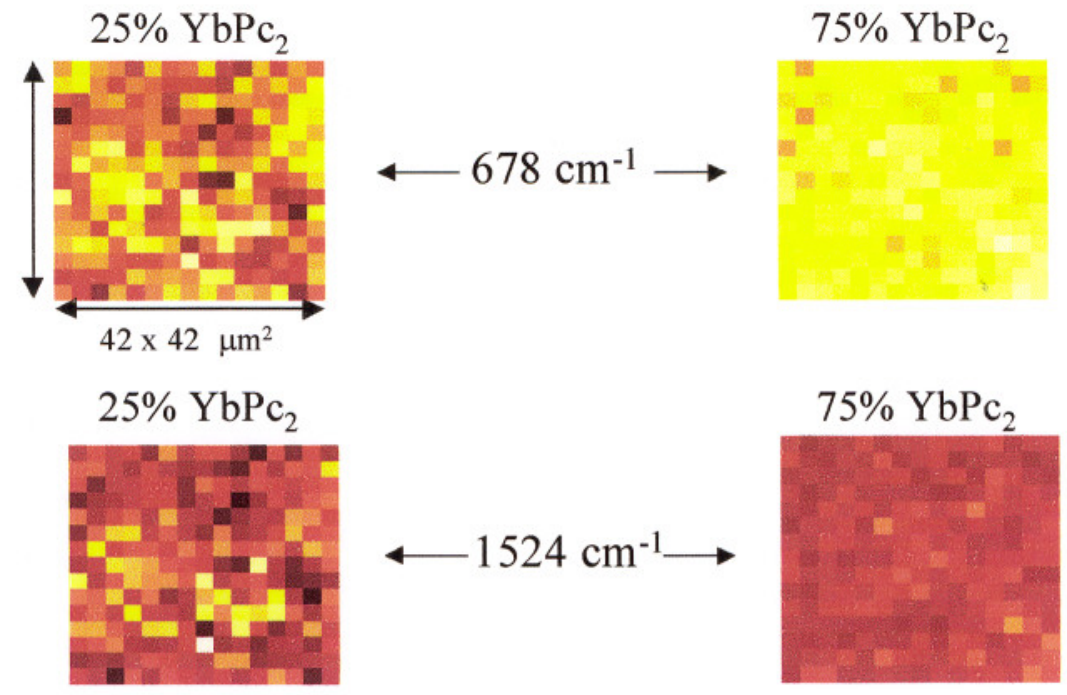

Figura 4.12: Mapeamento de área RRS usando a área integrada para os picos 678 e $1524 \mathrm{~cm}^{-1}$ para filmes LB mistos 75/25\% e 25/75\% $\mathrm{YbPc}_{2} /$ ácido esteárico (5 monocamadas) usando linha de laser $633 \mathrm{~nm}$

As diferentes cores na figura 4.12 mostram diferenças na homogeneidade do filme. O filme com $25 \%$ de $\mathrm{YbPc}_{2}$ é menos homogêneo que o filme com $75 \%$ de $\mathrm{YbPc}_{2}$. Isso também pode ser observado nas figuras 4.10 e 4.11 .

As figuras 4.13 e 4.15 mostram imagens AFM para filmes LB mistos com 5 camadas de $\mathrm{YbPc}_{2} /$ ácido esteárico $(25 / 75 \%, 75 / 25 \%)$ sobre mica. Na figura 4.15 observa-se maior homogeneidade para um filme misto de $\mathrm{YbPc}_{2} /$ ácido esteárico 75/25\%. O aumento da proporção de $\mathrm{YbPc}_{2}$ em ácido esteárico aumenta as regiões claras definidas como pontos sobre uma matriz mais escura. As figuras 4.14 e 4.16 mostram uma análise das seções transversais dos filmes LB mistos $\mathrm{YbPc}_{2} /$ ácido esteárico em diferentes proporções. Consistente com a menor homogeneidade, a rugosidade (Rms) foi maior para o filme de $\mathrm{YbPc}_{2}$ / ácido esteárico 25/75\% $(\mathrm{Rms}=1,6$ $\mathrm{nm})$, comparada ao filme $\mathrm{YbPc}_{2} /$ ácido esteárico 75/25\% (Rms=0,9 nm). 


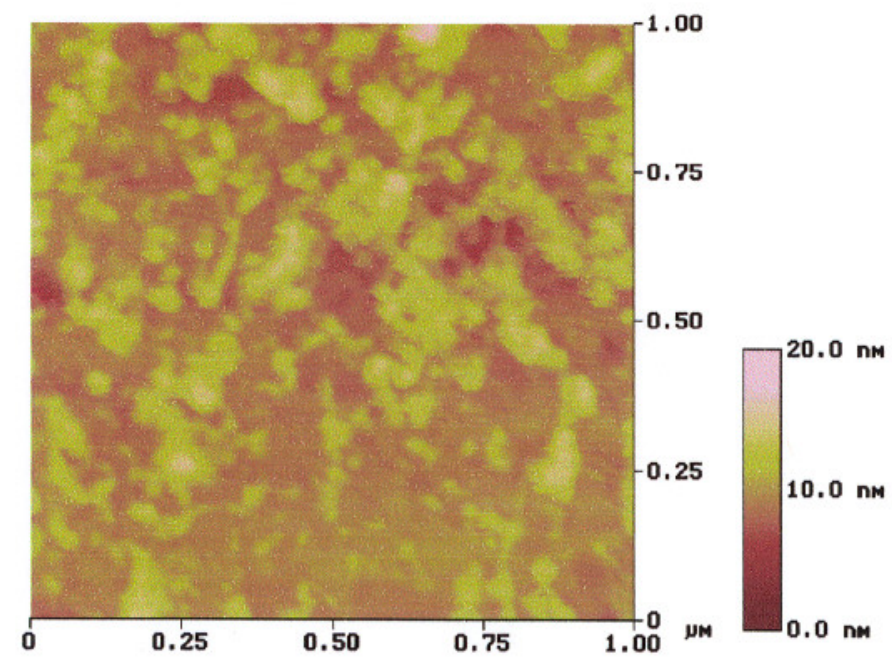

Figura 4.13: Imagem de AFM para um filme LB de $\mathrm{YbPc}_{2} /$ ácido esteárico 25/75\%

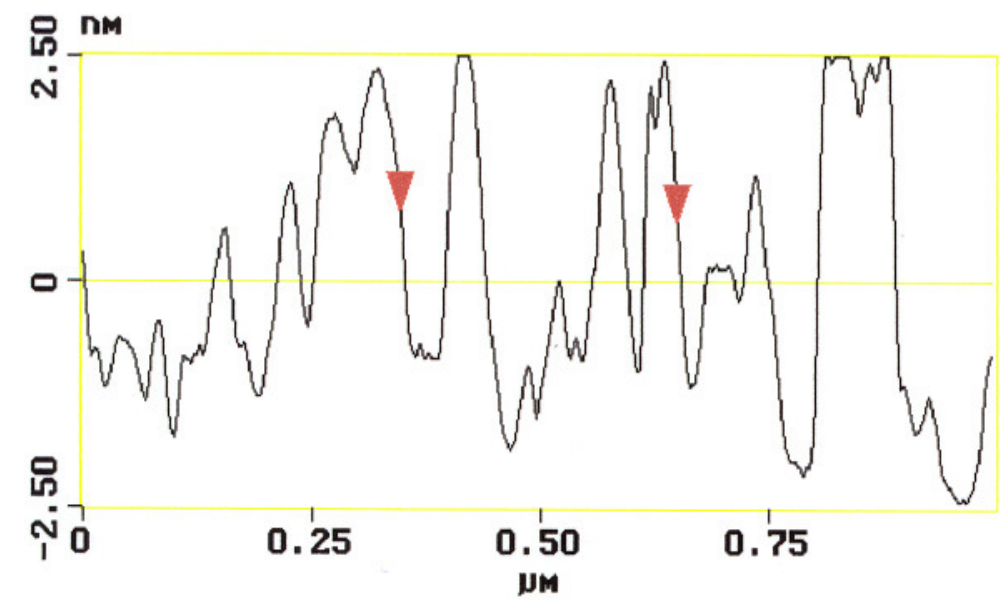

Figura 4.14: Análise da seção transversal de um filme LB de $\mathrm{YbPc}_{2}$ /ácido esteárico 25/75\% 


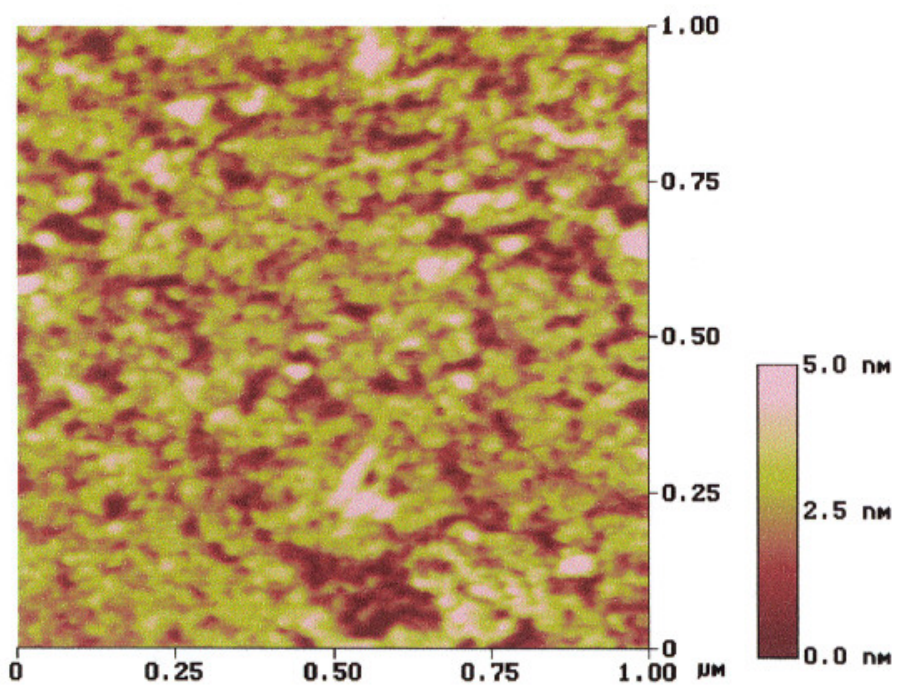

Figura 4.15: Imagem de AFM para um filme $\mathrm{LB} \mathrm{YbPc}_{2} /$ ácido esteárico 75/25\%

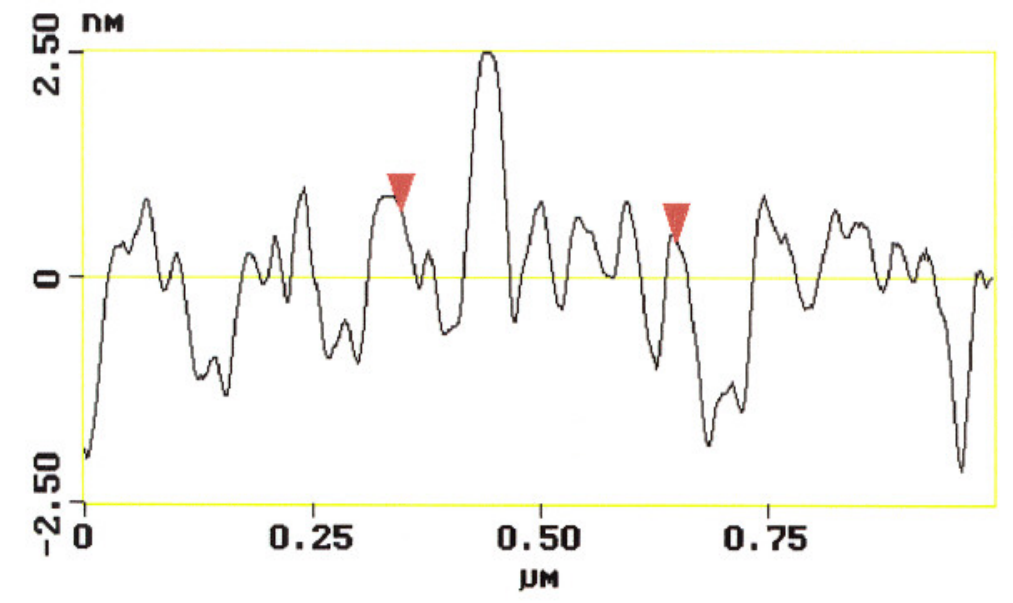

Figura 4.16: Análise da seção transversal de um filme LB de $\mathrm{YbPc}_{2} /$ ácido esteárico $75 / 25 \%$

Tanto para os mapeamentos Raman quanto para as imagens AFM foi observado que o filme LB misto contendo $75 \%$ de $\mathrm{YbPc}_{2}$ apresenta uma melhor homogeneidade e intensidades relativas mais fortes na média da atividade Raman na escala micrométrica. Este comportamento foi confirmado nas imagens Raman usando integrais das áreas para os picos Raman em $678 \mathrm{~cm}^{-1}$ e $1524 \mathrm{~cm}^{-1}$ para os filmes LB mistos em ambas as proporções (figura 4.12). A comparação dos resultados de Raman e AFM indica, portanto, que o comportamento encontrado na escala micrométrica (Raman) pode ser extrapolado para a escala nanométrica (AFM). 


\subsection{Resultados de Espectroscopia Raman para a Ftalocianina de Paládio (PdPc)}

A PdPc, apesar de apresentar dificuldades de solubilização, pôde ser utilizada em trabalhos com a técnica de espectroscopia Raman. A dificuldade de solubilização da PdPc em solventes orgânicos impossibilitou a formação de filmes através da técnica LB. Um outro método de preparação de filmes que pode ser utilizado é o método de sublimação. Nesse método, não há necessidade de solubilização do composto em solvente orgânico, pois o composto é sublimado de seu estado sólido para o substrato. Essa técnica permite a formação de filmes homogêneos, podendo ser controlada a espessura. Os resultados de espectroscopia Raman obtidos com filmes evaporados de PdPc são mostrados a seguir.

\subsubsection{Experimental}

Filmes da PdPc foram depositados sobre substratos transparentes de vidro (Corning 7059) e os mesmos contendo prata evaporada. Os filmes de prata foram preparados em uma evaporadora a vácuo Balzers. Esferas de prata foram termicamente evaporadas para o substrato pré-aquecido a $200^{\circ} \mathrm{C}$ utilizando uma pressão de $10^{-6}$ Torr. A espessura da prata depositada foi de $6 \mathrm{~nm}$. A PdPc foi evaporada sobre vidro e ilhas de prata em uma espessura de $10 \mathrm{~nm}$. $O$ sistema de evaporação para a PdPc foi o mesmo utilizado para a prata, com exceção do aquecimento.

O SERRS, RRS e mapeamento para os filmes da PdPc foram obtidos com um sistema Renishaw Research Raman Microscope RM2000 (mesmo equipamento utilizado para estudar os filmes da $\mathrm{YbPc}_{2}$ ). Duas linhas de laser foram usadas para excitação do espalhamento de luz: 633 e $780 \mathrm{~nm}$. Os espectros UV-Visível dos filmes e da solução foram obtidos em um espectrofotômetro Varian Cary 50 Scan.

\subsubsection{Resultados e Discussão}

O espectro de absorção da $\mathrm{PdPc}$ (solução em tolueno) na região do UV-Vis. da figura 4.17 apresenta a banda $\mathrm{B}$ em $333 \mathrm{~nm}$ e as bandas Q referentes às formas dimérica e monomérica em 612 e $653 \mathrm{~nm}$, respectivamente. Os espectros de filmes 
da PdPc sublimados sobre prata e vidro e o espectro do plasmon das ilhas de prata também são apresentados nesta figura, observando-se que o laser em $633 \mathrm{~nm}$ está em ressonância com o espectro de absorção do composto, condição necessária para se obter o espectro Raman ressonante em superfície (RRS).

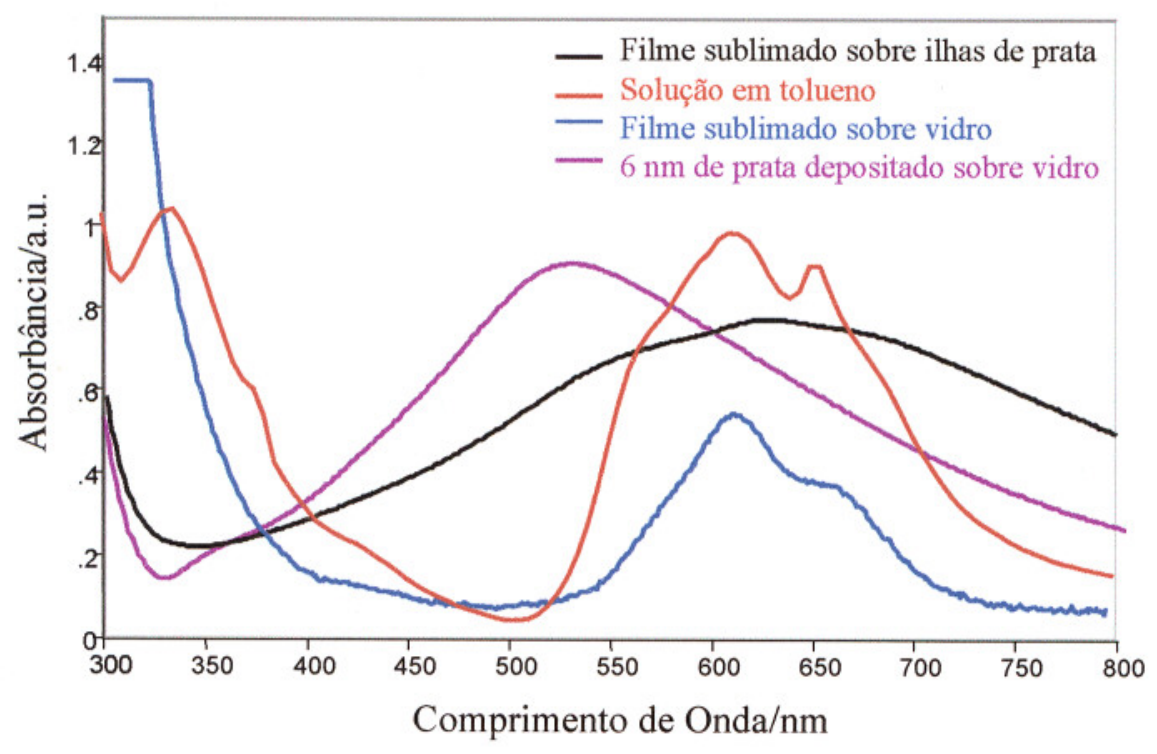

Figura 4.17: Espectros de absorção na região do UV-Vis. para a PdPc em: solução de tolueno, filme sublimado sobre vidro, filme sublimado sobre ilhas de prata e prata depositada sobre vidro

O RRS utilizando excitação em $633 \mathrm{~nm}$ para um filme sublimado da PdPc (10 $\mathrm{nm}$ ) é apresentado na figura 4.18. O espectro RRS apresenta baixas intensidades e não são observadas as bandas harmônicas. 


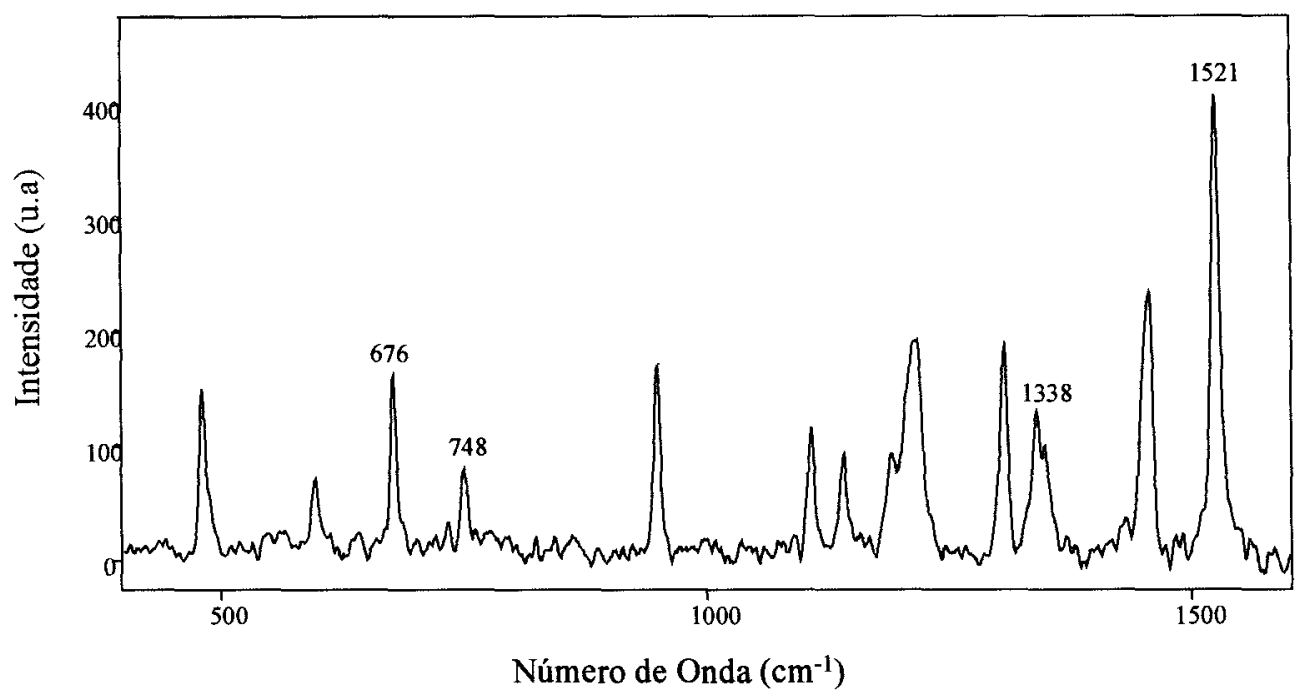

Figura 4.18: Espectro RRS (excitação $633 \mathrm{~nm}$ ) para um filme sublimado da PdPc sobre vidro

$\mathrm{Na}$ figura 4.19 observa-se um espectro de um filme de PdPc depositado sobre ilhas de prata, onde foi depositada prata novamente sobre o filme de PdPc. Quando é feita essa deposição, obtêm-se sinais amplificados, podendo-se observar que principalmente as bandas harmônicas, observadas a partir de $1800 \mathrm{~cm}^{-1}$, passaram a ter maiores intensidades.

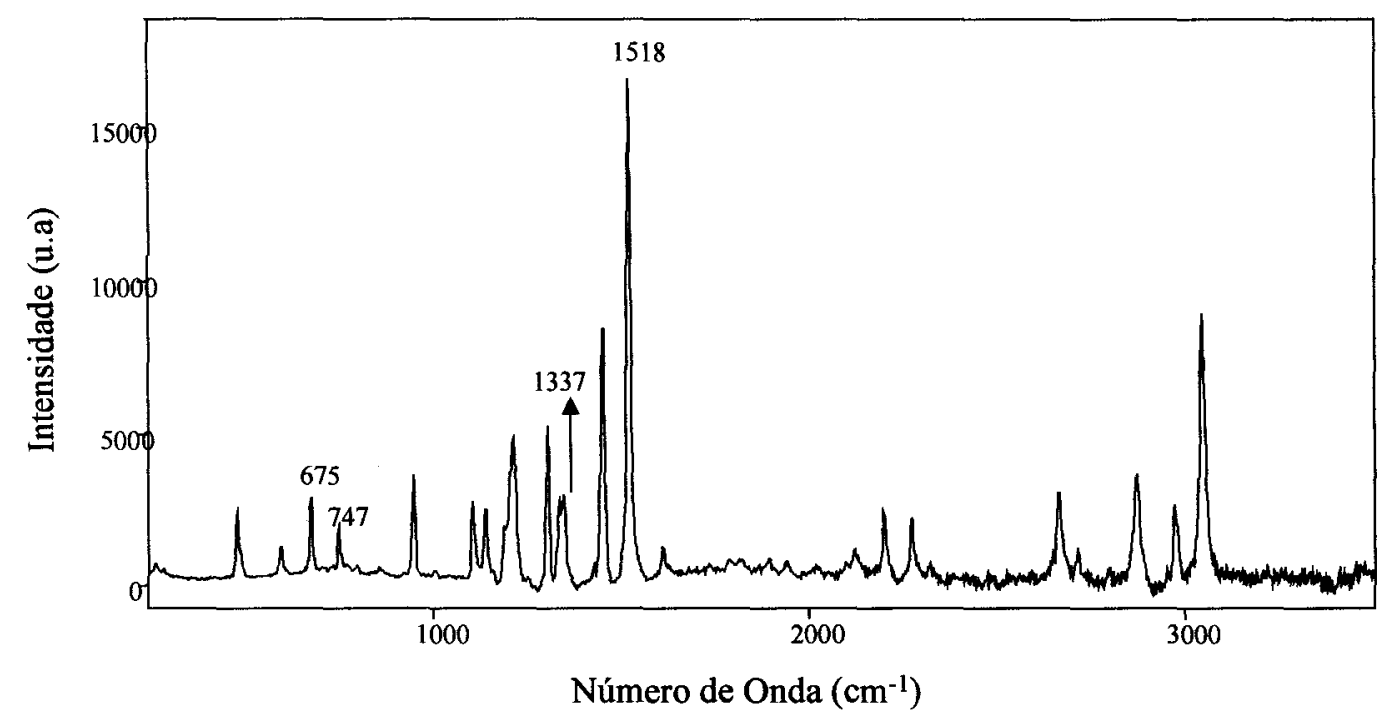

Figura 4.19: Espectro Raman ressonante por superficie (SERRS) para um filme sublimado da PdPc sobre ilhas de prata com prata depositada sobre a PdPc (excitação $633 \mathrm{~nm}$ ) 
As intensidades relativas das bandas do espectro RRS e do espectro amplificado são idênticas, havendo aumento na intensidade do espectro amplificado. $O$ fato de os espectros serem muito semelhantes indica a não existência de interação química entre o composto e o substrato. A banda mais intensa é em aproximadamente $1520 \mathrm{~cm}^{-1}$ para ambos os espectros.

A linha de laser em $780 \mathrm{~nm}$ não está em ressonância com o espectro de absorção da PdPc, como pode ser observado na figura 4.17. O espectro da figura 4.20 apresenta o espectro SERS da PdPc obtido com essa linha de laser.

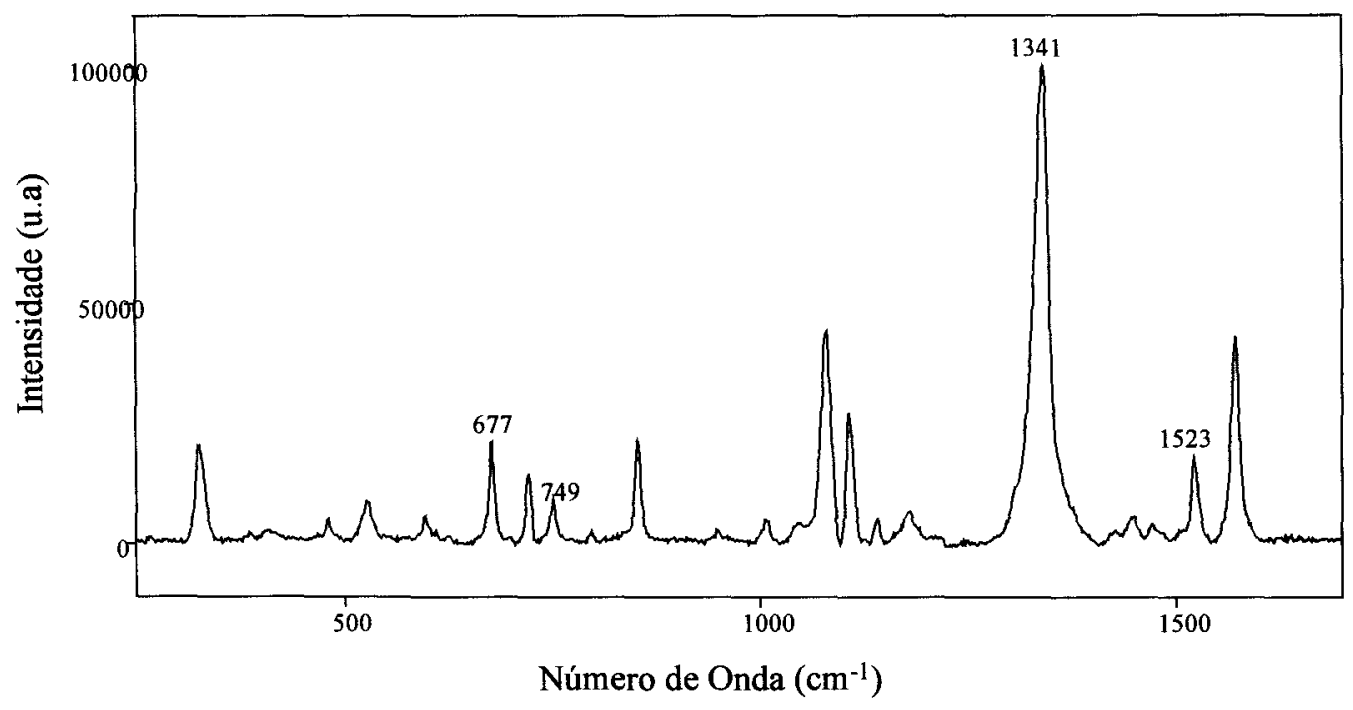

Figura 4.20: Espectro SERS (excitação $780 \mathrm{~nm}$ ) para um filme sublimado da PdPc sobre ilhas de prata

A banda de maior intensidade para a PdPc usando excitação em $780 \mathrm{~nm}$ é em $1340 \mathrm{~cm}^{-1}$, enquanto que para excitação em $633 \mathrm{~nm}$, a banda mais intensa foi em $1520 \mathrm{~cm}^{-1}$. As bandas dos espectros RRS, SERRS e SERS para filmes da PdPc estão atribuídas na tabela 4.4. As intensidades relativas estão indicadas entre parênteses.

Comparando os espectros da $\mathrm{PdPc}$ e da $\mathrm{YbPc}_{2}$ utilizando linha de laser em $633 \mathrm{~nm}$, observou-se que a banda de maior intensidade para a $\mathrm{YbPc}_{2}$ foi observada em $677 \mathrm{~cm}^{-1}$ independentemente do substrato utilizado. Já para a PdPc, a banda de maior intensidade foi em $1340 \mathrm{~cm}^{-1}$ quando depositada sobre ilhas de prata, e em $1524 \mathrm{~cm}^{-1}$ quando depositada sobre vidro. Utilizando a linha de laser em $780 \mathrm{~nm}$ em filmes depositados sobre prata, as bandas mais intensas foram em $1340 \mathrm{~cm}^{-1}$ para a PdPc e em $740 \mathrm{~cm}^{-1}$ para a $\mathrm{YbPc}_{2}$. Uma análise mais detalhada desses resultados, comparando-os com dados da literatura, será feita no final deste capítulo juntamente com os resultados da $\mathrm{RhPc}$. 
Tabela 4.4: Deslocamentos Raman em filmes sublimados da PdPc. Os valores entre parênteses são as intensidades relativas das bandas.

\begin{tabular}{|c|c|c|c|}
\hline $\begin{array}{l}\text { RRS/633 } \\
\text { nm } \\
\text { espessura } \\
100 \mathrm{~nm} \\
\text { vidro }\end{array}$ & $\begin{array}{c}\text { SERRS/633nm } \\
\text { espessura } \\
100 \mathrm{~nm} \\
\text { ilhas de } \\
\text { prata/PdPc/ } \\
\text { ilhas de prata }\end{array}$ & $\begin{array}{l}\text { SERS/780nm } \\
\text { espessura } \\
100 \mathrm{~nm} \\
\text { ilhas de prata }\end{array}$ & Atribuições Tentativas \\
\hline \multirow[t]{2}{*}{$482(37)$} & $482(13)$ & $480(4)$ & Deformação do anel pirrol \\
\hline & & $527(7)$ & \\
\hline $563(3)$ & & & $\begin{array}{c}\text { Deformação angular } \\
\text { C-C-C }\end{array}$ \\
\hline $597(16)$ & $597(5)$ & $597(4)$ & Deformação do anel benzênico \\
\hline $639(5)$ & & & Respiração \\
\hline \multirow[t]{2}{*}{$678(38)$} & $678(15)$ & $677(21)$ & Respiração do anel macrocíclico \\
\hline & & $721(15)$ & $\begin{array}{c}\text { Deformação do anel fora do } \\
\text { plano }\end{array}$ \\
\hline \multirow[t]{2}{*}{$751(16)$} & $751(9)$ & $751(8)$ & Deformação do anel no plano \\
\hline & & $798(1)$ & Respiração do anel benzênico \\
\hline $843(3)$ & & $854(21)$ & Deformação C-H fora do plano \\
\hline $863(4)$ & & & C-H fora do plano \\
\hline \multirow[t]{4}{*}{$950(44)$} & $950(20)$ & & \\
\hline & & $1009(4)$ & Deformação angular de C-H \\
\hline & & $1057(4)$ & Deformação angular de C-H \\
\hline & & $1080(47)$ & Deformação angular de C-H \\
\hline $1109(32)$ & $1108(13)$ & $1109(29)$ & Deformação angular de C-H \\
\hline $1141(24)$ & $1141(12)$ & $1142(4)$ & Pirrol \\
\hline \multirow[t]{2}{*}{$1191(25)$} & & & Deformação C-H no plano \\
\hline & & $1181(6)$ & Deformação C-H no plano \\
\hline $1214(64)$ & $1212(27)$ & & Deformação C-H no plano \\
\hline $1306(54)$ & $1306(34)$ & & Deformação C-H no plano \\
\hline \multirow[t]{2}{*}{$1343(37)$} & $1344(18)$ & $1340(100)$ & Estiramento pirrol C-C-C \\
\hline & & $1429(3)$ & Estiramento isoindol \\
\hline \multirow[t]{2}{*}{$1454(67)$} & $1454(52)$ & $1449(5)$ & Deformação angular de C-H \\
\hline & & $1475(2)$ & \\
\hline \multirow[t]{9}{*}{$1524(100)$} & $1523(100)$ & $1524(18)$ & Estiramento pirrol $\mathrm{C}=\mathrm{N}$ \\
\hline & & $1573(45)$ & Deformação C-H fora do plano \\
\hline & $2123(4)$ & & Deformação angular de C-H \\
\hline & $2202(11)$ & & Deformação angular de C-H \\
\hline & $2275(11)$ & & Pirrol \\
\hline & $2667(16)$ & & Estiramento pirrol C-C-C \\
\hline & $2712(5)$ & & \\
\hline & $2873(21)$ & & Estiramento isoindol \\
\hline & $2974(11)$ & & \\
\hline
\end{tabular}




\subsection{Resultados de Espectroscopia Raman para a Ftalocianina de Ródio (RhPc)}

Das sínteses da $\mathrm{RhPc}$, o produto obtido através do método que utiliza $o$ cianobenzamida como um dos reagentes de partida foi o que apresentou melhores resultados. Após a purificação do produto bruto, obteve-se uma das frações praticamente pura que foi utilizada para fabricação de filmes LB e caracterização por espectroscopia Raman. Os resultados são mostrados a seguir.

\subsubsection{Experimental}

Filmes LB da RhPc foram preparados em uma cuba de Langmuir LB Lauda. A subfase utilizada foi água ultrapura $(18,2 \mathrm{M} \Omega \mathrm{cm})$ à temperatura ambiente. Para a formação dos filmes, foi espalhada uma solução de RhPc em clorofórmio a uma concentração de $0,1 \mathrm{mg} / \mathrm{mL}$ na subfase. Os filmes LB foram transferidos para substratos onde previamente havia sido depositada prata. $\mathrm{O}$ método de deposição da prata foi descrito anteriormente nos procedimentos experimentais da $\mathrm{YbPc}_{2}$ e da PdPc. Os espectros SERS, SERRS, RRS e mapeamento para filmes da RhPc foram obtidos no mesmo equipamento citado anteriormente para as medidas da $\mathrm{YbPc}_{2}$ e da PdPc. As linhas de laser para excitação do espalhamento de luz foram 633 e $780 \mathrm{~nm}$. Para o mapeamento foi empregada a linha de laser em $633 \mathrm{~nm}$. A área usada no mapeamento foi de 40 por $40 \mu \mathrm{m}$. Um espectrofotômetro Varian Cary 50 Scan foi utilizado para obtenção dos espectros UV-Vis. dos filmes e solução.

\subsubsection{Resultados e Discussão}

O espectro de absorção da RhPc (solução) da figura 4.21 apresenta as bandas Q e B normalmente exibidas pelas Pcs. O espectro é do composto na forma monomérica, sendo observadas a banda B em $345 \mathrm{~nm}$ e a banda $Q$ em $654 \mathrm{~nm}$. Na figura 4.21 estão também os espectros de filmes LB da RhPc depositados sobre ilhas de prata e vidro e o espectro do plasmon das ilhas de prata. A linha de laser em 633 nm está em ressonância com o espectro de absorção do composto, podendo-se assim 
obter o espectro SERRS. Já a linha de laser em 780 nm não está em ressonância com o espectro de absorção, obtendo-se o espectro SERS.

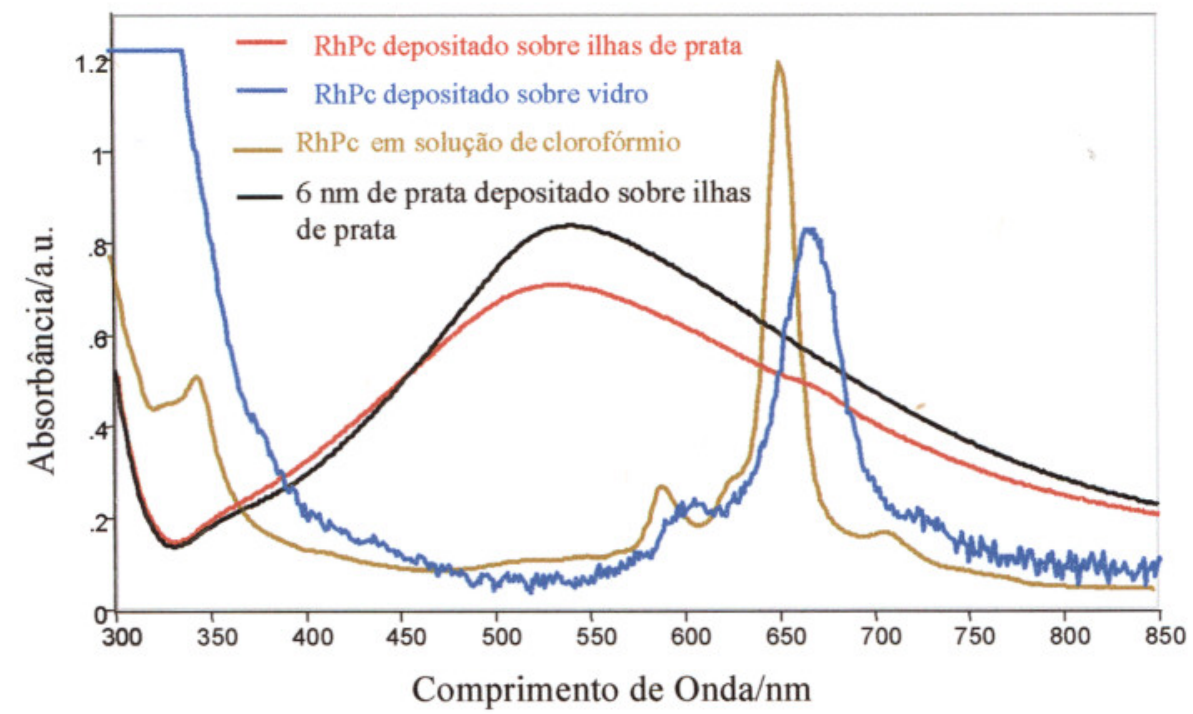

Figura 4.21: Espectros de absorção na região do UV-Vis. para a RhPc em: solução de clorofórmio, filme LB sobre vidro, filme LB sobre ilhas de prata e prata depositada sobre vidro

Os espectros SERRS e RRS com excitação em $633 \mathrm{~nm}$ para filmes LB da RhPc (1 monocamada) são apresentados na figura 4.22. Um grande aumento na intensidade foi observado para o espectro SERRS comparado ao RRS. Esse aumento de intensidade é devido à amplificação dos sinais proporcionada pelas ilhas de prata.

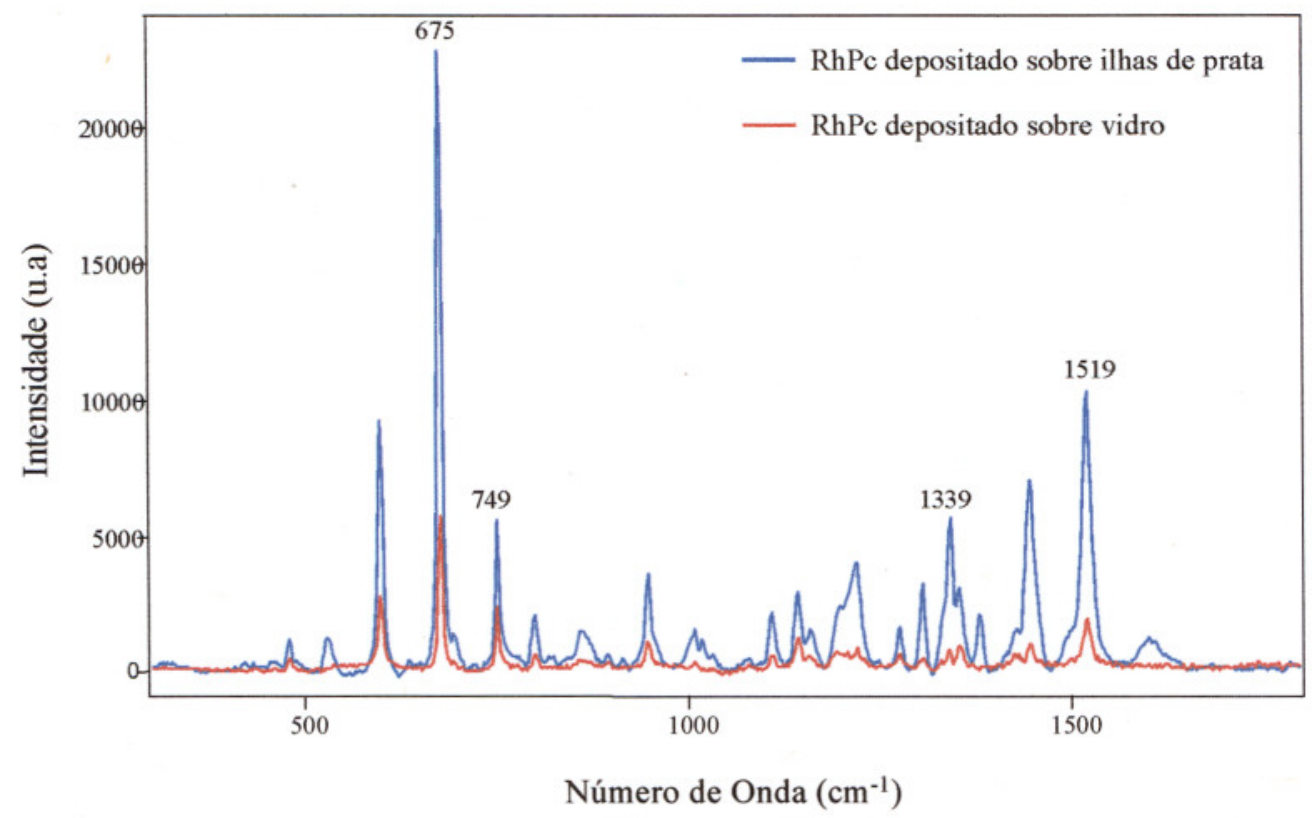

Figura 4.22: Espectros RRS e SERRS (excitação $633 \mathrm{~nm}$ ) para filmes LB da RhPc depositados sobre vidro e ilhas de prata 
Na figura 4.23, o espectro de um filme LB da RhPc também contendo uma monocamada, porém utilizando excitação em $780 \mathrm{~nm}$, apresenta também os sinais bastante intensificados. Utilizando a linha de laser em $633 \mathrm{~nm}$, algumas bandas são observadas no filme depositado sobre ilhas de prata e não no filme sobre vidro. Isso ocorre devido à amplificação dos sinais, sendo possível observar mais bandas no espectro do composto depositado sobre ilhas de prata.

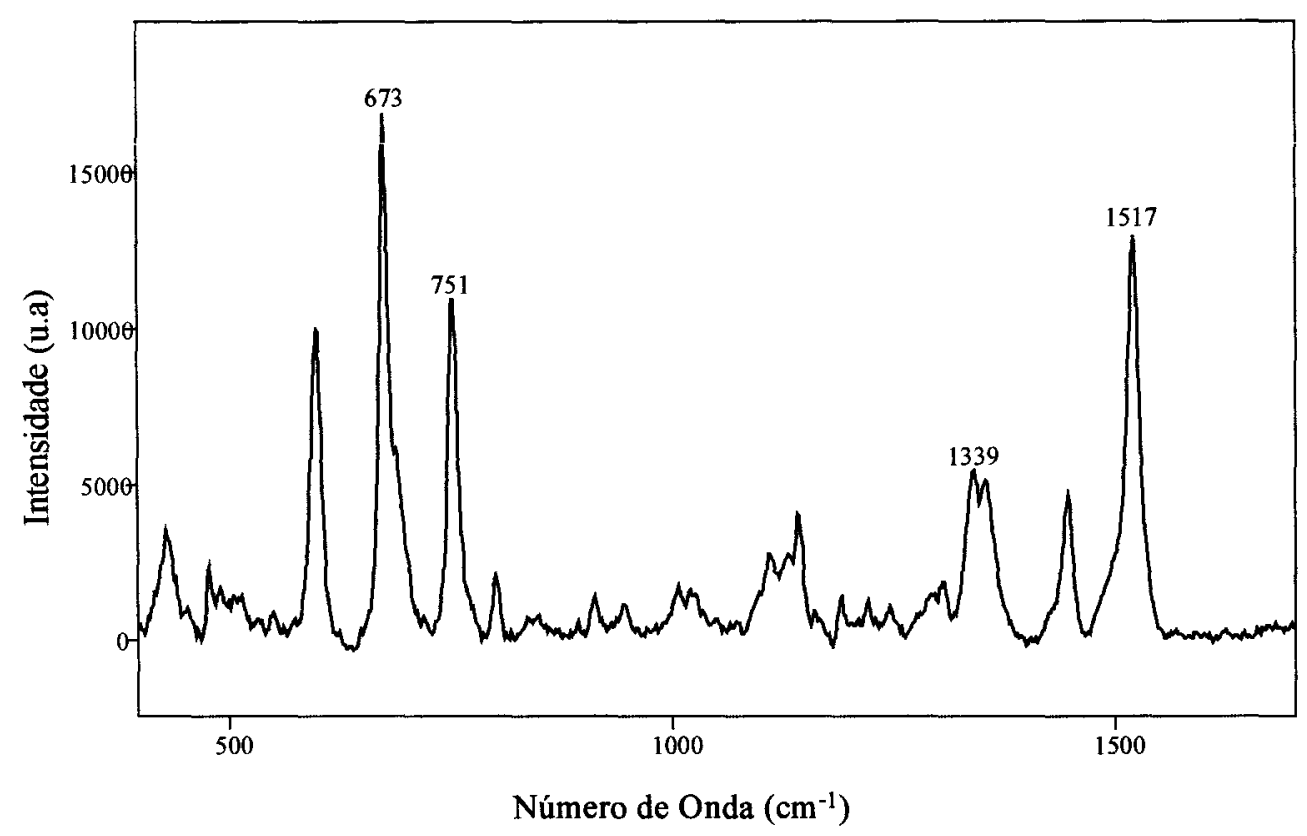

Figura 4.23: Espectro SERS (excitação $780 \mathrm{~nm}$ ) para um filme LB da RhPc sobre ilhas de prata

As bandas nos espectros RRS, SERRS e SERS para filmes da RhPc estão atribuídas na tabela 4.5. As intensidades relativas das bandas estão indicadas entre parênteses. A banda de maior intensidade é a mesma para os três espectros, não sendo alterada com a mudança de substrato, nem com a troca da linha de laser. Apesar de a $\mathrm{RhPc}$ apresentar comportamento muito semelhante ao da $\mathrm{YbPc}_{2}$, elas diferem na banda de maior intensidade com a linha de laser em $780 \mathrm{~nm}$. A ftalocianina de alumínio [(AlPc) $\left.)_{2} \mathrm{O}\right]$ também tem a banda de maior intensidade alterada quando linhas de laser em ressonância e fora de ressonância são utilizadas para as medidas [8]. Já as ftalocianinas de magnésio $(\mathrm{MgPc})$, zinco $(\mathrm{ZnPc})$ e cobre $(\mathrm{CuPc})$ apresentam a mesma banda de maior intensidade, não dependendo se o laser está ou não em ressonância [9]. 
Tabela 4.5: Deslocamentos Raman observados em filmes LB da RhPc.

Os valores entre parênteses são as intensidades relativas das bandas.

\begin{tabular}{|c|c|c|c|}
\hline $\begin{array}{l}\text { SERS/780 } \\
\text { ilhas de prata }\end{array}$ & $\begin{array}{c}\text { SERRS/633 } \\
\text { ilhas de prata }\end{array}$ & $\begin{array}{c}\text { RRS/633 } \\
\text { vidro }\end{array}$ & Atribuições Tentativas \\
\hline $479(11)$ & $480(5)$ & $480(1)$ & Deformação do anel pirrol \\
\hline \multicolumn{4}{|l|}{$515(3)$} \\
\hline & $530(6)$ & & \\
\hline $551(3)$ & & & $\begin{array}{c}\text { Deformação angular de } \\
\text { C-C-C }\end{array}$ \\
\hline $600(71)$ & $599(43)$ & $599(48)$ & Deformação do anel benzênico \\
\hline \multirow[t]{2}{*}{$673(100)$} & $675(100)$ & $677(100)$ & $\begin{array}{l}\text { Respiração do anel } \\
\text { macrocíclico }\end{array}$ \\
\hline & $680(11)$ & & \\
\hline $751(75)$ & $749(24)$ & $751(41)$ & Deformação do anel no plano \\
\hline \multirow[t]{2}{*}{$802(13)$} & $800(8)$ & $801(10)$ & Respiração do anel benzênico \\
\hline & $863(5)$ & $863(5)$ & C-H fora do plano \\
\hline $913(6)$ & & $895(3)$ & Deformação C-H fora do plano \\
\hline $946(4)$ & $948(14)$ & $947(17)$ & Estiramento isoindol \\
\hline $1007(8)$ & $1006(6)$ & $1009(4)$ & Deformação angular de C-H \\
\hline \multirow[t]{3}{*}{$1023(7)$} & $1020(3)$ & & Deformação angular de C-H \\
\hline & & $1067(3)$ & Deformação angular de C-H \\
\hline & & $1079(4)$ & Deformação angular de C-H \\
\hline $1107(7)$ & $1110(9)$ & $1110(10)$ & Deformação angular de C-H \\
\hline \multirow[t]{2}{*}{$1143(17)$} & $1143(13)$ & $1144(21)$ & Pirrol \\
\hline & $1160(6)$ & $1158(7)$ & Deformação angular de C-H \\
\hline \multirow[t]{2}{*}{$1191(8)$} & $1198(11)$ & $1195(11)$ & Deformação C-H no plano \\
\hline & & $1206(7)$ & \\
\hline \multirow[t]{2}{*}{$1221(4)$} & $1219(18)$ & $1221(11)$ & Deformação C-H no plano \\
\hline & $1277(7)$ & $1277(9)$ & Deformação angular de C-H \\
\hline $1293(6)$ & & & Deformação C-H no plano \\
\hline $1307(7)$ & $1306(17)$ & $1307(7)$ & Deformação C-H no plano \\
\hline $1339(24)$ & $1339(25)$ & $1340(15)$ & Estiramento pirrol C-C-C \\
\hline \multirow[t]{3}{*}{$1354(30)$} & $1358(14)$ & $1356(19)$ & Estiramento isoindol \\
\hline & $1380(11)$ & & \\
\hline & $1425(6)$ & $1428(7)$ & Estiramento isoindol \\
\hline $1445(30)$ & $1447(31)$ & $1447(15)$ & Deformação angular de C-H \\
\hline \multirow[t]{2}{*}{$1517(84)$} & $1519(10)$ & & Estiramento pirrol $\mathrm{C}=\mathrm{N}$ \\
\hline & $1521(39)$ & $1521(35)$ & Estiramento pirrol $\mathrm{C}=\mathrm{N}$ \\
\hline
\end{tabular}

No espectro do filme LB da RhPc depositada sobre ilhas de prata, utilizando a linha de laser $633 \mathrm{~nm}$, foi observada a existência de muitas bandas harmônicas. $\mathrm{Na}$ tabela 4.6 estão listados os números de onda e atribuições das bandas harmônicas do espectro SERRS da figura 4.24. 


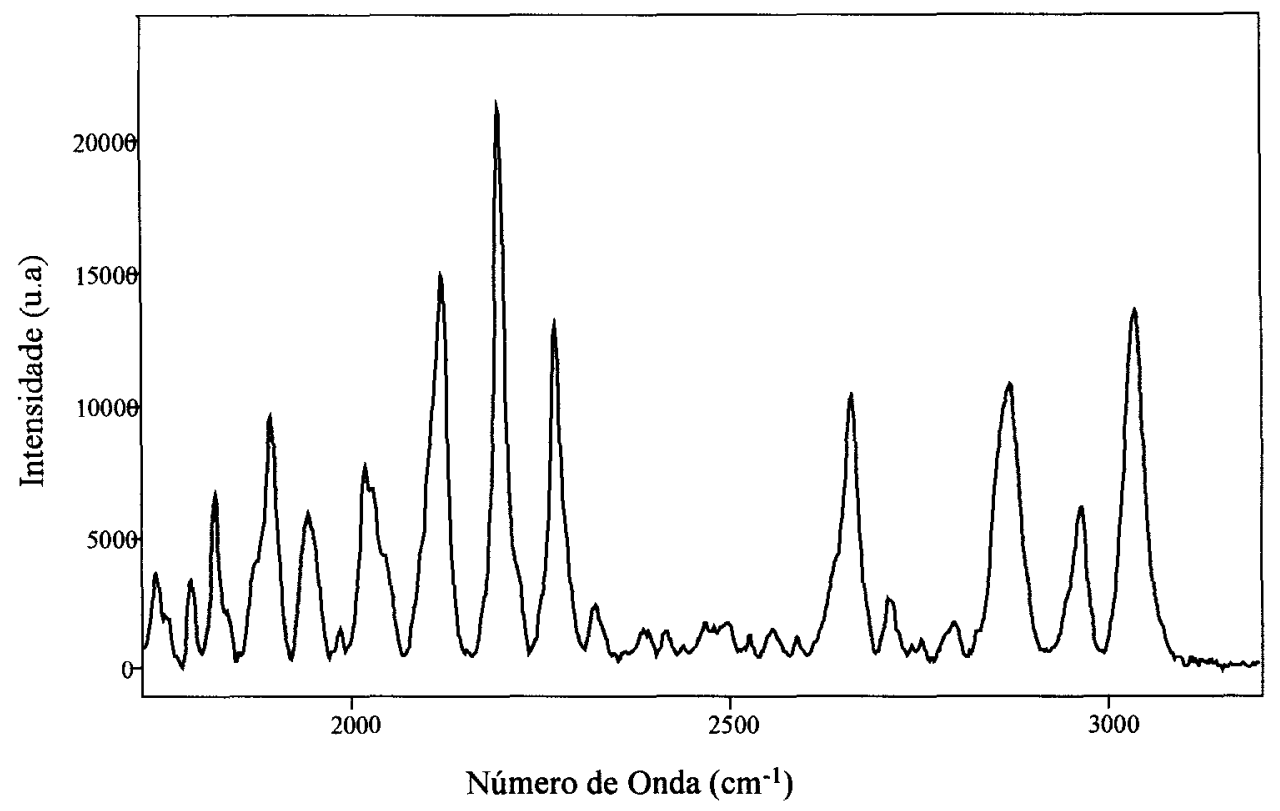

Figura 4.24: Espectro (excitação $633 \mathrm{~nm}$ ) para um filme LB da RhPc sobre ilhas de prata (bandas harmônicas)

Tabela 4.6: Bandas harmônicas observados em um filme LB da RhPc

\begin{tabular}{|c|c|}
\hline $\begin{array}{c}\text { RhPc depositado sobre } \\
\text { ilhas de prata (633 nm) }\end{array}$ & Atribuições Tentativas \\
\hline 1788 & \\
\hline 1820 & Deformação C-H fora do plano \\
\hline 1894 & Estiramento isoindol \\
\hline 1944 & \\
\hline 2020 & Deformação angular de C-H \\
\hline 2122 & \\
\hline 2198 & Deformação angular de C-H \\
\hline 2272 & Deformação angular de C-H \\
\hline 2324 & \\
\hline 2392 & Deformação C-H no plano \\
\hline 2560 & \\
\hline 2592 & Deformação C-H no plano \\
\hline 2664 & Estiramento pirrol C-C-C \\
\hline 2714 & \\
\hline 2872 & \\
\hline 3040 & \\
\hline
\end{tabular}

Para um mapeamento Raman, são obtidos vários espectros de uma certa região do filme. Através desses espectros observa-se a existência de aglomerados no filme e podem ser obtidas informações sobre diferentes fases, caso o filme seja misto. Para o mapeamento da RhPc, foi usada uma área do filme de 40 por $40 \mu \mathrm{m}$. 
Foram obtidos espectros de 3 em $3 \mu \mathrm{m}$ nessa área, obtendo-se assim a imagem da figura 4.25. As intensidades dos espectros são praticamente as mesmas em toda a região observada, o que indica uniformidade do filme. Em apenas alguns pontos do filme, foram observadas maiores intensidades, o que pode indicar maior quantidade de material.

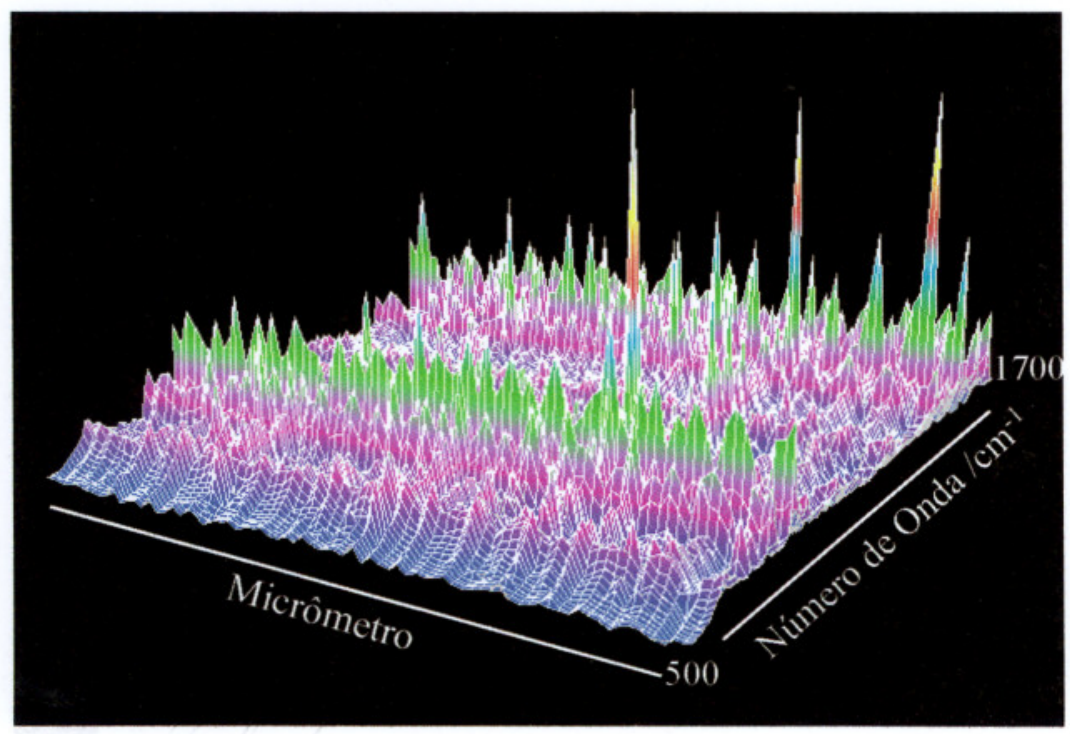

Figura 4.25: Mapeamento Raman para a RhPc

A tabela 4.7 apresenta uma comparação entre a primeira e segunda bandas de maior intensidade para os espectros SER(R)S da RhPc, PdPc e $\mathrm{YbPc}_{2}$. Para os espectros da RhPc a banda de maior intensidade é em $678 \mathrm{~cm}^{-1}$, independentemente da linha de laser utilizada, sendo que a segunda mais intensa muda dependendo da linha de laser. O substrato não interfere nos resultados, indicando que não deve estar ocorrendo interação química entre o composto e o substrato. Utilizando a linha de laser em $633 \mathrm{~nm}$, a $\mathrm{YbPc}_{2}$ apresenta a banda em $680 \mathrm{~cm}^{-1}$ como sendo a mais intensa e a segunda mais intensa em $1524 \mathrm{~cm}^{-1}$. Com o laser em $780 \mathrm{~nm}$, as bandas mais intensas passam a ser observadas em $741 \mathrm{~cm}^{-1}$ e $678 \mathrm{~cm}^{-1}$. Para a PdPc as bandas mais intensas são em $1524 \mathrm{~cm}^{-1} \mathrm{e} 1454 \mathrm{~cm}^{-1}$ para a linha de laser em $633 \mathrm{~nm}$. Com o laser em $780 \mathrm{~nm}$, as bandas de maior intensidade são observadas em 1340 e 1080 $\mathrm{cm}^{-1}$. Resultados da literatura para as bisftalocianinas de túlio $\left(\mathrm{TmPc}_{2}\right)$ [10], cério $\left(\mathrm{CePc}_{2}\right)$ [11], lutécio $\left(\mathrm{LuPc}_{2}\right)$ e $\mathrm{YbPc}_{2}$ [12], apresentam a banda de maior intensidade em torno de $680 \mathrm{~cm}^{-1}$. É característico para as bisftalocianinas apresentarem a banda referente à respiração do anel Pc como sendo a mais intensa. Trabalhos encontrados 
na literatura para monoftalocianinas apresentaram a banda de maior intensidade em torno de $1520 \mathrm{~cm}^{-1}$, como foi observado para a PdPc. As ftalocianinas de vanádio (VOPc) e titânio (TiOPc) se apresentam na forma monomérica, mas contendo um oxigênio ligado ao metal [13], o que pode interferir na simetria da molécula. A ftalocianina de cobre tetrasulfonada [14] também apresenta a banda mais intensa na região entre 1520 e $1540 \mathrm{~cm}^{-1}$. A semelhança encontrada entre essas ftalocianinas e a PdPc pode estar relacionada ao estado de oxidação do metal. O estado de oxidação +2 é um dos mais comuns para os metais $\mathrm{V}, \mathrm{Ti}, \mathrm{Cu}$ e $\mathrm{Pd}$, podendo alterar a simetria dos compostos em relação à $\mathrm{YbPc}_{2}$, apresentando espectros Raman com diferentes intensidades relativas. Para a RhPc a banda de maior intensidade é em $680 \mathrm{~cm}^{-1}$, como observado para a $\mathrm{YbPc}_{2}$. A RhPc se encontra na forma monomérica não contendo substituintes, sendo semelhante às ftalocianinas de magnésio $(\mathrm{MgPc})$, zinco $(\mathrm{ZnPc})$ e cobre $(\mathrm{CuPc})$ encontradas na literatura [9]. Resultados de espectroscopia Raman para essas ftalocianinas apresentam a banda de maior intensidade em regiões próximas a $1500 \mathrm{~cm}^{-1}$. O esperado era que os resultados para a RhPc fossem parecidos com os dessas ftalocianinas, por possuírem as mesmas características, o que não ocorreu.

Gobernado-Mitre e colaboradores [15] realizaram trabalhos com a ftalocianina de estanho ( $\mathrm{SnPc}$ ), e com a tetra-tert-butil ftalocianina de estanho (SnTTPc), mostrando que existe forte influência dos substituintes no estado de oxidação dos metais, e consequentemente nos resultados de espectroscopia Raman. O Sn na SnTTPc tem número de oxidação +4 , apresentando a banda mas intensa em $1333 \mathrm{~cm}^{-1}$, enquanto que na $\mathrm{SnPc}$, o $\mathrm{Sn}$ apresenta número de oxidação +2 e banda de maior intensidade em $1527 \mathrm{~cm}^{-1}$. A banda de maior intensidade para a PdPc é em $1524 \mathrm{~cm}^{-1}$, assim como para as ftalocianinas de magnésio, zinco e cobre. $\mathrm{O}$ número de oxidação que os metais $\mathrm{Mg}$ e $\mathrm{Zn}$ assume é +2 , assim como o Sn na SnPc. O Cu pode assumir os estados $+1 \mathrm{e}+2$. $\mathrm{O}$ ródio na $\mathrm{RhPc}$ e o itérbio na $\mathrm{YbPc}_{2}$ provavelmente estão no estado de oxidação +3 , o que justificaria o fato dessas duas ftalocianinas possuírem as mesmas características em espectroscopia Raman. Resultados de espectroscopia Raman para as ftalocianinas de ródio ou rutênio não são encontrados na literatura, não sendo possível uma comparação direta com nossos resultados para a RhPc. 
Tabela 4.7: Comparação de resultados de espectroscopia Raman para a $\mathrm{YbPc}_{2}$, $\mathrm{PdPc}$

e RhPc. Os valores em porcentagem são as intensidades relativas das bandas.

\begin{tabular}{|c|c|c|}
\hline & $\begin{array}{c}\text { 633 nm (SERRS) } \\
\text { (em ressonância) }\end{array}$ & $\begin{array}{c}\text { 780 nm (SERS) } \\
\text { (fora de ressonância) }\end{array}$ \\
\hline YbPc $_{2}$ & $\begin{array}{c}\text { Respiração do anel Pc }\left(680 \mathrm{~cm}^{-1}\right) \\
100 \%\end{array}$ & $\begin{array}{c}\text { Deformação do anel macrocíclico } \\
\left(741 \mathrm{~cm}^{-1}\right) 100 \%\end{array}$ \\
& Pirrol C=N $\left(1524 \mathrm{~cm}^{-1}\right) 33 \%$ & $\begin{array}{c}\text { Respiração do anel Pc }\left(678 \mathrm{~cm}^{-1}\right) \\
92 \%\end{array}$ \\
\hline PdPc & $\begin{array}{c}\text { Pirrol C=N }\left(1524 \mathrm{~cm}^{-1}\right) 100 \% \\
\text { Deformação angular de C-H } \\
\text { RhPc }\end{array}$ & $\begin{array}{c}\text { Pirrol C-C-C }\left(1340 \mathrm{~cm}^{-1}\right) 100 \% \\
\text { Deformação angular de C-H }\end{array}$ \\
& $\begin{array}{c}\text { Respiração do anel macrocíclico } \\
\left(680 \mathrm{~cm}^{-1}\right) 100 \%\end{array}$ & $\begin{array}{c}\text { Respiração do anel macrocíclico } \\
\left(678 \mathrm{~cm}^{-1}\right) 100 \%\end{array}$ \\
& $\begin{array}{c}\text { Deformação do anel benzênico } \\
\left(599 \mathrm{~cm}^{-1}\right) 43 \%\end{array}$ & $\begin{array}{c}\text { Estiramento pirrol C=N } \\
\left(1519 \mathrm{~cm}^{-1}\right) 84 \%\end{array}$ \\
\hline
\end{tabular}

\subsection{Conclusões}

Os resultados de espectroscopia Raman apresentaram algumas diferenças nas intensidades relativas quando comparados os espectros da RhPc, da PdPc e da $\mathrm{YbPc}_{2}$. A banda de maior intensidade encontrada para a RhPc foi a mesma da $\mathrm{YbPc}_{2}$ $\left(675 \mathrm{~cm}^{-1}\right)$ quando utilizada a linha de laser em $633 \mathrm{~nm}$. Para a linha de laser em 780 $\mathrm{nm}$ a banda de maior intensidade para a RhPc permanece a mesma, enquanto que para a $\mathrm{YbPc}_{2}$ passa a ser em $741 \mathrm{~cm}^{-1}$. A PdPc apresentou a banda de maior intensidade em $1523 \mathrm{~cm}^{-1}$ independentemente do substrato, utilizando o laser em 633 nm. Já com o laser em $780 \mathrm{~nm}$, a banda de maior intensidade foi observada em 1340 $\mathrm{cm}^{-1}$. Os resultados para a $\mathrm{YbPc}_{2}$ e $\mathrm{RhPc}$ foram parecidos, com a PdPc apresentando comportamento diferente. Gobernado-Mitre e colaboradores [15] mostraram forte influência do estado de oxidação dos metais nos resultados de espectroscopia Raman. Pode-se inferir, assim, que a semelhança nos resultados da $\mathrm{RhPc}$ e $\mathrm{YbPc}_{2}$ pode ser explicada por elas possuírem o mesmo estado de oxidação, provavelmente +3 . A PdPc apresentou resultados parecidos com os da literatura para ftalocianinas cujo metal possivelmente se encontra no estado de oxidação +2 , como $\mathrm{Mg}, \mathrm{Zn}$ e $\mathrm{Cu}$ e $\mathrm{Sn}$. $\mathrm{Na}$ comparação de imagens de micro espectroscopia Raman e AFM observou-se que filmes contendo $75 \%$ de $\mathrm{YbPc}_{2}$ e $25 \%$ de ácido esteárico apresentam maior homogeneidade que filmes contendo apenas $25 \%$ de $\mathrm{YbPc}_{2}$. 


\subsection{Blibliografia}

1. SALA, O., Fundamentos da Espectroscopia Raman e no Infravermelho, Editora da Universidade Estadual Paulista, São Paulo, 1996.

2. FARIA, D. L. A.; TEMPERINI, M., L., A.; SALA, O., Química Nova, v.22(4), p.541, 1999.

3. AROCA, R.; KOVACS, G.J. in Vibrational Spectra and Structure, Edited by Durig, J.R., Elsevier, Amsterdam, p. 55, 1991.

4. LEZNOFF, C. C.; LEVER, A. B. P., Phtlalocyanines Properties and Applications, Vol.1, V. C. H. Publishers, New York, 1989.

5. MENDONÇA, C. R.; GAFFO, L.; MISOGUTI, L.; MOREIRA, W. C.; OLIVEIRA JR., O. N.; ZILIO, S. C. Chemical Physics Letters, v.323, p.300, 2000.

6. BERNO, B.; NARZI, A.; AROCA, R., Journal of Raman Spectroscopy, v.27, p.41, 1996.

7. AROCA, R.; CLAVIJO, R. E.; JENNINGS, C. A.; KOVACS, G. J.; DUFF, J. M.; LOUTFY, R. O., Spectrochimica Acta, v.45A(9), p.957, 1989.

8. ZENG, Z. Q.; AROCA, R.; HOR, A. M.; LOUTFY, R. O., Journal of Raman Spectroscopy, v.20, p.467, 1989.

9. JENNINGS, C.; AROCA, R.; HOR, A. M.; LOUTFY, R. O., Journal of Raman Spectroscopy, v.15, p.34, 1984.

10. MOREIRA, W. C.; AROCA, R., Spectrochimica Acta, v.51A, p.2325, 1995.

11. AROCA, R.; BOLOURCHI, H.; BATTISTI, D., Langmuir, v.9, p.3138, 1993.

12. CLAVIJO, R.E.; BATTISIT, D.; AROCA, R.; KOVACS, G.J.; JENNINGS, C. A., Langmuir, v.8, p.113, 1992.

13. JENNINGS, C. A.; AROCA, R.; KOVACS, G. J.; HSAIO, C., Journal of Raman Spectroscopy, v.27, p.867, 1996.

14. AROCA, R.; MARTIN, F., Journal of Raman Spectroscopy, v.17, p.243, 1986.

15. GOBERNADO-MITRE, M. I.; AROCA, R.; DE SAJA, J. A., Journal of Molecular Structure, v.293, p.315, 1993. 


\section{Capítulo V}

\subsection{Voltametria Cíclica de Filmes da Bisftalocianina de Itérbio e da Ftalocianina de Paládio}

A técnica de voltametria cíclica tornou-se popular nas últimas décadas por estudar as reações eletroquímicas. Químicos inorgânicos têm usado essa técnica para estudar o efeito dos ligantes no potencial de oxidação-redução do íon metálico central em clusters. Em um experimento de eletroquímica, a voltagem aplicada no eletrodo de trabalho é escaneada linearmente de um valor inicial para um outro valor pré-determinado, onde a direção do scan é revertida. A corrente de resposta é plotada como função do potencial aplicado. Frequentemente existe uma pequena diferença entre o primeiro ciclo e os sucessivos scans [1].

As ftalocianinas metálicas têm atraído interesse devido à possibilidade de aplicações em dispositivos eletrocrômicos. Os estudos sobre o comportamento eletroquímico das ftalocianinas encontrados na literatura são geralmente realizados em solução, mas também foram encontrados alguns utilizando filmes. Devido à orientação molecular dos anéis ftalocianinas em filmes, as propriedades eletrônicas e ópticas podem ser afetadas [2]. A técnica LB é uma das técnicas que permitem controle molecular e é bastante utilizada para formação de filmes finos de ftalocianinas $[3,4]$. Um tipo de comportamento que pode ser observado, tanto em solução [5] quanto em filmes LB, é a mudança de coloração das ftalocianinas de itérbio e lutécio com a aplicação de diferentes potenciais [6]. Estudos de voltametria cíclica com algumas ftalocianinas de cobalto substituídas em solução apresentaram comportamento redox irreversível [7], dependência com o pH [8], e espécies reversíveis e irreversíveis [9]. São encontrados trabalhos de voltametria cíclica em solução de ftalocianinas de ródio substituídas, em que as atividades redox são atribuidas à natureza do ligante axial $[10,11]$. Na literatura são relatados trabalhos sobre voltametria cíclica e eletroquímica das ftalocianinas de platina, európio e molibdênio realizados em solução e de filmes da ftalocianina de cobre [11-15]. Propriedades eletrocrômicas para várias ftalocianinas de lantanídeos podem ser observadas em filmes LB [16-18]. Jones e colaboradores [19] realizaram estudos 
sobre o eletrocromismo em filmes LB de bisftalocianinas dos lantanídeos. As bisftalocianinas foram a de lutécio substituída $\left[\mathrm{LuPc}_{2}(\mathrm{OBu})_{16}\right]$ e não substituída $\left(\mathrm{LuPc}_{2}\right)$, e a de érbio não substituída $\left(\mathrm{ErPc}_{2}\right)$. Os filmes de $\mathrm{ErPc}_{2}$ mostraram dois picos de oxidação-redução correspondentes às mudanças de cores. Uma grande diferença foi observada entre filmes $L B$ da $\mathrm{LuPc}_{2}$ pura e substituída $\mathrm{LuPc}_{2}(\mathrm{OBu})_{16}$, onde $\mathrm{OBu}$ é o substituinte octa (n-butoxi). Os materiais substituídos não mostram mudanças de cores de verde para azul. Isso pode ser devido aos grupos OBu estarem bloqueando a migração dos íons através do filme.

As bisftalocianinas de lantanídeos apresentam diferentes formas eletrocrômicas. As estruturas propostas para as formas mais estáveis, denominadas azul e verde, são respectivamente a ionizada $\left[\mathrm{LnPc}_{2}\right]^{-}$e protonada [ $\left.\mathrm{LnPc}_{2} \mathrm{H}\right]$. A aplicação de potencial nesse tipo de composto pode provocar a oxidação ou redução tanto do metal quanto dos anéis ftalocianina, levando à mudança da forma eletrocrômica [5].

Neste trabalho, utilizou-se voltametria cíclica para estudar a $\mathrm{YbPc}_{2}$ e a $\mathrm{PdPc}$, observando também o comportamento destas diante da aplicação de diferentes potenciais. Para as medidas foram utilizados filmes $\mathrm{LB}$ da $\mathrm{YbPc}_{2}$ e filmes cast da PdPc, ambos depositados em ITO (índio/óxido de estanho).

\subsection{Voltametria Cíclica da Bisftalocianina de Itérbio ( $\left.\mathbf{Y b P c}_{2}\right)$}

\subsubsection{Experimental}

A transferência das monocamadas foi realizada em uma cuba de Langmuir $\mathrm{KSV} 5000$. Os experimentos foram realizados à temperatura de $25^{\circ} \mathrm{C}$. Filmes de $\mathrm{YbPc}_{2}$ puros foram fabricados a partir de uma solução $0,5 \mathrm{mg} / \mathrm{mL}$ em clorofórmio. Para formação dos filmes mistos, foi utilizada uma solução [1:1] em massa de $\mathrm{YbPc}_{2}$ /ácido esteárico em clorofórmio. A proporção utilizada em massa é correspondente a 4,22 moléculas de $\mathrm{YbPc}_{2}$ para cada molécula de ácido esteárico. As subfases utilizadas para o espalhamento dessa solução foram água pura e água contendo cloreto de cádmio e bicarbonato de sódio. A pressão superficial para a deposição foi $31 \mathrm{mN} / \mathrm{m}$ e a velocidade de imersão e retirada do substrato foi $3 \mathrm{~mm} / \mathrm{min}$. As medidas eletroquímicas foram realizadas em filmes contendo 1, 3, 9, 
19 e 35 monocamadas. As medidas de voltametria cíclica foram realizadas em um potenciostato/galvanostato EG\&G Instruments, modelo 283. Utilizou-se uma cela de três eletrodos: calomelano saturado (referência), platina (contraeletrodo), e o filme sobre ITO (eletrodo de trabalho). Utilizou-se como eletrólito suporte uma solução $0.1 \mathrm{M} \mathrm{HCl}-0.1 \mathrm{M} \mathrm{KCl}(\mathrm{pH} \mathrm{1.0)}$. Foram feitas medidas em várias velocidades de varredura, $20,50,70,150$ e $200 \mathrm{mV} / \mathrm{s}$, e em vários ciclos de varredura. A faixa de potencial mais adequada para as medidas foi de $500 \mathrm{a}-500 \mathrm{mV}$. Para as medidas eletrocrômicas realizadas "in-situ" em um espectrofotômetro UV-Vis-NIR Cary 5G acoplado a um potenciostato/galvanostato EG\&G, modelo $263 \mathrm{~A}$, utilizou-se o mesmo tipo de cela alterando o eletrodo de referência para $\mathrm{Ag} / \mathrm{AgCl}$ e um filme contendo 51 monocamadas. Medidas de infravermelho de filmes puros de $\mathrm{YbPc}_{2}$ e contendo ácido esteárico foram realizadas em um espectrofotômetro Bomen, modelo MB 102. Tais medidas foram realizadas para observar a existência ou não de interação química entre a $\mathrm{YbPc}_{2}$ e o ácido esteárico ou estearato de cádmio. Os filmes LB para medidas de infravermelho foram depositados sobre substratos de silício (35 monocamadas).

\subsubsection{Resultados e Discussão}

Para os estudos eletroquímicos, foram depositados filmes utilizando uma solução de $\mathrm{YbPc}_{2}$ e ácido esteárico em tolueno [1:1]. A proporção utilizada em massa é correspondente a 3,24 moléculas de $\mathrm{YbPc}_{2}$ para cada molécula de ácido esteárico. $\mathrm{Na}$ isoterma $\pi$-A obtida para $\mathrm{YbPc}_{2}$ /ácido esteárico, a área ocupada por molécula encontrada foi baseada no número de moléculas de ácido esteárico. A área por molécula no estado condensado foi $48 \AA^{2}$, enquanto a área crítica para a subida do potencial foi cerca de $100 \AA^{2}$ (figura 5.1). Os formatos das curvas de pressão e potencial de superfície são semelhantes ao do ácido esteárico, indicando a formação de filmes estáveis. Isso foi comprovado com a deposição de filmes LB do tipo Y, com razão de transferência igual a um. 


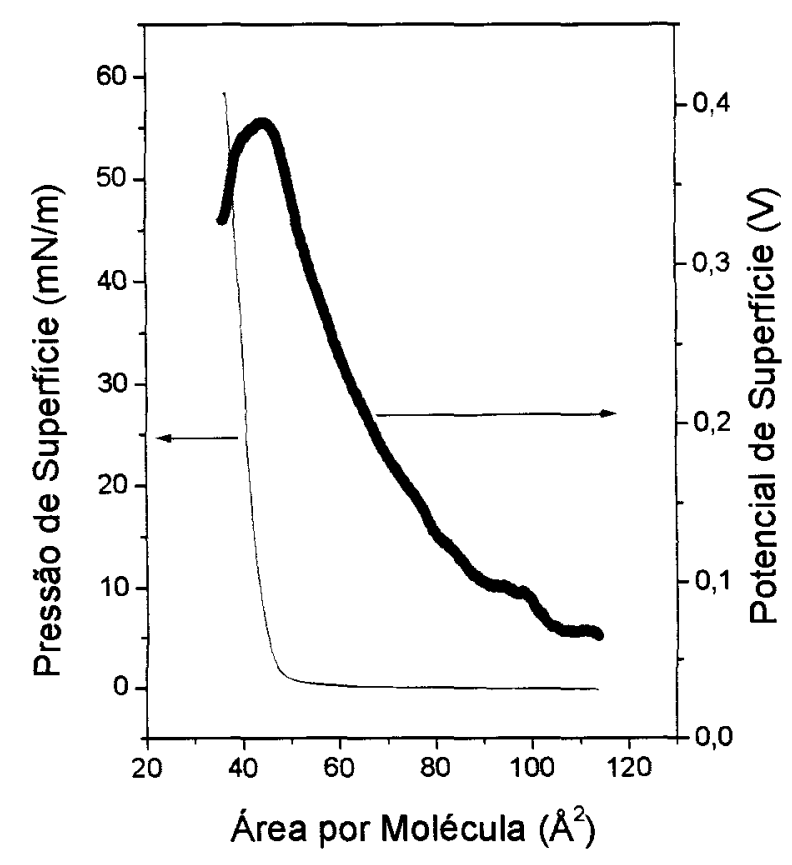

Figura 5.1: Isotermas $\pi-\mathrm{A}$ e $\Delta \mathrm{V}-\mathrm{A}$ da $\mathrm{YbPc}_{2} /$ ácido esteárico

Nas medidas eletroquímicas, foram observados dois picos de oxidação e dois de redução, sendo que a intensidade de corrente aumentou com o número de camadas, como mostrado na figura 5.2. Esse aumento não é linear, indicando que o aumento na intensidade deve ter influência de outros fatores além do aumento na quantidade de material. $\mathrm{O}$ aumento do número de camadas depositadas provocou um deslocamento no potencial de pico no processo anódico de -95 a $-113 \mathrm{mV}$ para o primeiro pico de oxidação, e de 195 a $362 \mathrm{mV}$, para o segundo. Essas variações podem estar relacionadas com a facilidade ou dificuldade na oxidação das espécies quando é aumentado o número de camadas depositadas. No processo catódico observou-se que filmes com menor número de camadas exibem dois picos, e com o aumento do número de camadas para 35 , os picos se superpõem em apenas um. 


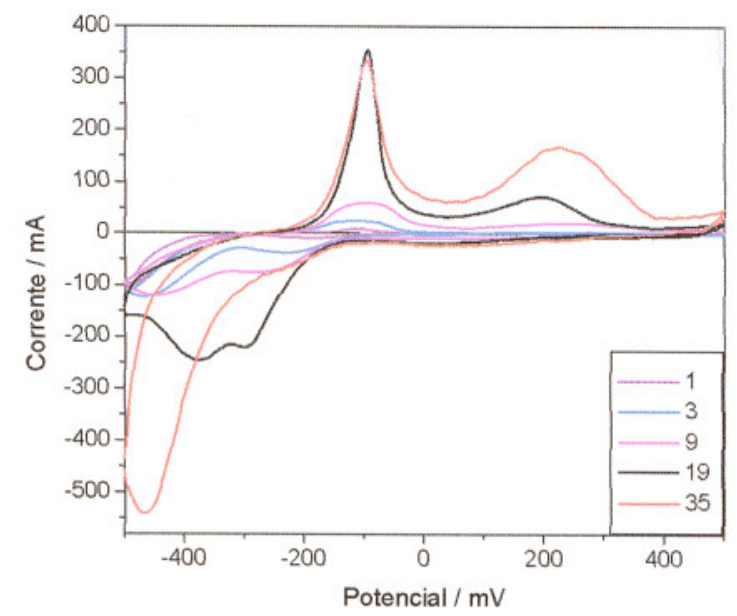

Figura 5.2: Voltamograma cíclico de filmes LB em ITO com diferentes números de camadas

Velocidades de varredura maiores levam a maior intensidade dos picos, indicando um processo limitado por difusão. Filmes mais espessos apresentaram apenas um pico catódico em velocidades de varredura maiores, que se resolvem em dois com a diminuição da velocidade (figura 5.3), semelhante ao observado para filmes menos espessos a uma velocidade fixa. Nenhuma variação foi observada no comportamento de filmes menos espessos com a mudança da velocidade de varredura. A figura 5.4 mostra um gráfico da corrente em função da velocidade de varredura para os voltamogramas da figura 5.3, obtendo-se uma reta. Isso indica que existe uma dependência linear da corrente de pico com a velocidade de varredura, sugerindo que o processo é controlado por difusão.

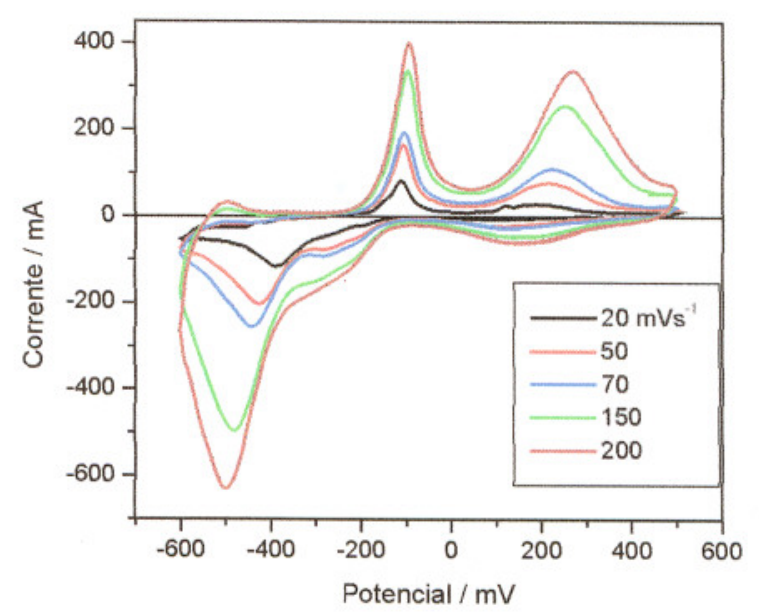

Figura 5.3: Voltamograma cíclico para filmes LB em ITO da $\mathrm{YbPc}_{2} /$ ácido esteárico (35 monocamadas) em diferentes velocidades de varredura 


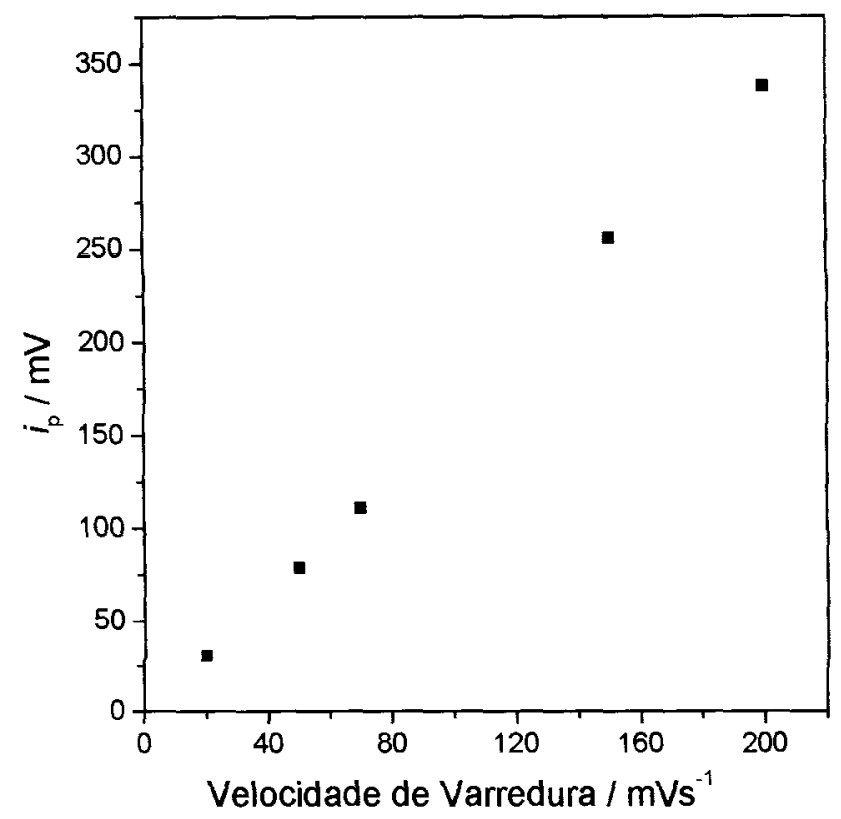

Figura 5.4: Gráfico da corrente em função da velocidade de varredura de voltamogramas de um filme LB da $\mathrm{YbPc}_{2}$ /ácido esteárico (35 monocamadas) em diferentes velocidades de varredura

Vários ciclos de varredura foram realizados no filme de 35 camadas (figura 5.5), observando-se que com o aumento do número de ciclos o processo catódico que apresentava um só pico passou a apresentar dois. A observação de dois picos para filmes menos espessos ou após várias varreduras está associada a um efeito cinético, que só pode ser observado com baixas velocidades de varredura ou maior número de ciclos, devido ao efeito de espessura do filme. Esse efeito cinético está relacionado a um processo de difusão e a dois processos de redução que ocorrem com diferentes velocidades. Utilizando apenas um ciclo de varredura em filmes mais espessos, o processo de maior velocidade ocorre, mas não há tempo suficiente para que o processo mais lento ocorra. Quando são realizados mais ciclos ou utilizadas baixas velocidades de varredura, há tempo suficiente para difusão dos íons em todo o filme. Além disso, o processo ocorre de forma mais lenta, podendo-se observar os dois picos. 


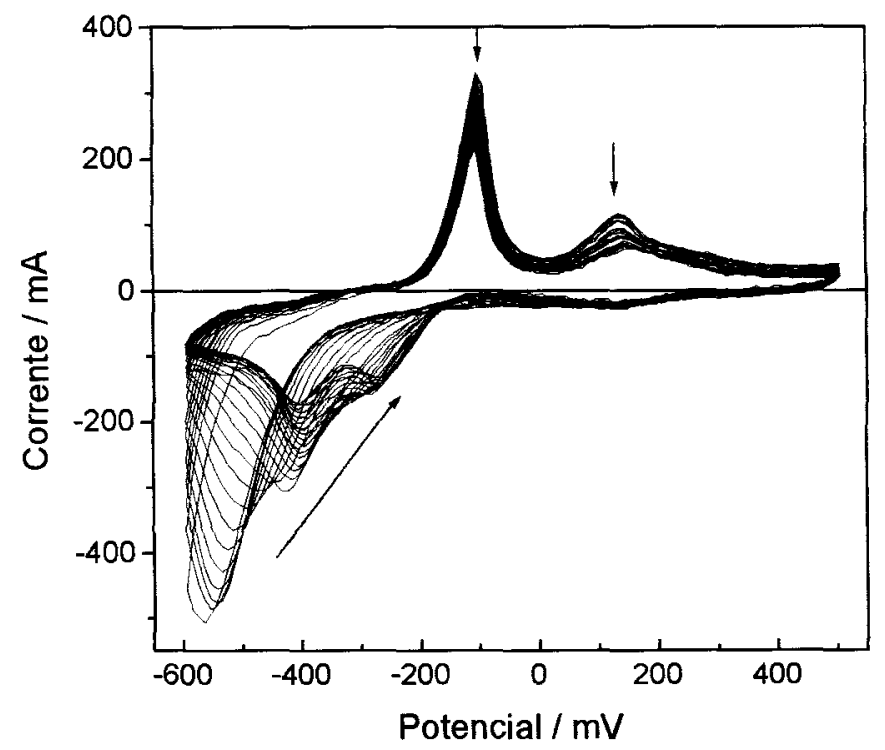

Figura 5.5: Voltamograma cíclico para 20 ciclos de um filme LB em ITO da $\mathrm{YbPc}_{2} /$ ácido esteárico

Na figura 5.6 são apresentados voltamogramas cíclicos de filmes LB puros e mistos da $\mathrm{YbPc}_{2}$ contendo 35 monocamadas. $\mathrm{O}$ segundo processo de redução ocorre mais facilmente em filmes de $\mathrm{YbPc}_{2}$ puros, indicando que estes são mais eletroativos. Os filmes contendo ácido esteárico ou estearato de cádmio apresentaram uma maior dificuldade no processo de redução. Isso pode indicar que as moléculas de ácido esteárico ou estearato de cádmio no filme podem aumentar a distância entre as moléculas de ftalocianina, dificultando o processo de redução. Uma outra hipótese seria a de estar ocorrendo interação química entre as moléculas de ftalocianina e de ácido esteárico, o que provocaria alteração nos valores de potenciais de oxidação e redução. Para confirmar a existência ou não de interação química, foram feitos espectros de i.v. da $\mathrm{YbPc}_{2}$ em pastilha de $\mathrm{KBr}$, e depositada em filmes LB (pura e mista com ácido esteárico). 


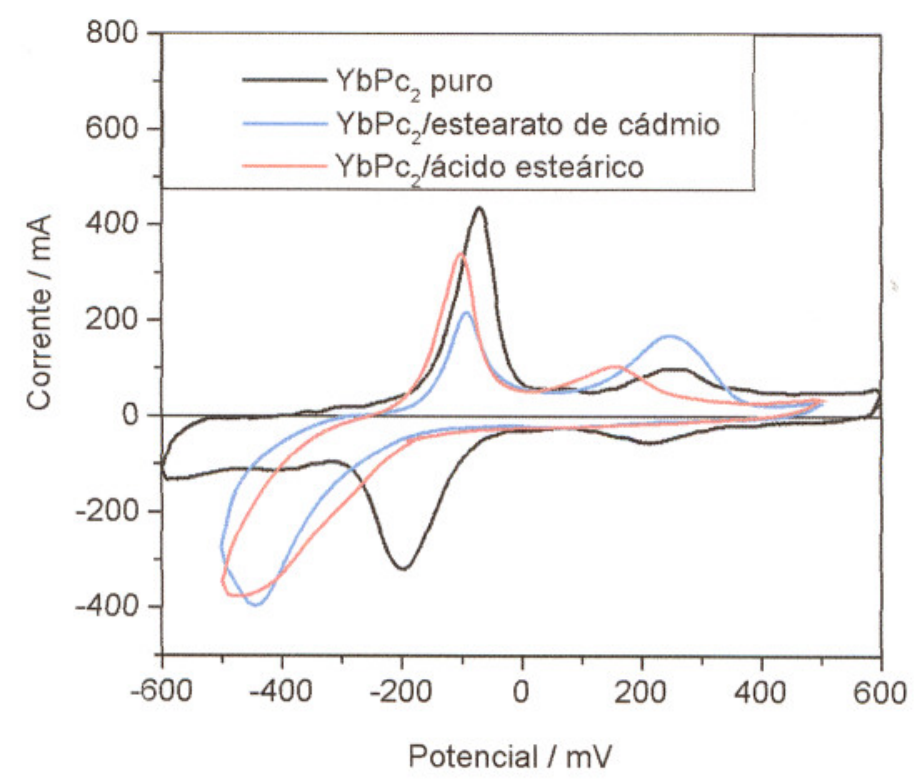

Figura 5.6: Voltamograma cíclico de filmes $\mathrm{LB}$ da $\mathrm{YbPc}_{2}$ puro, e na presença e ausência de estearato de cádmio

A figura 5.7 apresenta espectros de uma pastilha de $\mathrm{KBr}$ contendo $\mathrm{YbPc}_{2}$ e de filmes LB puro $\left(\mathrm{YbPc}_{2}\right)$ e misto $\left(\mathrm{YbPc}_{2} /\right.$ ácido esteárico). Não foram observadas alterações nas posições das bandas do ácido esteárico $\left(2846\right.$ e $\left.2915 \mathrm{~cm}^{-1}\right)$, indicando que não houve interação química entre a $\mathrm{YbPc}_{2}$ e o ácido esteárico. As bandas das ftalocianinas em 727 e $740 \mathrm{~cm}^{-1}$, que fornecem informações sobre orientação dos filmes sobre o substrato, também não foram alteradas. Isso também indica ausência de interação química.

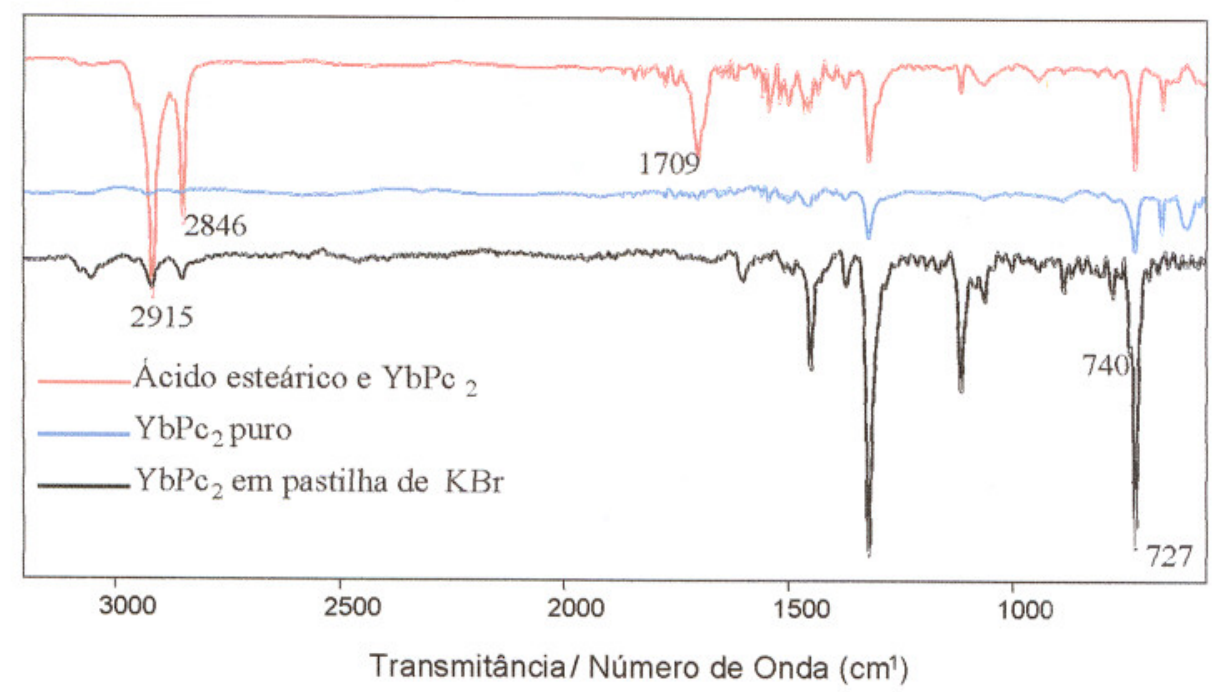

Figura 5.7: Espectro de absorção na região do i.v. de um filme LB misto ( $\mathrm{YbPc}_{2} /$ ácido esteárico), um filme LB puro $\left(\mathrm{YbPc}_{2}\right)$ e da $\mathrm{YbPc}_{2}$ em pastilha de $\mathrm{KBr}$ 
O estudo de espectroeletroquímica foi motivado por relatos da literatura para bisftalocianinas dos lantanídeos. Estas possuem diversas formas eletrocrômicas que podem sofrer alterações com a aplicação de diferentes potenciais. O eletrocromismo se manifesta em bisftalocianinas com a mudança da forma eletrocrômica e mudança de cor, que pode ser observada visualmente.

Os resultados de espectroeletroquímica (figura 5.8) apresentaram mudanças no espectro de UV-Vis., indicando que ocorrem alterações nas formas eletrocrômicas da $\mathrm{YbPc}_{2}$. Resultados similares foram relatados na literatura [19]. Sem aplicação de potencial (i. e. potencial zero), observa-se através do espectro UV-Vis. que o composto se encontra na forma eletrocrômica e coloração verde. Aplicando potenciais negativos $(-0,064 \mathrm{~V})$, a cor do filme muda para azul esverdeado e a potenciais mais positivos $(+0,206 \mathrm{~V})$ o filme se torna azul e encontra-se na forma reduzida. Aplicando os potenciais $+0,596$ e $+1,000 \mathrm{~V}$, o filme passa para a cor laranja, encontrando-se em sua forma oxidada. Aplicando-se novamente potencial 0 $\mathrm{V}$, o filme volta para a forma inicial (sem aplicação de potencial), ou seja, apresenta novamente o espectro mostrado na curva azul da figura 5.8.

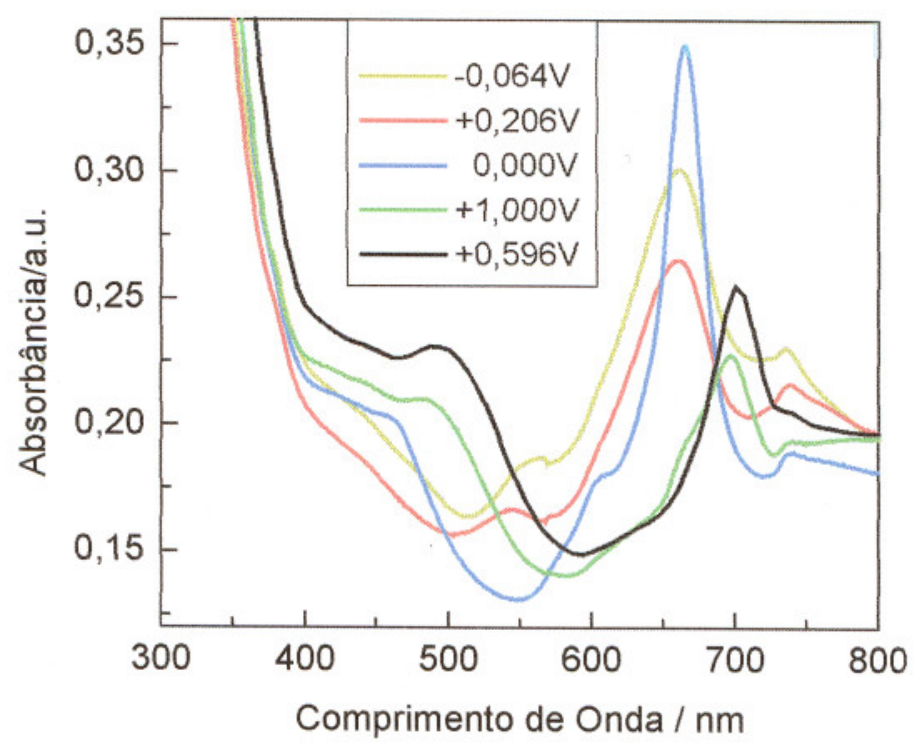

Figura 5.8: Espectros de absorção na região do UV-Vis. para um filme LB da $\mathrm{YbPc}_{2}$ /ácido esteárico (51 camadas) com a aplicação de diferentes potenciais 
As reações redox ocorridas no filme são mostradas a seguir:

$$
\begin{aligned}
{\left[\mathrm{Pc}_{2} \mathrm{Yb}\right]^{-}(\mathrm{azul}) } & \rightleftarrows\left[\mathrm{Pc}_{2} \mathrm{Yb}\right]+\mathrm{e}^{-}(\text {verde }) \\
{\left[\mathrm{Pc}_{2} \mathrm{Yb}\right](\text { verde }) } & \rightleftarrows\left[\mathrm{Pc}_{2} \mathrm{Yb}\right]^{+}+\mathrm{e}^{-} \text {(laranja) }
\end{aligned}
$$

\subsection{Voltametria Cíclica da Ftalocianina de Paládio (PdPc)}

Nesta parte do trabalho foi investigado o comportamento eletroquímico de filmes da ftalocianina de paládio depositados através da técnica casting, em que algumas condições experimentais foram alteradas sistematicamente.

\subsubsection{Experimental}

Para a realização de estudos de voltametria cíclica, foram depositados filmes da PdPc sobre substratos de ITO. Foi utilizada a técnica casting para deposição dos filmes. Foi comentado em outros capítulos deste trabalho que a $\mathrm{PdPc}$ é de dificil solubilização, não sendo possível estudá-la através da técnica LB. Porém, filmes preparados através da técnica casting puderam ser obtidos, devido a uma pequena solubilização apresentada pelo composto em tolueno. Para preparação da solução, aproximadamente $1 \mathrm{mg}$ do composto era colocado em $10 \mathrm{~mL}$ de tolueno e deixado em ultra-som por uma hora. Uma parte do composto era solubilizada e o restante ficava depositado no fundo do balão. A parte do composto que solubilizou era então espalhada sobre ITO, esperando-se a evaporação do solvente para espalhar mais solução. Isso era repetido várias vezes até a obtenção de um filme com certa coloração sobre o ITO.

As medidas de voltametria cíclica foram realizadas em um potenciostato/galvanostato EG\&G Instruments, modelo 283 , com uma cela de três eletrodos: prata (referência), platina (contraeletrodo), e o filme (eletrodo de trabalho). Como eletrólito suporte foi utilizado perclorato de tetrabutilamônio (PTBA) em acetonitrila e em diclorometano $\left(\mathrm{CH}_{2} \mathrm{Cl}_{2}\right)$ na concentração de $0.01 \mathrm{~mol} / \mathrm{L}$. Os filmes foram estudados em diferentes velocidades de varredura, 40,80,100,130, 150 e 200 $\mathrm{mVs}^{-1}$, com um número de ciclos de até 10 . A faixa de potencial mais adequada para 
as medidas foi de 0.0 a 1,80 V. Para observar o comportamento eletrocrômico dos filmes, registraram-se os espectros eletrônicos em diferentes potenciais aplicados em um espectrofotômetro UV-Vis-NIR Cary 5G.

\subsubsection{Resultados e Discussão}

Tanto as bisftalocianinas $\left(\mathrm{MPc}_{2}\right)$ quanto as ftalocianinas (MPc) podem apresentar diferentes formas eletrocrômicas. A aplicação de potencial em compostos altamente conjugados como estes pode causar a oxidação ou redução do metal ou dos anéis ftalocianina, alterando a forma eletrocrômica e consequentemente as cores $[5,20]$. Pouco se conhece sobre o comportamento eletroquímico e eletrocrômico da PdPc. Os estudos relatados aqui são os primeiros contendo resultados de voltametria cíclica em filmes finos da PdPc.

As figuras 5.9 e 5.10 mostram voltamogramas cíclicos de filmes cast da $\mathrm{PdPc}$, usando perclorato de tetrabutilamônio (PTBA) na concentração de $0,01 \mathrm{~mol} / \mathrm{L}$ nos solventes diclorometano $\left(\mathrm{CH}_{2} \mathrm{Cl}_{2}\right)$ e acetonitrila como eletrólito. Para ambos os casos foram observados dois picos de oxidação e dois de redução. Utilizando o solvente acetonitrila, no primeiro ciclo, apenas um pico $(1,13 \mathrm{~V})$ foi observado na figura 5.9. Para o segundo ciclo, dois picos passam a ser observados no processo de oxidação, em 0,95 e 1,17 V. Provavelmente, no primeiro ciclo não há tempo para que os processos ocorram separadamente, sendo necessário tempo para que ocorra estabilização. No processo de redução, dois picos foram observados em 0.78 e 0.30 V. Os resultados se alteram quando é utilizado diclorometano como solvente. Nesse caso já no primeiro ciclo dois picos de oxidação foram observados em 1.09 e $1.43 \mathrm{~V}$ (figura 5.10). A partir do segundo ciclo, dois picos de oxidação continuam sendo observados, porém o primeiro pico muda de 1.09 para $0.99 \mathrm{~V}$. No processo de redução, dois picos são observados em 1.27 e 0.64 V. As diferenças nos voltamogramas com a utilização de diclorometano e acetonitrila provavelmente estão relacionadas às diferenças de acidez dos solventes. 


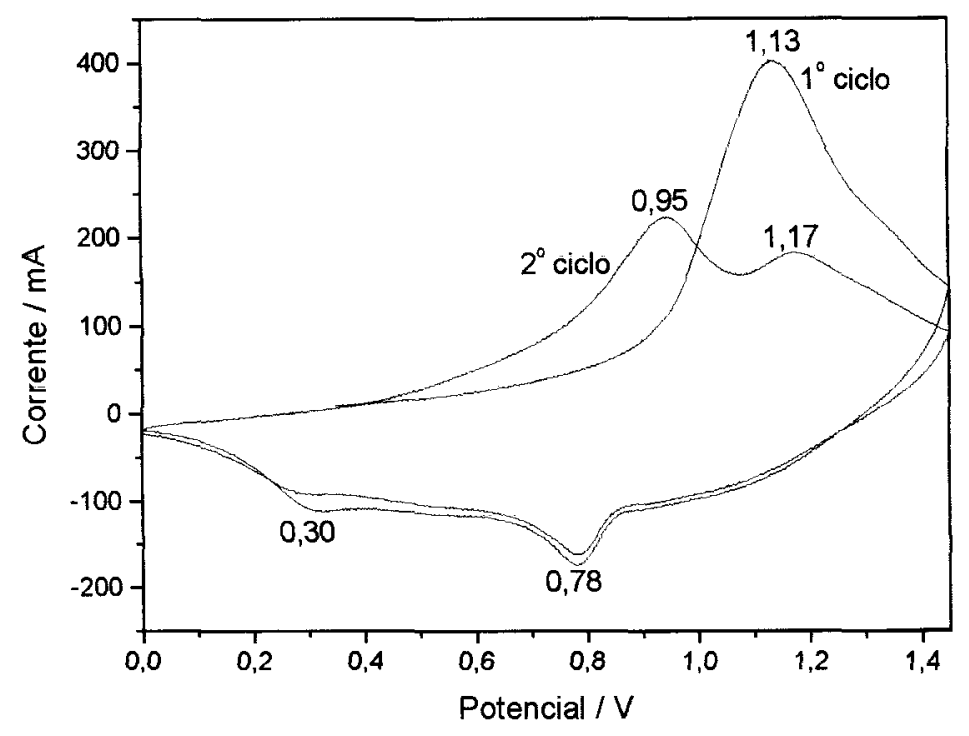

Figura 5.9: Voltamograma cíclico (primeiro e segundo ciclos) para um filme cast da PdPc depositado sobre ITO (acetonitrila)

A figura 5.11 mostra voltamogramas cíclicos da PdPc em diferentes velocidades de varredura utilizando acetonitrila como solvente. $\mathrm{O}$ aumento na velocidade de varredura provocou um aumento na intensidade dos sinais, característico de um processo limite de difusão. $\mathrm{Na}$ figura 5.12 é apresentado um gráfico da corrente em função da velocidade de varredura para os voltamogramas da figura 5.11, obtendo-se uma reta, confirmando que o processo é controlado por difusão.

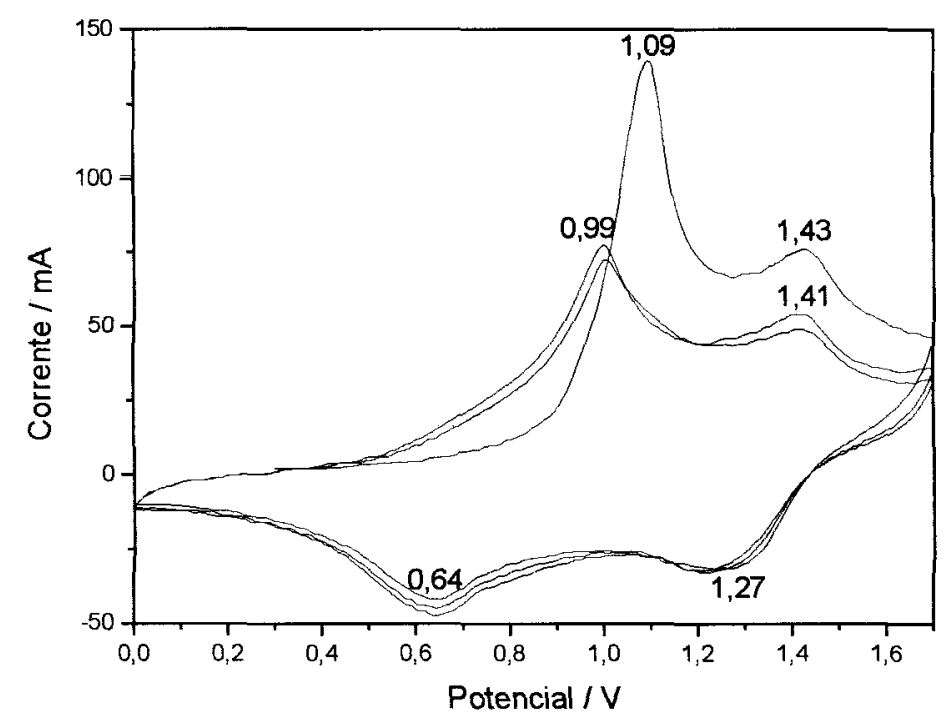

Figura 5.10: Voltamograma cíclico para um

filme cast da PdPc depositado sobre ITO $\left(\mathrm{CH}_{2} \mathrm{Cl}_{2}\right)$ 


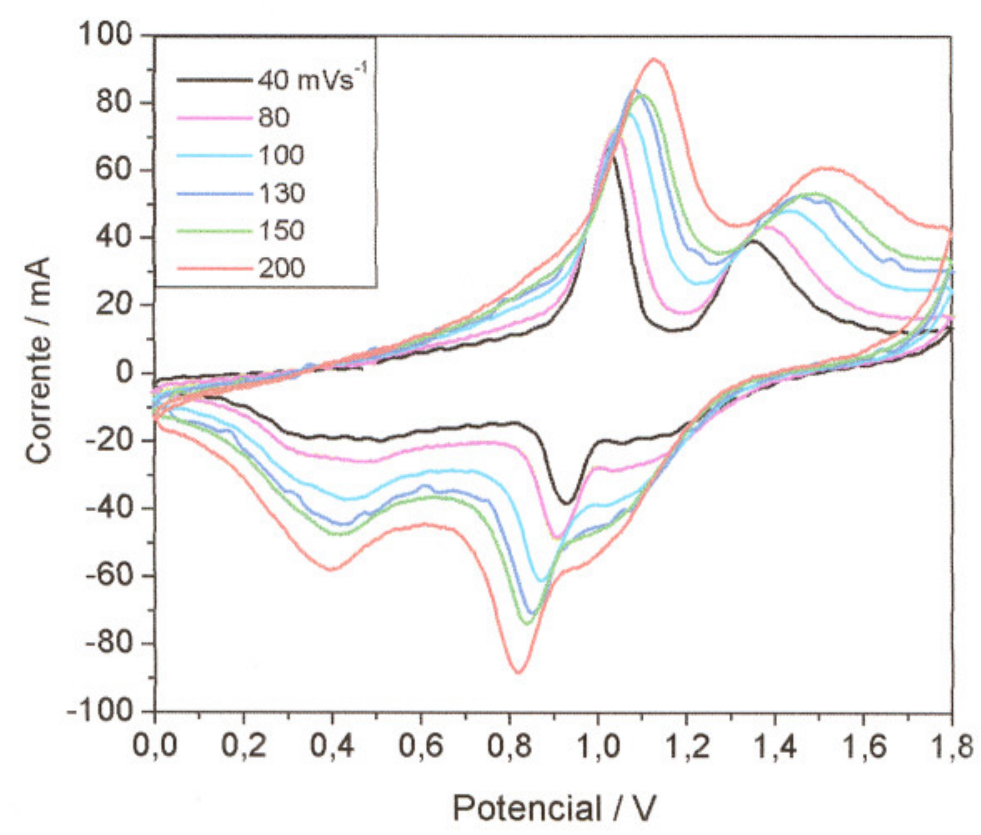

Figura 5.11: Voltamograma cíclico para um filme cast da PdPc sobre ITO em diferentes velocidades de varredura

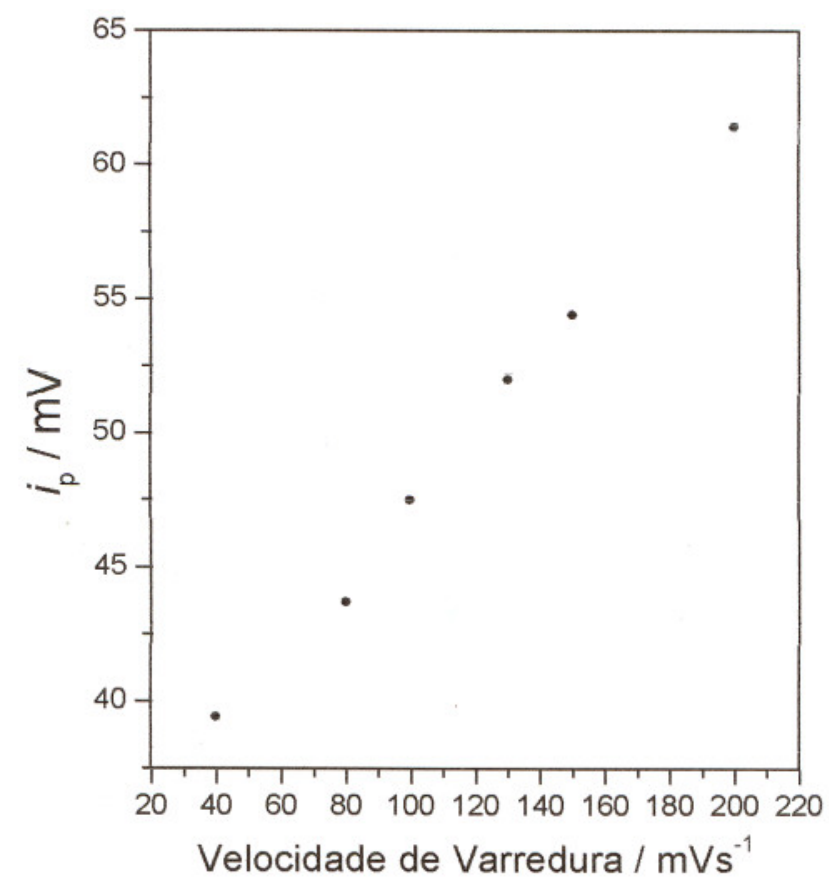

Figura 5.12: Gráfico da corrente em função da velocidade de varredura de voltamogramas de um filme cast da PdPc em diferentes velocidades de varredura

Durante o processo eletroquímico foram observadas diferentes cores no filme de PdPc, como pode ser verificado na figura 5.13 através dos espectros de UV- 
Visível. Inicialmente a cor observada visualmente era azul claro e o espectro de UVVis. apresentava duas bandas Q, em 620 e $660 \mathrm{~nm}$ (espectro a). Aplicando o primeiro e segundo potenciais de oxidação $(1,15$ e 1,39 V) a cor passou a ser roxo e apenas uma banda Q alargada foi observada em aproximadamente $600 \mathrm{~nm}$ (espectros $d$ e $e$ ). Esses espectros são muito semelhantes e diferem somente na intensidade. No processo inverso, com a aplicação do primeiro potencial de redução, 0,89 V (espectro $c$ ), o filme apresentou ainda cor roxa. Aplicando o segundo potencial de redução, $0,37 \mathrm{~V}$ (espectro $b$ ), o filme voltou para a cor inicial. Com a aplicação dos diferentes potenciais de oxidação-redução, ocorre diminuição e aumento na intensidade das bandas, entretanto ao final das medidas a intensidade observada é menor do que o espectro original. Isso pode ser um indicativo de perda de material durante os processos de oxidação-redução. Aplicado o potencial o filme muda de cor e a mantém mesmo sem a aplicação contínua de potencial. Este fato não é comum para outras ftalocianinas, onde a cor só permanece enquanto o potencial está sendo aplicado.

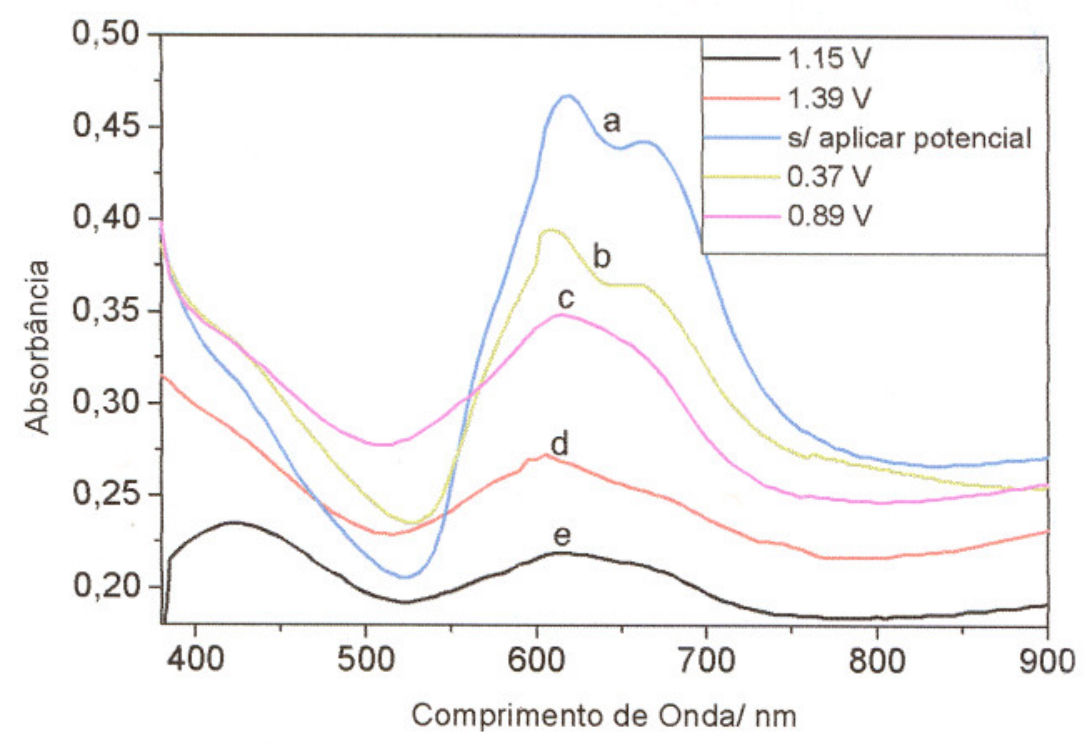

Figura 5.13: Espectros de absorção na região do UV-Vis. para filmes cast da PdPc em ITO com a aplicação de diferentes potenciais

Existe ainda uma certa dificuldade na interpretação dos dados obtidos. Para entender melhor os processos e escrever as equações que ocorrem, como foi mostrado para a $\mathrm{YbPc}_{2}$, seria necessário conhecer o estado de oxidação do metal no filme nas cores azul e roxa. Para isso seria necessária uma medida de XPS 
(espectroscopia fotoeletrônica por raios $\mathrm{X}$ ), o que ainda não foi realizado. Também não é possível encontrar resultados na literatura envolvendo eletroquímica da PdPc. Os processos anódico/catódico podem ser ainda estar associados à oxidação do dímero ou dímero/monômero.

\subsection{Conclusões}

A influência da espessura de filmes LB de ftalocianinas no comportamento eletroquímico foi investigada, algo que ainda não há na literatura. As alterações observadas com variação da espessura dos filmes $\mathrm{LB}$ de $\mathrm{YbPc}_{2}$, da velocidade de varredura e com a realização de vários ciclos, parecem estar relacionadas ao processo de controle de difusão. A presença de estearato de cádmio ou ácido esteárico no filme influencia os processos, principalmente de redução, provavelmente devido ao espaçamento entre as moléculas de $\mathrm{YbPc}_{2}$. Nas medidas eletrocrômicas observaramse mudanças nas posições das bandas de absorção eletrônica com aplicação de diferentes potenciais, indicando diferentes estados de oxidação-redução da $\mathrm{YbPc}_{2}$.

Comparando as medidas eletroquímicas da $\mathrm{YbPc}_{2}$ com as medidas da PdPc, observou-se a ocorrência de dois picos anódicos para ambas e de dois picos catódicos para a $\mathrm{YbPc}_{2}$ e três para a PdPc. Para a PdPc foi observada perda de material após várias ciclagens, o que não ocorria para a $\mathrm{YbPc}_{2}$. A solução eletrolítica utilizada para a $\mathrm{YbPc}_{2}$ era aquosa enquanto que para a $\mathrm{PdPc}$ era acetonitrila. $\mathrm{A} \mathrm{YbPc}_{2}$ não é solúvel em água, já a PdPc é um pouco solúvel em acetonitrila, o que pode explicar a perda de material. As diferentes soluções eletrolíticas também interferem na faixa de potencial utilizada, que foi de $-0,6$ a $+0,6 \mathrm{~V}$ para a $\mathrm{YbPc}_{2}$ e de 0,0 a $1,8 \mathrm{~V}$ para a $\mathrm{PdPc}$. Nos resultados de eletrocromismo, a $\mathrm{YbPc}_{2}$ apresentou basicamente as formas azul, verde e laranja e a $\mathrm{PdPc}$ apresentou as formas azul e roxa. $\mathrm{A} \mathrm{YbPc}_{2}$ é uma bisftalocianina contendo dois anéis $\mathrm{Pc}$, enquanto a PdPc apresenta-se na forma dimérica. Tais características interferem na solubilidade dos compostos e nas propriedades de oxidação/redução dos anéis.

\subsection{Bibliografia}

1. MABBOTT, G.A.; Journal of Chemical Education, v.60(9), p.697, 1983. 
2. HARNOODE, C.; TAKAMURA, K.; KUBOTA, H.; SHO, K.; FUJISAWA, K.; KITAMURA, F.; OHSAKA, T.; TOKUDA, K., Electrochemistry, v.67(8), p.832, 1999.

3. ZHANG, X.; SHEN, J., Advanced Materials, v.11, p.1139, 1999.

4. NYOKONG, T., J. Chem. Soc. Dalton Trans., p.1359, 1994.

5. COOPER, T.; CAMPBELL, A. L.; CRANE, R., Langmuir, v.11, p.2713, 1995.

6. TAKAHASHI, K.; TOMITA, Y.; HADA, Y.; TSUBOTA, K.; HANDA, M.; KASUGA, K.; SOGABE, K.; TOKII, T., Chemistry Letters, p.759, 1992.

7. WAltON, D.; ELY, B.; ELLIOTT, G., Photoelectrolysis Cathode, v.128, p. 2479,1981

8. SAKAMOTO, K.; OHNO, E., Dyes and Pigments, v.35, p.375, 1997.

9. SCHLETTWEIN, D.; YOSHIDA, T., Jounal of Electroanalytical Chemistry, v.44, p. 139,1998

10. SAKAMOTO, K.; OHNO, E. Dyes and Pigments, v.37, p.291, 1998.

11. LEVER, A. B. P.; TSE, Y.; MANIVANNAN, V.; SEYMOUR, P.; STRELETS, V.; PERSAUD, L. S., Inorg. Chem., v.35, p.725, 1996.

12. NYOKONG, T., Polyedron, v. 13, p.215, 1994.

13. JIANG, J.; LIU, W.; LAW, W. F.; DENNIS, K. P. Ng, Inorganica Chimica Acta, v.268, p.49, 1998.

14. KOGAN, I. L.; YAKUSHI, K., Electrochimica Acta, v.43, p.2053, 1998.

15. BROWN, K. L.; MOTTOLA, H. A., Langmuir, v.14, p.3411, 1998.

16. LIU, Y.; SHIGEHARA, K.; YAMADA, A., Thin Solid Films, v.179, p.303, 1989

17. PETTY, M.; LOVETT, D. R.; O'CONNOR, J. M.; SILVER, J., Thin Solid Films, v. 179, p. $387,1989$.

18. LUKAS, B.; LOVETT, D. R.; SILVER, J., Thin Solid Films, v.210/211, p.213, 1992.

19. JONES, R.; KRIER, A.; DAVIDSON, K., Thin Solid Films, v.298, p.228, 1997.

20. GAFFO, L.; GONÇALVES, D; DHANABALAN, A; MOREIRA, W. C; OLIVEIRA JR, O. N., Synthetic Metals, v. 124, p.351, 2001. 


\section{Capítulo VI}

\subsection{Conclusões}

Este projeto de doutorado envolveu a síntese de ftalocianinas dos metais ródio, rutênio e paládio, para serem empregadas na fabricação de filmes finos juntamente com as bisftalocianinas de itérbio e samário, sintetizadas durante o mestrado. $\mathrm{O}$ objetivo inicial era obter bisftalocianinas a partir de todos os metais usados. Para tanto foram usadas diferentes rotas de síntese, mas acabou-se por obter monoftalocianinas de ródio, rutênio e paládio nas formas monomérica e dimérica. Os complexos são interessantes de toda forma, pois preservam as características das ftalocianinas, e há poucos estudos na literatura sobre ftalocianinas desses metais. Com relação aos resultados das sínteses, a PdPc pode ser obtida utilizando a rota sintética descrita por Kirin. Foi observado um efeito do solvente sobre o equilibrio monômero/dímero da PdPc, indicando que mais de uma espécie foi formada na síntese. Para a síntese da RhPc e RuPc, outro método de síntese foi utilizado, já que o método de Kirin não foi eficiente. Ambas apresentam mais de uma fase quando são sintetizadas, e isso requereu grande esforço de purificação. Um estudo sistemático envolvendo espectroscopia UV-vis., FTIR e análise elementar foi realizado para acompanhar a formação dos produtos e verificar a sua pureza. A monoftalocianina de Ru acabou não sendo usada em estudos posteriores devido à impossibilidade de obtê-la suficientemente pura.

Uma vez obtidas as ftalocianinas, empregou-se a técnica LB para formação de filmes finos. Para a $\mathrm{YbPc}_{2}$ foram realizados vários estudos, e a ênfase neste material foi motivada pela possibilidade de comparação com dados da literatura, além da disponibilidade de grandes quantidades. A PdPc não é solúvel em solventes orgânicos comumente usados para as ftalocianinas, impossibilitando a fabricação de filmes LB. Em vez da técnica LB, foram fabricados filmes por sublimação de PdPc.

Foram estudadas as características de filmes de Langmuir da $\mathrm{YbPc}_{2}$ através de isotermas de pressão e de potencial de superfície. Foi analisada a influência que diferentes condições experimentais causam nas isotermas. A área ocupada por molécula variou de 62 a $68 \AA^{2}$, dependendo das condições experimentais. Os valores de potencial de superficie dependem da velocidade de compressão, porém o 
potencial dos filmes após a deposição na forma de filmes LB independe da velocidade utilizada para compressão da monocamada. Isso indica que independentemente da velocidade de compressão, o empacotamento no filme LB é o mesmo, ou seja, há um rearranjo molecular durante ou logo após a deposição.

Utilizando voltametria cíclica, foi investigada a influência da espessura de filmes LB de $\mathrm{YbPc}_{2}$ no comportamento eletroquímico. Foram observadas alterações com a variação da espessura dos filmes, da velocidade de varredura e com a realização de vários ciclos. Tais variações foram associadas a um processo de controle de difusão. Quando se formam filmes mistos de $\mathrm{YbPc}_{2}$ contendo ácido esteárico ou estearato de cádmio, os processos de oxi-redução são dificultados uma vez que os anfifílicos se comportam como espaçadores entre moléculas de $\mathrm{YbPc}_{2}$. Filmes contendo somente $\mathrm{YbPc}_{2}$ são mais eletroativos, com uma transferência de elétrons mais rápida. Estudos eletrocrômicos mostraram mudanças nas posições das bandas de absorção eletrônica quando diferentes potenciais são aplicados, indicando diferentes estados de oxidação-redução da $\mathrm{YbPc}_{2}$. Tais estudos mostraram que a $\mathrm{YbPc}_{2}$ é um material promissor para uso em sensores e dispositivos eletrocrômicos. Um mecanismo foi proposto para explicar as mudanças de estados. Os estudos de espectroscopia Raman para a $\mathrm{YbPc}_{2}$ mostraram que não há interação química entre o substrato e o composto. Comparando imagens de micro espectroscopia Raman e AFM pôde-se inferir que o comportamento encontrado na escala micrométrica (Raman) pode ser extrapolado para a escala nanométrica (AFM) e que filmes contendo $75 \%$ de $\mathrm{YbPc}_{2}$ e $25 \%$ de ácido esteárico apresentam maior homogeneidade que filmes contendo apenas $25 \%$ de $\mathrm{YbPc}_{2}$. Isto é, apesar de o ácido esteárico favorecer a deposição do filme, a interação entre os dois componentes faz com que os filmes mais homogêneos sejam obtidos com maior quantidade de $\mathrm{YbPc}_{2}$.

Os filmes de PdPc obtidos por sublimação foram analisados por espectroscopia Raman. Não foi observada interação química entre o substrato e o composto. Estudos de Raman para a RhPc também não mostraram interação química entre composto e substrato. Através do mapeamento Raman observou-se a existência de aglomerados no filme, devido a não uniformidade apresentada nas imagens de micro espectroscopia Raman. O comportamento da $\mathrm{RhPc}$ e $\mathrm{YbPc}_{2}$ foi semelhante, porém ambos foram distintos do comportamento da PdPc. As diferenças podem estar 
relacionadas a diferentes estados de oxidação do metal que interfere na simetria das moléculas.

Observou-se que a mudança do metal no anel ftalocianina altera suas propriedades. Diferentes metais podem levar à formação de bisftalocianina ou monoftalocianinas nas formas monomérica e dimérica. Isso altera a simetria dos compostos, a solubilidade e consequentemente todas as suas propriedades. As maiores diferenças observadas até o momento foram com a PdPc que, sendo muito pouco solúvel em solventes orgânicos, não pode ser estudada através da técnica LB. Uma outra diferença marcante foi encontrada para a RhPc que interage com ácido esteárico, principalmente quando está em solução, o que não foi observado para a $\mathrm{YbPc}_{2}$ e PdPc.

\subsection{Perspectivas de Trabalho Futuro}

- Realizar medidas de espectroscopia fotoeletrônica por raios-X (XPS) da ftalocianina de paládio;

- Estudar propriedades eletroquímicas de filmes LB da ftalocianina de ródio;

- Sintetizar ftalocianinas utilizando outros metais para estudo de propriedades ópicas na forma de filmes finos. 
- "Characterization of dynamic optical nonlinearities in ytterbium bisphthalocyanine solution", C. R. Mendonça, L. Gaffo, L. Misoguti, W. C. Moreira, O. N. Oliveira Jr., and S. C. Zilio, Chem Phys Lett 323: (3-4), 300-304 (2000).

- "Langmuir films of ytterbium and samarium phthalocyanines", L. Gaffo, A. Dhanabalan, W. C. Moreira, et al. Synthetic Met 102: (1-3), 1456-1456 (1999).

- "Surface pressure and surface potential isotherms of ytterbium bisphthalocyanine Langmuir monolayers", A. Dhanabalan, L. Gaffo, A. M. Barros, et al., Langmuir 15: (11), 3944-3949 (1999).

- “Optical properties of ytterbium bis-phthalocyanine solution", C. R. Mendonça, L. Gaffo, W. C. Moreira, O. N. Oliveira Jr., and S. C. Zilio, Synthetic Metals, 121, 1477-1478 (2001).

- "Electrochromic and Redox Properties of Langmuir-Blodgett Films of Ytterbium Bisphthalocyanine”, L. Gaffo, D. Gonçalves, A. Dhanabalan, W.C. Moreira, O. N. Oliveira Jr., Synthetic Metals, 124, 351-356 (2001).

“Atomic Force Microscopy and Micro-Raman Imaging of LangmuirBlodgett Films of Ytterbium Bisphthalocyanine", L. Gaffo, C. J. L. Constantino, W. C. Moreira, R. F. Aroca, O. N. Oliveira Jr., Langmuir, in press.

- "Reversible Electrochemical Response of Thin MEH-PPV Films", L. F. Santos, L. Gaffo, L. M. Carvalho, D. Gonçalves, R. M. Faria, Molecular Crystals Liquid Crystals, in press. 